\title{
DETECTING, DEFINING AND DEVELOPING SOFT SKILLS IN BUSINESS AND ICT CONTEXTS
}

\author{
Kai Johannes Schleutker \\ Dissertation submitted for the degree of Doctor of Philosophy at Universitat \\ Politècnica de València
}

Doctorate Program: Industrias de la Comunicación y Culturales

Supervisors: Dr. Nuria Lloret Romero y Dr. José Luis Poza-Luján (UPV), Dr. Vesa Taatila (Turku UAS)

Noviembre 2021

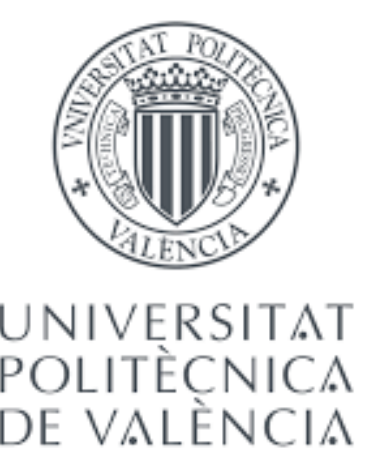




\section{Abstract}

The motivation to this research project emerged from both personal and professional sources. In the field of business, as well as many other fields, the definition of professional competence has undergone a major evolution over the past 20 years. As working environments become increasingly digital, but also based on teams and networks, the role of individual skills grow. Employers in business and ICT organizations seek for technical 'hard skills', yet they increasingly look for graduates able to manage themselves, work in teams and networks and solve problems. The need for these 'Soft Skills' has been expressed from the part of Organizations and employers, and their role is believed to grow additionally in the future.

However, there are many reasons why educational institutions have found it difficult to capture this challenge. As a result, the labour market is reported to suffer from 'skills gaps', which cause problems for the employers as well as the graduates, and indirectly also to the educators. A main reason for this is that educators lack the awareness of the skills needed in Organizations. In addition, they feel unsure about whether Soft Skills can be promoted, and how this should be conducted.

In this research, I elucidate the 'skills gap' and possible solutions to reduce it. I start by defining the character and role of Soft Skills. Subsequently, I inspect the skills acquisition process from the aspect of the mentioned parts, called 'stakeholders'. My objective is to create a method that can consider Soft Skills in a systematic way, in respect to their role for the different stakeholders. To achieve this, a framework of the essential Soft Skills, viable for HEls and Organizations is composed. Next, a threedimensional model of the Soft Skills acquisition process is presented. The Method Soft Skills Status indicator (3Si) is then suggested, by operationalizing the elements of the model into three statistical dimensions, 'Significance', 'Learnability' and 'Level'. The proposed Method is subsequently experimented, by launching a survey to 381 business and ICT professionals in four European countries. 
In the Results section, the outcomes of the survey are presented and discussed. Next, the results are applied to test the Method, which allows a classification in eight classes of Soft Skills. These classes provide specific descriptions for each of the Soft Skills, applicable for educators and trainers working on Soft Skills. The results affirm the hypothesis set to the research.

Key words: skills, competences, working life skills, Soft Skills, Soft Skills framework, promotion of Soft Skills, method for detecting Soft Skills, classification of Soft Skills, Soft Skills Status indicator 



\section{Resumen}

La motivación de este proyecto de investigación surgió de fuentes tanto personales como profesionales. En el campo de los negocios, así como en muchos otros campos, la definición de competencia profesional ha experimentado una importante evolución en los últimos 20 años. A medida que los entornos de trabajo se vuelven cada vez más digitales, pero también basados en equipos y redes, el papel de las habilidades individuales crece. Los empleadores de las empresas y las organizaciones de TIC buscan "habilidades técnicas", pero cada vez más buscan graduados capaces de administrarse por sí mismos, trabajar en equipos y redes y resolver problemas. La necesidad de estas "habilidades blandas" ha sido expresada por parte de organizaciones y empleadores, y se cree que su función crecerá adicionalmente en el futuro.

Sin embargo, hay muchas razones por las que las instituciones educativas han tenido dificultades para captar este desafío. Como resultado, se informa que el mercado laboral sufre de "brechas de habilidades", lo que causa problemas tanto a los empleadores como a los graduados, e indirectamente también a los educadores. Una de las principales razones de esto es que los educadores carecen de la conciencia de las habilidades necesarias en las organizaciones. Además, no están seguros de si se pueden promover las habilidades blandas y cómo se debe llevar a cabo.

En esta investigación, aclaro la "brecha de habilidades" y las posibles soluciones para reducirla. Empiezo por definir el carácter y el rol de Soft Skills. Posteriormente, inspecciono el proceso de adquisición de habilidades desde el aspecto de las partes mencionadas, llamadas "partes interesadas". Mi objetivo es crear un método que pueda considerar las Soft Skills de forma sistemática, con respecto a su rol para los diferentes stakeholders. Para lograrlo, se compone un marco de las Soft Skills esenciales, viable para Universidades y Organizaciones. A continuación, se presenta un modelo tridimensional del proceso de adquisición de Soft Skills. Luego se sugiere el indicador Method Soft Skills Status (3Si), operacionalizando los elementos del modelo en tres dimensiones estadísticas, "Significación", "Capacidad de aprendizaje" y "Nivel". Posteriormente se experimenta el Método propuesto mediante el lanzamiento de una encuesta a 381 profesionales de las TIC y empresas en cuatro países europeos. 
En la sección Resultados, se presentan y discuten los resultados de la encuesta. A continuación, se aplican los resultados para probar el Método, lo que permite una clasificación en ocho clases de Soft Skills. Estas clases proporcionan descripciones específicas para cada una de las Soft Skills, aplicables a los educadores y formadores que trabajan en Soft Skills. Los resultados afirman la hipótesis planteada a la investigación.

Palabras clave: habilidades, competencias, habilidades para la vida laboral, competencias transversales, marco de competencias transversales, promoción de habilidad, método de detección de competencias transversales, clasificación de competencias transversales, indicador de estado de competencias transversales 



\section{Resum}

La motivació d'aquest projecte d'investigació va sorgir de fonts tant personals com professionals. En el camp dels negocis, així com en molts altres camps, la definició de competència professional ha experimentat una important evolució en els últims 20 anys. A mesura que els entorns de treball es tornen cada vegada més digitals, però també basats en equips i xarxes, el paper de les habilitats individuals creix. Els ocupadors de les empreses i les organitzacions de TIC busquen "habilitats tècniques", però cada vegada més busquen graduats capaços d'administrar-se per si mateixos, treballar en equips i xarxes i resoldre problemes. La necessitat d'aquestes habilitats transversals ha sigut expressada per part d'organitzacions i ocupadors, i es creu que la seua funció creixerà addicionalment en el futur.

No obstant això, hi ha moltes raons per les quals les institucions educatives han tingut dificultats per a captar aquest desafiament. Com a resultat, s'informa que el mercat laboral pateix de "bretxes d'habilitats", la qual cosa causa problemes tant als ocupadors com als graduats, i indirectament també als educadors. Una de les principals raons d'això és que els educadors manquen de la consciència de les habilitats necessàries en les organitzacions. A més, no estan segurs de si es poden promoure les habilitats blanes $\mathrm{i}$ com s'ha de dur a terme.

En aquesta investigació, aclarisc la "bretxa d'habilitats" i les possibles solucions per a reduir-la. Comence per definir el caràcter i el rol de Soft Skills. Posteriorment, inspeccione el procés d'adquisició d'habilitats des de l'aspecte de les parts esmentades, anomenades "parts interessades". El meu objectiu és crear un mètode que puga considerar les Soft Skills de manera sistemàtica, respecte al seu rol per als diferents stakeholders. Per a aconseguir-ho, es compon un marc de les Soft Skills essencials, viable per a Universitats i Organitzacions. A continuació, es presenta un model tridimensional del procés d'adquisició de Soft Skills. Després se suggereix l'indicador "Method Soft Skills Status (3Si), transformant en operacions els elements del model en tres dimensions estadístiques, "Significació", "Capacitat d'aprenentatge" i "Nivell". Posteriorment s'experimenta el Mètode proposat mitjançant el llançament d'una enquesta a 381 professionals de les TIC i empreses en quatre països europeus. En la secció Resultats, es presenten i discuteixen els resultats de l'enquesta. A continuació, s'apliquen els resultats per a provar el Mètode, la qual cosa permet una 
classificació en huit classes de Soft Skills. Aquestes classes proporcionen descripcions específiques per a cadascuna de les Soft Skills, aplicables als educadors i formadors que treballen en Soft Skills. Els resultats afirmen la hipòtesi plantejada a la investigació.

Paraules clau: habilitats, competències, habilitats per a la vida laboral, competències transversals, marc de competències transversals, promoció d'habilitats, mètode de detecció de competències transversals, classificació de competències transversals, indicador d'estat de competències transversals. 


\section{Acknowledgements}

After a considerable period of extra efforts along with daily work, I feel released and happy to finish my thesis. Besides hard work, it has been an animating and special time in my life. To put it in words, the thesis is a product of shared intention to inspect the 'skills that make the difference', crossing both cultural and faculty borders. Within this special subject, it has been highly enriching to meet colleague teachers and researchers across Europe, especially Spain, Portugal and Italy, and share your passion towards opening new paths in Soft Skills research and their application.

I am grateful for the opportunity to conduct my thesis research as a Finnish pioneer in the doctoral school of UPV, based on a recent pact between UPV and Turku UAS. I want to pass very special thanks to Dr. Nuria Lloret Romero for having the pleasure to be including in your doctoral degree program, and for your support and instructions along the whole process. Second, without Dr. Jose-Luis Poza-Luján this thesis would not have been possible. Your inspiration, strong dedication and good sense of humor have solved any problem and carried me through the tough times. Special thanks to your pictures and figures in this report.

At my home base in Turku, I could rely on the steady support and wise comments from Dr. Vesa Taatila when they were needed.

In addition, I want to thank all my co-writers and inspirers, especially Dr. Valeria Caggiano in Rome for your creative ideas and perseverance in promoting Soft Skills and publishing them, and PhD Susana Bastos in Porto for your dedicated cooperation and insights on business education. I want also to present my appreciation to my colleagues Dr. Keijo Varis and Dr. Jarmo Ahonen for your comments to the manuscript, and the head of my department, Jaana KallioGerlander, for your support along the way. The proofreading of the final manuscript was done by M.A. Elli Sillanpää and the formal revision by B.A. Milla Granlund, your efforts were highly important.

As a rule, when doctoral studies are being carried out on along with the work, the doctorand gets occupied to a high degree and aborted from his normal social life. At 
this stage, I feel released and grateful to my friends and colleagues for your understanding and support. Especially, I am grateful for the support and patience of Mari. A lot of our common time was offered for this effort. Now I know it was worth it. Thank you.

The research process has been funded by the Turku foundation for business education, the Wallenberg foundation and Salon Liikesivistyksen tuki r.y. In addition to very welcomed economical support, these grants have given me motivation and trust to carry on along with my work, especially in the hard moments. 
1.1 MOTIVATION FOR THIS THESIS 1

1.2 HYPOTHESIS 2

1.3 AIMS AND TARGETS 4

1.4 METHOdology 4

1.5 DOCUMENT DESCRIPTION

2 STATE OF THE ART $\quad 10$

2.1 THE CHARACTER OF SOFT SKILLS 10

2.1.1 About competences and Skills 10

2.1.2 Definition of Soft Skills 12

2.1.3 Soft Skills in Working Contexts 14

2.1.4 Skills gap - lack of Soft Skills 16

2.1.5 Skills gap and HEIs 17

2.1.6 Discussion 21

2.2 SOFT SKILLS MAPS ANALYSIS 22

2.2.1 About Skills Maps $\quad 22$

2.2.2 Existing skills maps and analysis 23

2.2.3 Exploratory research on titles 24

2.2.4 Map of graduates - MOSSA 29

2.2.5 University map - Universitat Politècnica de València 30

2.2.6 The proposed Soft Skills Framework 35

2.3 SOFT SKILLS DETECTION METHOdS $\quad 41$

2.3.1 Methods to detect skills 42

2.4 CONDITIONS FOR MATCHING SOFT SKILLS 46

2.4.1 The acquisition process of Soft Skills $\quad 47$

2.4.2 The Dimensions of the Process 50

$\begin{array}{lll}2.5 & \text { SUMMARY } & 54\end{array}$

$3 \quad$ PRACTICAL IMPLICATIONS $\quad 57$

3.1 COMMUNICATION BASED TAXONOMY

3.1.1 Guidelines for Skills Clusters 58

3.1.2 Communication based Taxonomy of Soft Skills 60

3.1.3 Applications of the Taxonomy 69 
3.2 THE PROPOSED METHOD: SOFT SKILLS STATUS INDICATOR (3SI)

3.2.1 The Soft Skills Match - the process of defining and detecting Core Soft Skills 71

3.2.2 The 3Si Survey Questionnaire 75

3.2.3 The 3Si Method 81

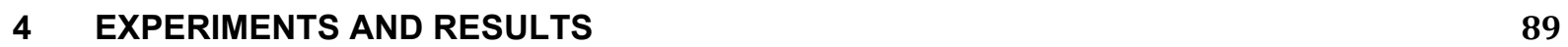

4.1 INTERVIEW WITH EXPERTS 90

4.2 LAUNCHING THE SURVEY 3SI TO BUSINESS PROFESSIONALS 92

4.2.1 Background data 93

4.2.2 The Results of the 3Si Survey 95

4.3 Statistical Analysis of the SurVey Results 104

4.3.1 Implementation of the 3Si Classification 104

4.3.2 The role of the threshold 110

$\begin{array}{lll}4.4 & \text { RESULTS ANALYSIS } & 112\end{array}$

4.4.1 Regarding the 3Si survey 112

4.4.2 Regarding the Outcomes from Classification 3Si 115

$\begin{array}{llr}5 & \text { DISCUSSION } & 119\end{array}$

5.1 ABOUt THE OUTSET OF THE RESEARCH PROJECT 119

5.1.1 About the survey 120

5.1.2 About the Method 3Si and the Classification 123

5.1.3 Limitations of the research and the Method 124

5.2 CONTRIBUtIONS OF THE RESEARCH/RESULTS 126

5.2.1 To Higher Education in business and ICT 127

5.2.2 To Business and ICT Organizations 128

6 SCIENTIFIC PUBLICATIONS AND DISSEMINATION OF THE RESULTS 131

6.1 SCIENTIFIC Publications 131

6.1.1 Journal articles 132

6.1.2 Conference presentations 139

$\begin{array}{lll}6.2 & \text { DISSEMINATION OF THE RESULTS } & 147\end{array}$

6.2.1 Project Coski21 - creation of project website 147

6.2.2 Workshops with Teachers, Managers and Researchers 152

6.2.3 Workshops with researchers 154

$\begin{array}{lll}7 & \text { CONCLUSIONS } & 161\end{array}$

$\begin{array}{lll}7.1 & \text { TARGETS REACHED } & 162\end{array}$

$\begin{array}{lll}7.2 & \text { FUTURE WORK } & 163\end{array}$

1 BIBLIOGRAPHY 1

1 ATTACHMENT 1 
1. ATtACHMENT: THE 3SI QUESTIONNAIRE

2. ATtACHMENT: TABLES AND GRAPHS 10

3. COSKI21 RESULTS (THE WHOLE SHEET CAN BE FOUND HERE) 11

Figure 1 Bridging the 'skills gap' is a common goal of graduates, employers and educators ............................. 2

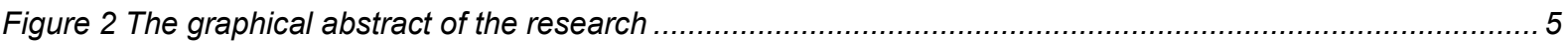

Figure 3 Definition of the core Soft Skills is a step towards developing them .............................................. 8

Figure 4 The thesis aims to combine the aspects of students, teachers and employers ................................ 19

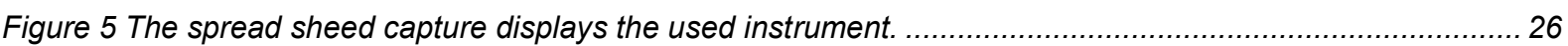

Figure 6 The roles and interest of the stakeholders in the acquisition of skills. ..................................................49

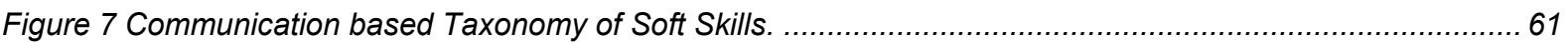

Figure 8 The Soft Skills match - the process of defining and detecting Core Soft Skills............................... 72

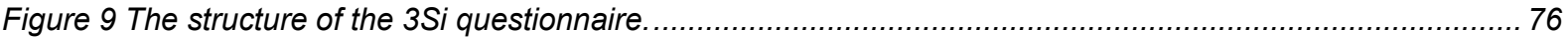

Figure 10 The main block of the Questionnaire with three statistical dimensions....................................... 78

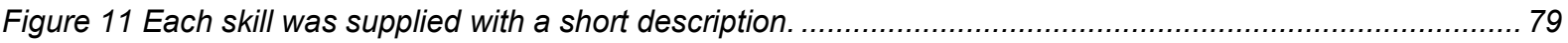

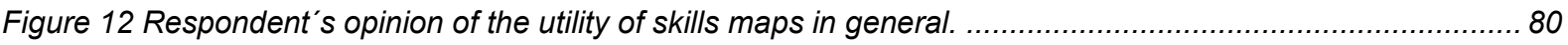

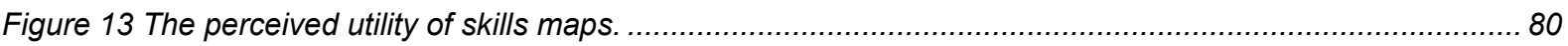

Figure 14 The evaluated significance of Soft Skills in work positions, by country.......................................96

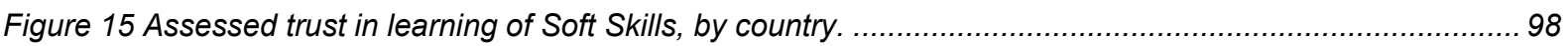

Figure 16 Assessed Level of graduates' Soft Skills, by country. ............................................................ 100

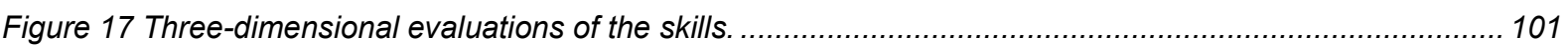

Figure 18 The impact of the threshold on the distribution of skills classes. ................................................. 111

Figure 19 Summary of scientific publications and academic conferences participated during the thesis. .......... 132

Figure 20 The outlook of the website www.skill-4u.eu.............................................................. 147

Figure 21 The visitor can choose different initiations. .................................................................... 148

Figure 22 Free material can be loaded from the website.............................................................. 149

Figure 23 Promotion of Soft Skills begins from self-awareness........................................................ 150

Figure 24 The content strategy for promotion in social media. .......................................................... 151

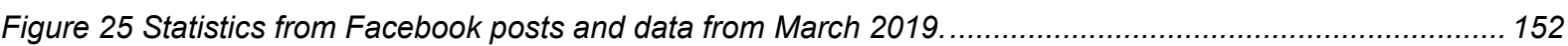

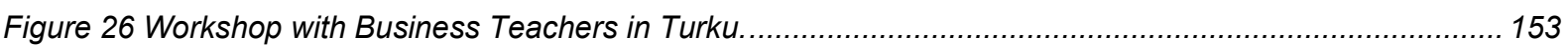

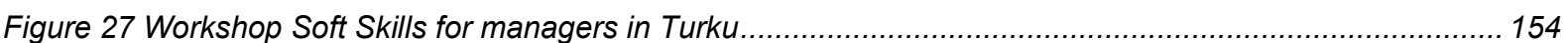

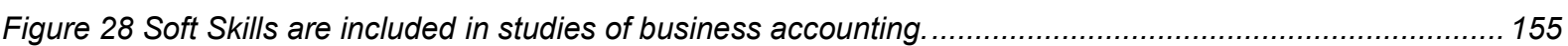

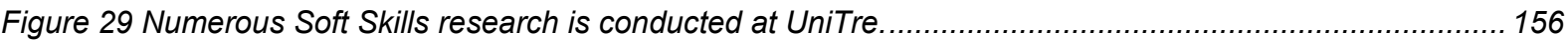

Figure 30 The Turku conference brought together business and higher education................................... 157 
Table 1 Hard and Soft Skills, as considered in different professional fields.......

Table 2 The MOSSA Map of Soft Skills.

Table 3 UPV competence clusters and Soft Skills related with them.

Table 4 The Soft Skills framework proposed 38

Table 5 Comparison of research methods. . 44

Table 6 Research methods to be applied in the current research. 46

Table 7 The Soft Skills matrix used in the questionnaire, result of the Framework presented in chapter $2.4 \ldots \ldots . .77$

Table 8 Description of the Soft Skills classes with High significance. .. 84

Table 9 Soft Skills with less import in the HEI - Organization context....... .. 87

Table 10 The 21 Soft Skills defined in classes (H/L) according to survey results. 106

Table 11 The 21 Soft Skills presented in the 3Si Classification. 107

Table 12 Distribution of Soft Skills in classes when applying two alternative thresholds. 


\section{Acronyms and definitions}

\begin{tabular}{|c|c|}
\hline Business & $\begin{array}{l}\text { Activity of making money by producing or buying and selling } \\
\text { goods or providing services, in a variety of branches. (Longman } \\
\text { Business Dictionary). } \\
\text { Business is the essential field in this thesis as the doctorand is } \\
\text { working as a business teacher. }\end{array}$ \\
\hline $\begin{array}{l}\text { Business } \\
\text { Organization }\end{array}$ & $\begin{array}{l}\text { A body that has been established to manage business in a } \\
\text { certain branch and environment. It has resources and staff to } \\
\text { reach it goals (see Organization). }\end{array}$ \\
\hline Competence & $\begin{array}{l}\text { A set of characteristics and skills that enable successful } \\
\text { performance } \\
\begin{array}{ll}\text { Dictionary). } & \text { in a given job position (Cambridge }\end{array}\end{array}$ \\
\hline Core Skills & $\begin{array}{l}\text { Skills that are identified by employers as essential in any work } \\
\text { environment. (Cambridge Dictionary) }\end{array}$ \\
\hline Core Soft Skills & $\begin{array}{l}\text { Proposed in this thesis: Soft Skills with high significance in } \\
\text { work environments and high development potential at HEls. }\end{array}$ \\
\hline CoSki21 & $\begin{array}{l}\text { An European research \& development project (Core Skills for } \\
21 \text {. Century professionals) } 30.09 .2017-02.10 .2019 \text {, which } \\
\text { supported the conduct of this thesis. The partnering } \\
\text { Universities (UPV/Valencia, TUAS/Turku, PP/ISCAP/Porto and } \\
\text { HU/Utrecht) contributed to sample collection for the 3Si survey. }\end{array}$ \\
\hline Employee & $\begin{array}{l}\text { A person working in an Organization at any level of hierarchy. } \\
\text { Essentially, this thesis deals with the Soft Skills of employees } \\
\text { and graduates. (Zigarmi et al., 2009) }\end{array}$ \\
\hline ESCO & $\begin{array}{l}\text { European system for matching work positions and skills } \\
\text { (ESCO). }\end{array}$ \\
\hline Graduate & $\begin{array}{l}\text { A person between the status of student and employee. } \\
\text { This thesis deals essentially with the Soft Skills of graduates. }\end{array}$ \\
\hline Hard skills & $\begin{array}{l}\text { Competencies that employees possess such as numeracy, } \\
\text { literacy, fluency in a foreign language, and specific job-related } \\
\text { technical abilities (operating a machine, creating a } \\
\text { spreadsheet, touch-typing, driving, dressing a wound, and so } \\
\text { forth). Typically, these skills are relatively easy to measure, and } \\
\text { are often validated with some form of qualification. (Oxford } \\
\text { Reference, 2020) }\end{array}$ \\
\hline HEl* $^{*}$ & $\begin{array}{l}\text { Higher Education Institution, covering universities and } \\
\text { universities of applied sciences. The scope of this thesis is } \\
\text { especially in the Soft Skills needed and taught at Business and } \\
\text { ICT HEls. }\end{array}$ \\
\hline
\end{tabular}




\begin{tabular}{|c|c|}
\hline HR & $\begin{array}{l}\text { Human Resources - refers to the administration of human } \\
\text { capital in Organizations. Responsible for the recruitment of } \\
\text { adequate employees and maintenance of their competence } \\
\text { and motivation. (HumanresourcesEdu) }\end{array}$ \\
\hline HRD & $\begin{array}{l}\text { Human Resource Development function, conducted in } \\
\text { Organizations to administer and develop employees. Includes } \\
\text { mapping of skills and development of them. (UNESCO) }\end{array}$ \\
\hline $\begin{array}{l}\text { HRD } \\
\text { professional }\end{array}$ & $\begin{array}{l}\text { A person specialized in the HRD function, responsible for } \\
\text { recruiting, administering and developing employees. }\end{array}$ \\
\hline ICT & $\begin{array}{l}\text { Information and Communication Technology. This research } \\
\text { focuses on the Soft Skills needed in business and ICT } \\
\text { Organizations, in particular. }\end{array}$ \\
\hline Industry 4.0 & $\begin{array}{l}\text { A concept describing the ongoing change in Organizations, } \\
\text { characterized by increasing adoption of computers and } \\
\text { automation, involving autonomous systems fueled by data and } \\
\text { machine learning. (Forbes, 2018) }\end{array}$ \\
\hline $\begin{array}{l}\text { Lifelong } \\
\text { learning }\end{array}$ & $\begin{array}{l}\text { A paradigm that emphasizes the continuous character of } \\
\text { learning for personal and professional purposes, being } \\
\text { necessary in a world with constant change and increasing } \\
\text { amounts of information and knowledge. (Dehmel, 2006) }\end{array}$ \\
\hline Organization* & $\begin{array}{l}\text { A private, public or non-governmental body that has a } \\
\text { resources and staff to reach its goals. (Kaplan \& Norton, 2004) } \\
\text { In this thesis Organizations are considered primarily as } \\
\text { employers of HEl graduates and employees, and consequently, } \\
\text { as stakeholders in the skills acquisition process. }\end{array}$ \\
\hline Skill & $\begin{array}{l}\text { The ability to perform an action with determined results, often } \\
\text { within a given resource. (Dictionary.com) }\end{array}$ \\
\hline Skills gap & $\begin{array}{l}\text { A status where the skills of a worker do not meet the needs of a } \\
\text { work task in an Organization. (OECD 2016) }\end{array}$ \\
\hline Skills mismatch & $\begin{array}{l}\text { Discrepancy between the skills that are sought by employers } \\
\text { and the skills that are possessed by individuals. Skills can be } \\
\text { defective or excessive. (ILO). }\end{array}$ \\
\hline Soft Skill* & $\begin{array}{l}\text { Non-domain-specific skill, increasingly needed in modern } \\
\text { working contexts (e.g., communication, team working, self- } \\
\text { management skills). (Heckman \& Kautz, 2012) }\end{array}$ \\
\hline $\begin{array}{l}\text { Soft Skills } \\
\text { acquisition } \\
\text { process }\end{array}$ & $\begin{array}{l}\text { A proposal of this thesis. It intends to model the acquisition of } \\
\text { Soft Skills in a long-term view, reflecting the theory of lifelong } \\
\text { learning (Steffe \& Gale, 1995; Field, 2000) }\end{array}$ \\
\hline $\begin{array}{l}\text { Soft Skills } \\
\text { taxonomy }\end{array}$ & $\begin{array}{l}\text { A categorization of Soft Skills that considers different contextual } \\
\text { dimensions of the skills and their application. }\end{array}$ \\
\hline
\end{tabular}




\begin{tabular}{|l|l|}
\hline Stakeholder & $\begin{array}{l}\text { Refers to organizational theories in business: a person, group, } \\
\text { or organization with an interest in a project or process. Often this } \\
\text { includes intercourse or interdependence with other actors within } \\
\text { the organization. (Corporate Finance Institute) } \\
\text { The concept 'Stakeholder' enables modeling the Soft Skills } \\
\text { acquisition process by reviewing it from the aspect of the actors } \\
\text { that have interest in it. }\end{array}$ \\
\hline $\begin{array}{l}\text { Transversal } \\
\text { skill }\end{array}$ & $\begin{array}{l}\text { Skills that can be used in a wide variety of situations and work } \\
\text { settings, thus not typically considered specifically related to a } \\
\text { particular job, task, academic discipline or area of knowledge. } \\
\text { (Unevoc, UNESCO) }\end{array}$ \\
\hline $\begin{array}{l}\text { *This thesis examines the Soft Skills gap between education and working life. For } \\
\text { this reason, capital letters are used when highlighting the actors, Higher Education } \\
\text { Institutions and Organizations. } \\
* * \text { When referring to these Soft Skills, the italic font is used (e.g., communication, } \\
\text { team working, initiative) }\end{array}$ \\
\hline
\end{tabular}


1 


\section{Introduction}

\subsection{Motivation for this Thesis}

My childhood and youth have been somewhat extraordinary, as I was born in Finland to a family with German roots and I grew up mainly with my mother and sister, in an environment characterized by a family enterprise run by my grandparents. This ambient shaped me to cultural adaptation as well as multiple types of personal communication. Also, I learned how important it is to be open to new possibilities and change.

My professional experience in a range of Organizations has also offered a window to follow the multiple transformation that is happening in working life, covering the pace of working, heightened individual efforts and goal-setting, working in teams in a variety of networks and digital platforms. The rise of the internet and globalization have provided an enormous amount of new options for us as consumers, whereby they offer both options and demands for Organizations. The increasing work in networks, 24/7 work and multicultural environments challenge each employee and professional in terms of adaptation and communication. However, the client and the decision-maker is always a human individual. For this reason, individual skills, such as flexibility, team working and effective communication continue making the difference between successful and less successful Organizations. This makes them highly important for business students.

Consequently, it felt both logical and motivating to study in more detail the individual competences needed in the 2020s' business environments. This thesis deals with the Soft Skills needed in Business environments in particular. Although the importance of these kinds of skills is widely acknowledged, their character and learning potential remain ambiguous.

For Organizations, employees with appropriate competence form the core of their performance. The interest towards competence thinking is growing, as there seems to be a 


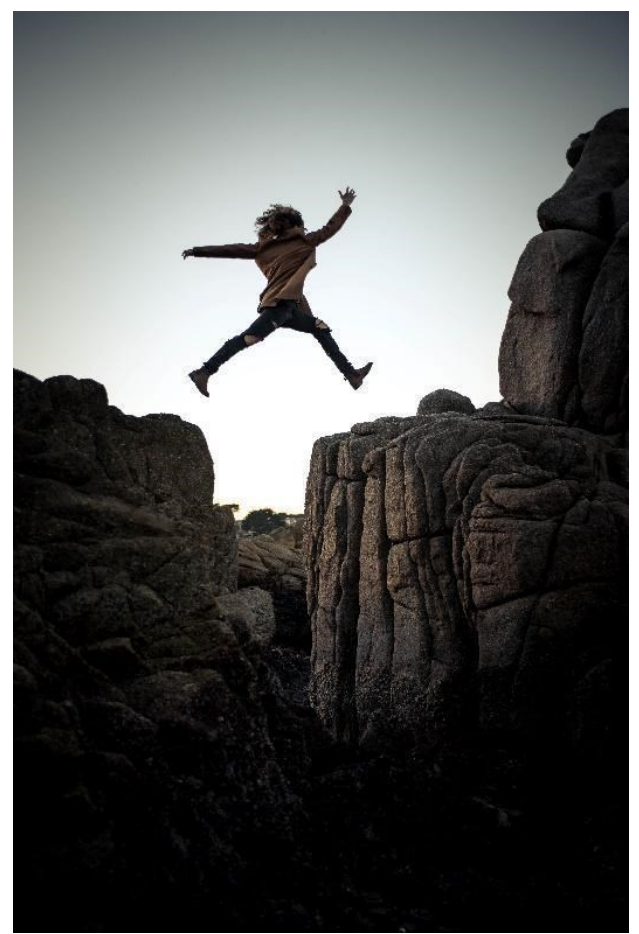

Figure 1 Bridging the 'skills gap' is a common goal of graduates, employers and educators. * skills mismatch and skills gaps, causing Organizations problems in recruiting skilled workforce (Bughin et al., 2018). The skills gap is presented in more detail in paragraph 2.4 .

To bridge the skills gap, Higher Education need more understanding of the competence needed in the different positions of business Organizations. As for this research, this understanding can best be transmitted by mapping out the skills needed by business and ICT professionals in their daily work. The aim of this thesis is to elucidate the Soft Skills needed in Business Organizations and provide indications on their promotion.

*Photo by Sammie Chaffin on Unsplash

\subsection{Hypothesis}

Regarding to the 'Soft Skills gap', there are various questions that enable finding solutions to the problem. First, when discussing 'Soft Skills', a broad set of skills are referred to, the variety of titles used in respect to them can be even confusing, which makes the definition of the 'right' skills titles difficult. This may lead to situations where the same skills are called with varying names. In addition, many of them are field-related and thus various actors and fields tend to use their specific titles (Cinque, 2015; Schleutker, 2017). If we want to enable a discussion between HEl sand Organizations, we have to define the most essential Soft Skills in the respective professional field, i.e. in the business context.

Moreover, the character of Soft Skills is somewhat ambiguous in respect to their character and application. They have often been considered 'inherent' (Gilbert, Balatti, Turner \& Whitehouse, 2004) or even 'inborn' (Grugulis \& Vincent, 2009). Unlike hard skills, which refer to the ability to perform a certain type of task or activity, Soft Skills are applicable in various professions and disciplines (Schulz, 2008). This means that various skills may have a different role and significance depending on the context they are used in. Also, it is obvious that various Soft Skills have internal dependence, for instance communication is likely to support considerably to team working or leadership. This means that when selecting Soft 
Skills for HEl curricula or training programs, we have to know more about their contexts of use and their interdependence. Communication, especially, is a centric Soft Skill when practicing other Soft Skills.

Third, while there are established learning methods for the majority of hard skills at HEls, these methods are only being sought so far, and it is has been said that there are few learning methods for them (Tulgan, 2015). Tradionally, Soft Skills have been described as 'hardly-teachable' (e.g., Bereiter \& Scardamalia, 2006). It is likely that some skills are easier to learn than others, yet learning of them also depends on personal traits and experience (Tulgan, 2015). It is widely agreed that learning of Soft Skills takes place through practice and personal experiences, (e.g., Muir, 2004; Mitchell, Skinner \& White, 2010; Tulgan, 2015) In addition, teaching of Soft Skills will probably cause extra effort for teachers (Redomero, Caggiano, Poza Luján \& Piccione, 2019). For these reasons it is obvious that educators and trainers are in a kind of 'where-to-start' position. This research aims to provide indication to the learnability of essential Soft Skills in business and ICT context.

The main hypothesis is:

"Based on the communication process, Soft Skills can be organized according to their significance to Organizations, universities and employees, and their development potential can be detected."

This hypothesis can be divided in the following operative objectives, in order to determine the aims of the thesis:

01: Soft Skills can be organized based on the communication process (conducted in 2.1 'State of the art' and in 3.1. 'Communication based Taxonomy')

O2: Certain Soft Skills are more significant in working contexts than others (conducted in 2.2 'State of the art' and in 3.2 'Experiments' ).

O3: At least some of these skills can be detected (in 2.3 ' State of the art' and in 3.2. 'The proposed Method 3Si')

04: And developed (in 2.4 'State of the art') 


\subsection{Aims and targets}

The research project is organized in the following operational phases:

1. Review of Soft Skills titles and maps in academic, working and organizational contexts by desktop studies and exploratory research, in order to uncover and reduce the number of Soft Skills titles that are in use, and

2. consecutively, select the most appropriate ones into a Framework, viable to be used as an instrument in this research,

3. and consider these skills from the aspect of communication levels and create a communication based Taxonomy of Soft Skills.

4. Consecutively, model the acquisition of the Soft Skills method in the scope of lifelong learning, and

5. based on this, create a method 'Soft Skills Status indicator (3Si)' for detecting and classifying Soft Skills.

6. Experiment this method by empirical research (survey), and subsequently

7. report and discuss the results.

8. Finally, disseminate the results of the research project.

\subsection{Methodology}

The first task is to examine the area of Soft Skills comprehensively, to such extent that it is possible to create a Soft Skills framework, adaptable for assessment and promotion measures for both Educational and Organizational bodies. This examination is expected to help in identifying essential Soft Skills and define the most commonly used ones in working and organizational contexts. Further on, the Framework, combined with a theoretical grounding is expected to serve in the creation of a method, capable of assessing and classifying Soft Skills. The research process is presented in the graphical abstract (Table 1). The justification of the selected research methods is presented in more detail in 2.3.1. 


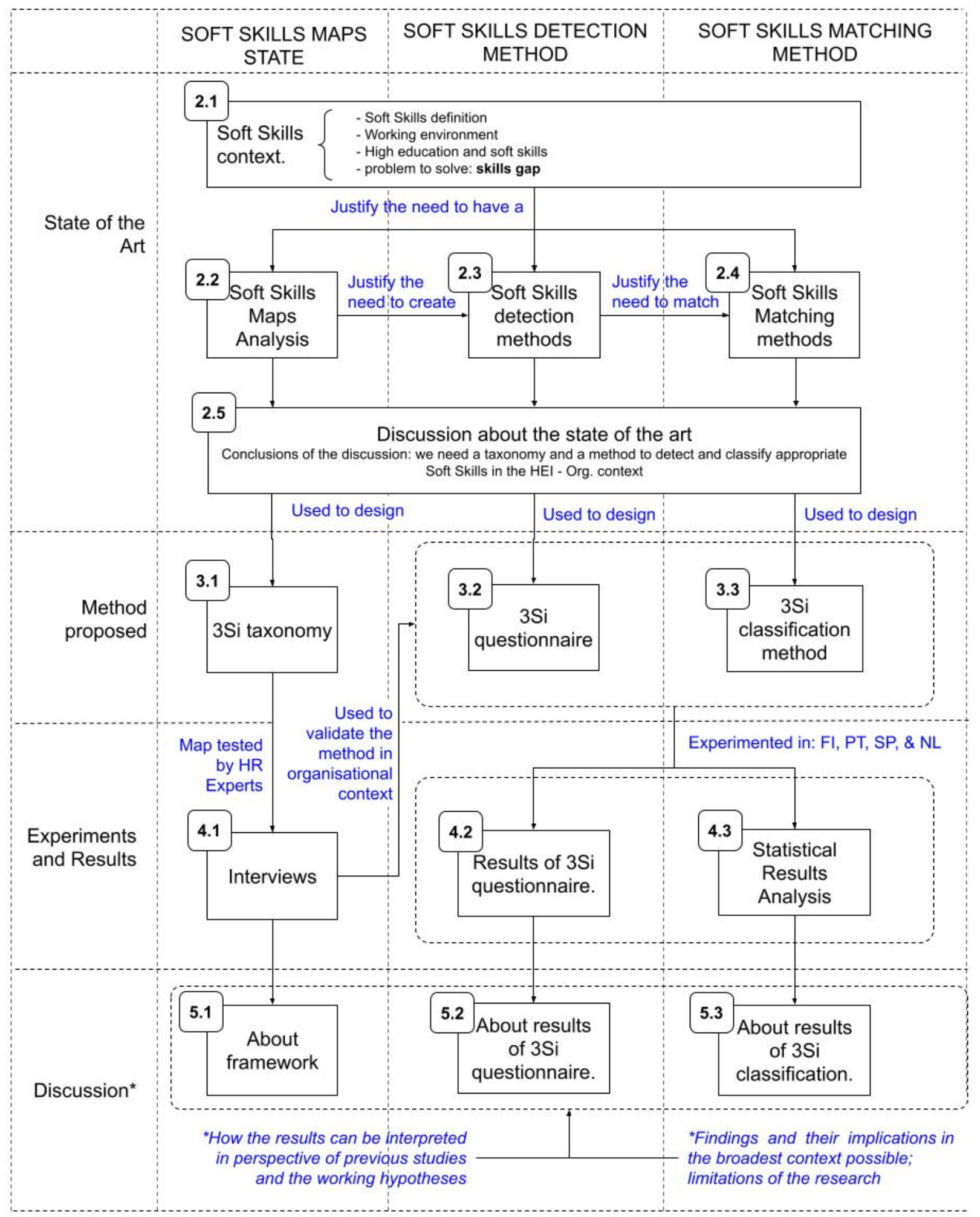

Figure 2 The graphical abstract of the research (Poza-Luján, Schleutker) 
The research applies both qualitative and quantitative research methods. The process starts with presenting the State of Art, first characterizing Soft Skills and their role in the context of Education (HEls) and working life (Organizations) (in 2.1). Next, the titles and terminology used to address Soft Skills is examined by reviewing existing Skills maps and methods. The review is conducted by using the exploratory research method, whereby adequate skills maps from a variety of professional and academic contexts will be selected for closer examination $(2.2,2.3)$. The aim of this phase is to define the range of Soft Skills used in different contexts, and subsequently to delimit to an appropriate number of skills to focus on, to enable a match of the Soft Skills provided by HEls with those needed in Organizations.

For this phase, exploratory research is considered adequate, as the number of titles used for Soft Skills is huge and it is necessary to reduce this number. A smaller number of selected and well-argued skills is needed in order to enable a better understanding between HEls and Organizations. Based on the outcomes of the exploratory research, a Framework for Soft Skills will be composed. In addition, the role and use of communication will be examined closer, as this skill obviously consists of different levels, such as intrapersonal and interpersonal levels. Communication has been reported to be one of the most important soft skills, and the Taxonomy (in 3.1) is suggested in order to understand better the central role of communication, for its better promotion at business HEls. In a further phase, the suggested Framework will be tested through an experiment conducted by interviews with a focus group (4.1).

The fundamental mission of the research is to examine Soft Skills in the context between HEls and Organizations and find out whether some of them are more important and potential than others. For this purpose, my aim is to create a Method, able to consider the acquisition process of Soft Skills over a longer period, and able to consider the interests of all the three stakeholders (educators, learners, employers) of the process. This process and the conditions for matching Soft Skills, i.e., those taught at HEls with the ones needed in working environments, are described and discussed in 2.4 .

The introduced three-dimensional approach enables to design a survey questionnaire in which most commonly used Soft Skills (from the Framework) are assessed in three statistical dimensions. The founding idea of the survey is that, when launching it to experienced people 
in a given field (in this case business and ICT), their assessment of the skills will offer a three-dimensional insight on each skill. As an outcome, we will get a Classification that considers the three main aspects, namely the Significance, the Learnability and the Level of performance (of graduate or employee) of each of the skills. These aspects are interesting for any learner or educator as such, yet they have a special value to educators, HR professionals, managers and organizational trainers in the business and ICT fields.

The proposed method, the 'Soft Skills Status indicator' (3Si), is the main outcome of the thesis. The method, including the 3Si survey tool, as well as the resulting 3Si Classification, is presented in 3.2 and 3.3 .

In order to prove the Method, its usefulness and relevance of the outcomes, it will be tested by two experiments. First, the Survey tool 3Si (the questionnaire) is presented to experts and focus groups with experience from Human Relations issues and skills maps (4.1), to confirm its validity.

After this step, the empirical phase follows. The survey will be launched in four countries (Finland, Spain, Portugal and the Netherlands). In accordance with the fundamentals of the Method, the sample consists of people who have considerable working experience in either the business or ICT fields and thus appropriate to assess these skills. The primary results are presented in 4.2, and the main outcome, the Classification 3Si based on this sample, in 4.3.

The results of the Survey, especially the main findings, are discussed in the light of their significance and previous research. Furthermore, the outcomes from the Classification in this sample are analyzed and their practical implications considered more profoundly. Finally, the relevance and contribution of the research and the Method 3Si are discussed.

The final stage of the thesis is the publication and dissemination of the outcomes and results of the research, to reach teachers, curricula planners, researchers and students at HEls as well as HR professionals and managers in Organizations. These activities are presented in chapter 6. 


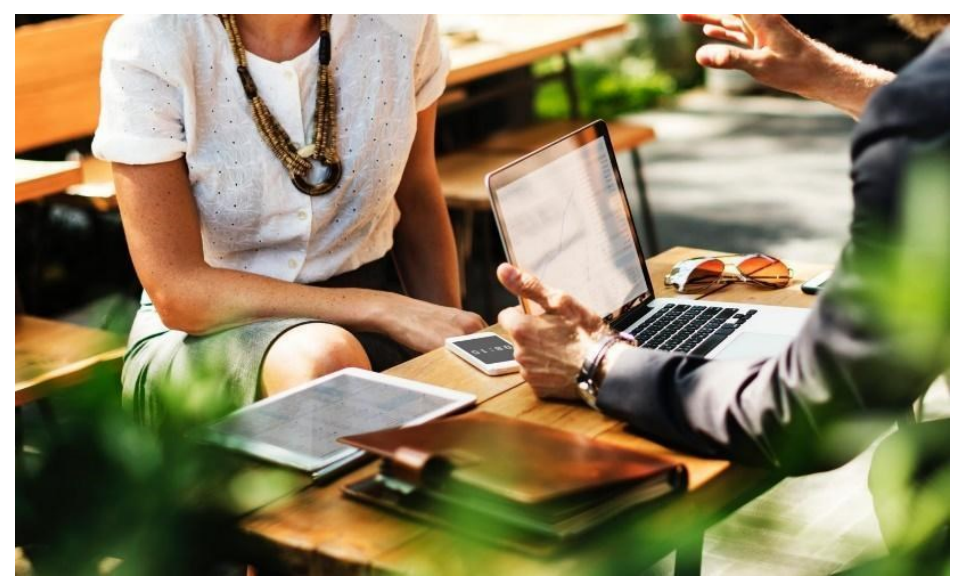

Figure 3 Definition of the core Soft Skills is a step towards developing them.

\subsection{Document description}

This report has been organized in the following order. Chapter 1 covers the premises of the research, presenting the purpose of it, as well as the set hypothesis. Chapter 2 presents the state of art of Soft Skills in the light of current research and practice. In particular, the reported skills gap between Higher Education and Organizations is presented and discussed.

Chapter 3 presents practical implications based on the research presented in chapter 2, and my design effort. First, the Taxonomy that exhibits Soft Skills in relationship to the type of communication they are used with is presented. Second, the foundations for the method $3 \mathrm{Si}$ are presented in figures and next, the classification $3 \mathrm{Si}$ is presented as a table.

Chapter 4 presents the practical experiments that were conducted to validate and test the method 3Si.

In chapter 5 , the findings and results are discussed and their contribution to the existing state of the art is considered.

In chapter 6 the publications and other dissemination activities carried out throughout the thesis work are presented. Chapter 7 concludes the thesis work and suggests objects for future research.

The bibliography and all annexes can be found at the end of the report. 


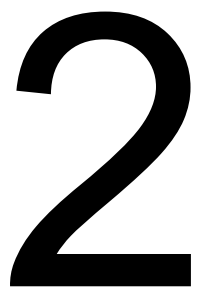




\section{State of the art}

Along with dynamic and turbulent working environments, new competencies and skills become necessary. The routine jobs of yesterday are being replaced by goal-oriented work in multi-professional teams, increasingly networking and digitizing. According to Koenig (2011), job categories that involve abstract reasoning and individual effort and service seem to be growing, wherefore modern workplaces wish to recruit employees with sufficient cognitive and affective skills. These types of 'Soft Skills' include being able to collaborate effectively with others, to adapt to rapidly changing environments and conditions for performing tasks, to manage one's work in goal-oriented manner, solve problems and think critically about tasks and acquire new skills (Koenig, 2011).

According to many studies worldwide, Soft Skills form an ever more important part of professional competence in many fields (e.g., Schulz, 2008; Mason et al., 2009; Mitchell, Skinner \& White, 2010; Robles, 2012; WEF, 2016; Bughin et al., 2018). Nevertheless, some recent research and reports indicate that graduates lack these skills (Cappelli, 2012; Mourshed, Patel \& Suder, 2014; Cinque, 2015; OECD, 2016). This is a major challenge for higher education, as education should provide graduates with appropriate skills needed in the current working life (Eurydice, 2014; Eurydice, 2019). Obviously, this challenge also concerns most Organizations, as Soft Skills evidently also raise the Organizational performance (Cimatti, 2016; Caggiano et al., 2016).

\subsection{The character of Soft Skills}

\subsubsection{About competences and Skills}

When discussing professional education, the concepts 'competence' and 'skill' are crucial. Basically, professional competence consists of a set of personal abilities and skills that enable performing jobs successfully (Sanghi, 2016). By a more detailed definition, competence is 'a combination of knowledge, skills and behaviour, including attitudes' (Le Boterf, 1997), thus involving individual attitudes in the concept. According to Perrenoud (1997), competence is composed of various skills, whereby skills are needed to mobilize and operationalize knowledge. Often the practical context is emphasized by calling 
competence as 'knowledge in use'; for instance Sanghi (2016) defines competence as "action in context". Berdrow and Evers (2010) stated further that competences are "complexities of contextualized know-how, and combinatorial, ongoing, contextual and evolutionary as well".

These definitions stress the contextuality of competences and skills, which allows to think that competences are field-related, indicating that various disciplines and professions have their typical competencies and skills. In addition, it is obvious that they include the idea of evolution, suggesting that competences and skills develop, partly in a generic way, probably often unconsciously.

Logically, 'competence' and 'skill' are often used in the context of education and learning, to describe the outcomes of HEI programs and disciplines. The European project for Tuning Skills (2003) defined competence as "a combination of dynamics of attributes, in relation to knowledge, skills, attitudes and responsibilities, which describe the learning outcomes of an educational program". In the European ESCO platform, competences are viewed as "a set of knowledge, skills and abilities related to the training program that allows the student to develop the professional tasks included in the degree program profile." These quotations affirm that 'competences' and 'skills' also exhibit goals and measures for educational activities.

To conclude, competence refers to various cognitive capacities and skills that are needed to 'act', i.e., to mobilize resources to match different situations with aimed results. Consequently, competence refers to a holistic ability to perform in a job, being composed of a set of skills. For this reason, educational activities are most often targeted at individual skills, to achieve aimed individual competence.

In addition to HEls, the concepts of competences and skills are used in Organizations and working life as measures of working performance.

Yet, it is possible that HEls do not always have a mutual understanding with Organizations of the important skills in a given subject. Educational institutions tend to follow a long-term plan (Garcia Aracil \& van der Velden, 2008; Tedesco, Opertti \& Amadeo, 2014), whereas Organizations may face needs for new competencies in shorter terms (Sanghi, 2016; Bughin 
et al., 2018). In addition, Organizational environments offer a broad variety of contexts and needs, whereby it has become evident that HEls cannot match all the competencies needed in working life (Mason, 2009; Mitchell et al., 2010; Caggiano et al., 2016). This may lead to the phenomena of 'skills gap' or 'skills mismatch', which will be discussed more profoundly later in this chapter.

\subsubsection{Definition of Soft Skills}

By some definitions, Soft Skills are a set of intrapersonal and interpersonal skills that include common sense, the ability to deal with people, and a positive flexible attitude (Koenig, 2011). For instance, communication, team working, self-management and certain cognitive skills can be considered Soft Skills. Also, Soft Skills can be seen as an umbrella term for skills under three key functional elements: people skills, social skills, and personal career attributes (Robles, 2012).

\section{"Soft Skills get little respect but they will make or break your career"' Peggy Klaus, author}

The concept 'Soft Skills' originates from 'social skills', needed in interaction between people in any working environment. In the early 1990s, Gardner (1994) and Goleman (in Schutte, Malouff, Hall, Haggert, Cooper, Golden \& Dornheim, 1998) introduced the concept of emotional intelligence, which induced an increasing discussion of the intrapersonal traits needed for successful social interrelations. Later, intrapersonal skills, such as goal orientation, strategic thinking, problem-solving and positive attitude have become under research and discussion (e.g., Bereiter \& Scardamalia, 2006; Robles, 2012; Cimatti, 2016), in complementary to interpersonal, or social skills, that had been acknowledged earlier.

Along with the increasing interest and the growing amount of research conducted, the relevance of Soft Skills is understood better. Currently, a huge number of worldwide Organizations and funders are investing in the training and development of this field (WEF, 2016; Mourshed et al, 2014; Bughin et al., 2018). In addition, the European Commission launched the program 'Agenda for new skills and jobs' to train and explain to young adults this new set of skills (Succi \& Canovi, 2019). 
As it seems obvious that Soft Skills are not directly field- or profession-specific such as many hard skills, we can assume that they have a more person-bound and ambiguous character than the latter ones. Indeed, it can be seen that such skills as communication, selfconfidence, decision making or customer orientation are often considered inherent (Gilbert et al., 2004; Cimatti, 2016). For these reasons, Soft Skills are also called 'generic', meaning that they are developed because of individual experiences, or 'transversal' in the sense that they are transferable to different contexts or working positions, or 'employability skills' as necessary abilities for graduated students and young professionals to get their first job. Initially, 'social skills' also refer to Soft Skills, even though on a more restricted scale, covering mostly skills needed in interaction with other people. Furthermore, '21st century skills' is used as title for these skills, originating from the U.S.A. (Mitchell et al., 2010) Thus, it is evident that many different terms are used, yet addressing the same types of skills. Also, it is obvious that specific professional fields have their own titles for Soft Skills (Schleutker, 2017).

Consequently, the character of Soft Skills has often been considered vague and unclear. Also, they have been seen as subjective and hard to specify, as they are often close to individual abilities (e.g., initiative, goal orientation, leadership). This has led to a thought that they are hard to teach (e.g., Bereiter \& Scardamalia, 2006; Mitchell et al., 2010) and assess (Capelli, 2012; Tedesco et al., 2014). The vagueness and the multiplicity of the titles also explain why these skills are not always clearly understood by employers and employees, which has confused the discussion between Organizations and educational bodies (Cinque, 2016). It is not unusual that employers feel that recruited people, perhaps graduated, miss some skills; yet, in some cases, they are not able to define the missing abilities. On the other hand, it is even more common that employers can express the deficit, but for an educator, it is difficult to fit in the skill in an educational context.

Undoubtedly, one of the advantages of Soft Skills lies in the fact that they are not restricted to a specific field, and thus they can be transferred to different contexts and job positions (Schulz, 2008; Jones et al., 2017).

However, recently it has been repeatedly reported that graduates lack Soft Skills, and that employers face problems in recruiting workforce (Mourshed et al., 2014; Cinque, 2015; 
Bughin et al., 2018). In the following chapters, I consider Soft Skills from the aspects of working life and from education, trying to elucidate causes of this skills gap.

\subsubsection{Soft Skills in Working Contexts}

One predominant reason for the increased need of Soft Skills is our time. As change and turbulence are the main driving forces of the working life of the 2000s (e.g., Koenig, 2011; Bughin et al., 2018; Silber-Varod, Eshet-Alkalai \& Geri, 2019), the role of individual mastery is increasing, as well as the ability to adapt to changes. Obviously, our time also needs more and more digital skills and other technical skills, yet, with mostly context-specific abilities, it would be hard to cope with new situations and work with a variety of people. The ductility of Soft Skills helps employees to adapt and behave positively so that they can deal effectively with the challenges of their professional and everyday life (Succi, 2015).

\section{"It is not the strongest or most intelligent who will survive but those who can best manage change." Charles Darwin, scientist}

Consequently, these kinds of skills are useful for workplace performance, regardless of the academic subject area. It is quite clear that communication and team working skills, for instance, are widely needed; yet there is a variety of other, less known Soft Skills that become essential, for instance initiative, goal orientation or customer orientation. These kinds of skills are increasingly appreciated and sought after by employers and Organizations (e.g., Mourshed et al., 2014; Succi, 2015; WEF, 2015; Bughin et al., 2018).

It is often said that the employees form the most important element of organizational performance. Along with turbulence and changes, prompt decisions and quick reactions help Organizations to survive in competition. Accordingly, the Soft Skills of managers and employees may help to obtain more consistent and accurate results, improving the quality of the measures and the strategies adopted (Schulz, 2008; Jones et al., 2017). Furthermore, Soft Skills are linked to personal objectives and motivations (Cimatti, 2016), which is useful in daily life and in workplaces. For instance, the performance and success of a salesperson highly depends on their skills to understand and affect people, and a team manager will benefit from having personal motivation and goal orientation. 
For the same reason, it has also been suggested that entrepreneurs benefit from appropriate Soft Skills (Caggiano, Akanazu, Furfari \& Hageman, 2016). An entrepreneur needs to maintain motivation, manage themselves and communicate with customers on many levels.

Work performance is also affected by personal values and context-related factors where the skills are applied. For example, an employee may have highly developed decision-making skills, but without the necessary autonomy to conduct the job role, the performance related to this skill is low. (Cinque, 2015)

\section{"Talent wins games, but team working and intelligence win championships." Michael Jordan, athlete}

Due to their value in the labour market, the development of Soft Skills in higher education students has been increasingly considered a key factor to ensure not only work success, but also an effective transition from higher education into the labour market (e.g., Jones et al., 2017; Eurydice, 2019).

In a McKinsey study (Mourshed et al., 2014), covering eight European countries (Spain, France, Italy, Germany, Portugal, Sweden, Netherlands and Greece), more than 3000 employers and managers were asked to rate a variety of skills that would probably be needed by employees in the near future. The results indicate not only the importance of digital literacy and technical skills, but also the growing need of skills such as creativity, problem solving, oral presentation, team working and work ethic.

Another comprehensive world-wide study (Bughin et al., 2018) highlighted future working skills needed along with the increasing digitalization. Managers and employers were asked to assess the contemporary (year 2020) and future (year 2030) share of working time dedicated to various types of activities. According to the report, Soft Skills (communication, team working, self-management and learning and use of knowledge) will exceed the share of technical skills by the year 2030 .

Regarding the field of business management, it has traditionally been considered more as a playground of inputs and outputs of economic resources, rather than human interaction. 
For times, a manager was expected to possess theoretical and strategic orientation, communicating the plans and strategies rather than interacting with people and motivating them. Starting from the late 1990s, the importance of paying attention to individuals and their needs started to become mainstream in Organizations. This new 'people-oriented' management style was called 'Leadership'. Consequently, in the early 2000s, higher business education was urged to promote individual readiness and practical skills, instead of purely theoretical knowledge (Bennis \& O'Toole, 2005; Lehtinen, 2006; Anthony \& Garner, 2016).

Even in the field of engineering and ICT, hard skills have traditionally been the core of professional competence. However, globalization and work in teams, increasingly in customer interfaces have provoked the need of skills such as leadership in project management (Stevenson \& Starkweather, 2010; Wikle \& Fagin, 2015).

In general, employers and Organizations have increasingly stressed the importance of Soft Skills, as complementary to hard skills (e.g., Andrews \& Highson, 2008; Mitchell et al., 2010; Jones, 2017). Also, the European Union (Eurydice 2014, 2019) has encouraged higher education and vocational schools to reform their educational programs to provide graduates with skills that match better the skills needed in the 2020 s.

\subsubsection{Skills gap - lack of Soft Skills}

Despite their evident significance as a part of professional competence, several studies (Mourshed et al., 2014; WEF 2016) indicate that the skills of graduates and young professionals do not fully match with the needs of Organizations and employers. This phenomenon is known as 'skills mismatch' (EC, 2015; OECD, 2016) or 'skills gap' (Mourshed et al., 2014; Tulgan, 2015). Although the existence of the skills gap has also been doubted (e.g., Cappelli, 2012), it is generally agreed that it is real (EC, 2015; Jones et al., 2017), which is affirmed by the mentioned reports.

According to the previously mentioned survey (Mourshed et al., 2014), the biggest skills gaps, considered by employers and managers, were found in Soft Skills such as problem solving, oral presentation, work ethic, team working and creativity. These skills relate 
predominantly to the levels 4 and 6 in the EQF classification, and to the 'transversal skills' in the ESCO classification elaborated in 2013-20 (ESCO).

The skills mismatches and skills gaps cause several kinds of problems. In addition to reduced organizational performance due to the mismatches, companies are also likely to face recruitment problems. As an example, the time to fill a vacancy has increased from 20 to 28 days from 2005 to 2017. (Bughin et al., 2018). For these reasons, the skills mismatch has been considered one of the main obstacles in the European labour market (OECD, 2016; Eurydice, 2019).

From the point of view of the graduates, basically they are supposed to be equipped with the right skills to get employed after their graduation. Skills gaps, especially when occurred in significant skills, suggest that graduates will have problems in employment. Later, if remaining, they are likely to slow down career development. Along with the high unemployment rates, the discussion of graduates' skills gaps has become even more acute.

It is obvious that the skills gaps pose a significant challenge for the educational sector, as one of the missions of education is that it should, at least to some extent, anticipate the need of future skills, and aim to provide graduates with them (Eurydice 2014, 2019; Redomero et al., 2019). For these reasons, higher and vocational institutions have been encouraged to adjust their degree programs and goal competencies more in affinity with the needs of the labour market (Eurydice 2015; Eurydice 2019).

It must be added that for the majority of HEls, a success in 'producing' skilled and competitive graduates is important for many reasons, one of the most important being that most HEls, at least the public ones, are measured by the employment rate and quality of their graduates. This has direct impact on their financial status. In addition, decent employment rates are likely to increase the attractiveness of a university among youth and students. This makes recruitment of high-level students easier.

\subsubsection{Skills gap and HEls}

In this chapter I will examine the status of Soft Skills at higher education institutions. This examination is, of course, on a general level, as there are no average universities. In my experience, there are a few HEls that are aware of Soft Skills, some of them putting effort 
on promoting these skills intentionally in practice. Probably, many HEls are applying mixed learning methods, which to some extent promote Soft Skills, although not intentionally.

Yet, in general, despite increased awareness about the relevance of Soft Skills, the explicit representation in the curricula of university studies has been poor (Gilbert et al., 2004; Nealy, 2005; Garcia Aracil \& van der Velden, 2008; Anthony \& Garner, 2016). The report Modernisation of Higher Education in Europe: Access, Retention and Employability (Eurydice, 2014) suggests that, while the employability of new graduates has become an important topic in the higher education policy discussion, the approach and levels of engagement towards the topic differ considerably.

According to Cinque (2015), some countries put the accent primarily on graduate employment rates, evidently by including all, even lower-lever employment in their statistics, while others focus on skills development, emphasizing the competences relevant for the labour market that need to be acquired through higher education. In addition, a number of countries seem to combine these two perspectives.

Moreover, the fact that Organizations increasingly value Soft Skills is becoming increasingly visible. According to Cinque (2015), hard skills, although still prominent in academic certificates, seem yet to be considered as being of less direct relevance to companies. Instead, employers and Organizations tend to emphasize more the candidates' personal qualities and attitudes, which cannot be recognized and validated by conventional diplomas or certificates.

Figure 4 displays the aspects in the skills gap discussion. An increasing variety of Soft Skills are needed in Organizations, but at the same time higher education can quite freely (Mason et al., 2009; Caggiano et al., 2020) choose the skills to be included in curricula and promoted. However, this does not guarantee that the 'right' skills will be taught and learned. 


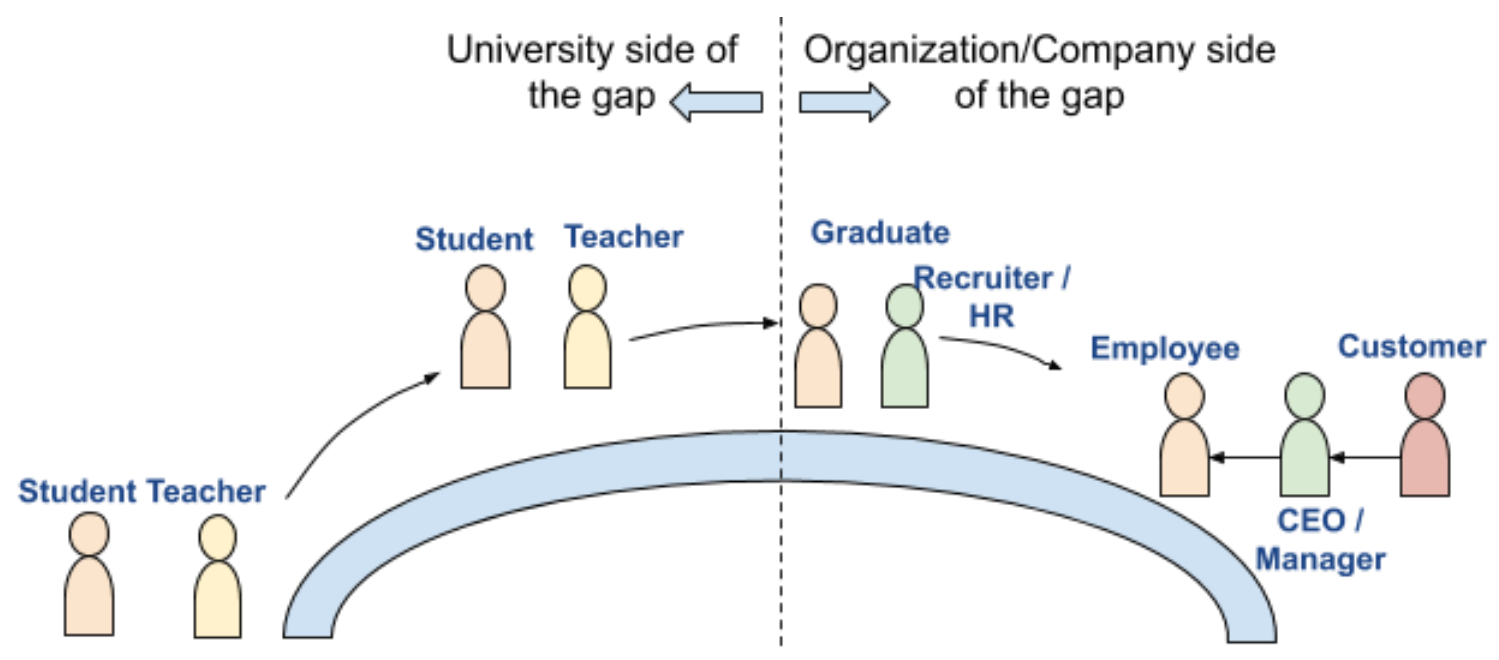

Figure 4 The thesis aims to combine the aspects of students, teachers and employers.

There are several reasons why the promotion of Soft Skills in degree programs has turned to be challenging. As they are relevant in the context of the research, I will shortly review some of them.

The first one is that most HEls create guidelines for the disciplines in cycles of 4-5 years, which offers limited possibilities to adapt with external changes, or include new skills. In addition, curricula are typically planned internally, mostly without regular intercourse with Organizations and employers (e.g., Garcia-Aracil, 2007; Tedesco et al., 2014). As working life undergoes constant changes (Sanghi, 2016; Bughin et al., 2018), educators may be short of a precise perception of skills needed currently. This may result in a situation where educators rely on traditional and well-known competences and skills, instead of seeking to update the sets of competencies and skills (Garcia-Aracil \& van der Velden, 2007; Anthony \& Garner, 2016; Redomero et al., 2019).

Second, when it comes to the character of Soft Skills, they have been considered 'generic' (Schulz, 2008), 'inherent' (Gilbert et al., 2004) and 'inborn' (Grugulis \& Vincent 2009), thus remaining somewhat ambiguous in the educational discussion. It is very common to believe that some people are more social than others, or better team workers or have better selfmanagement skills, by their nature. For this reason, Soft Skills are often considered as hardto-learn by researchers (e.g., Bereiter \& Scardamalia, 2006; Tulgan, 2015). This perception 
may also reflect to the educational sector, perhaps inducing an opinion that 'hard skills can be measured, whether Soft Skills are more difficult to define and promote'.

Third, we have the real problem of learnability, even if Soft Skills would be taken seriously and efforts would be made to include them in the curricula, in the next step, teachers and trainers face the challenge 'How?'. While some Soft Skills, such as oral presentation or analytic thinking may be considered to be taught easily, others, such as team working, communication or self-management might sound more challenging to teach and learn. At least, it is evident that they can hardly be learnt by traditional classroom methods (Bereiter \& Scardamalia, 2006; Gewertz, 2007; Tedesco et al., 2014).

In addition, there are other macro-level factors affecting the curricula of HEls and pressuring them. Obviously, there has been a revolution in the design of curricula in higher education around the world in the last 20 years in several ways. Some of the most remarkable sequences are:

a) The emergence of new job positions with new attributions has fostered an increase in the number of degrees offered by the universities.

b) For different types of degrees, different approaches can coexist, whereby the contents of degrees at HEls may vary.

These items require the recognition of (1) the equivalence of degrees from different institutions, (2) the qualification for taking certain job positions, (3) the acquisition of competences by the students, and (4) inner quality system to check that the previous items are correctly acquired by the students. All these points are certified by the evaluations of quality and accreditation agencies.

To conclude, Soft Skills are not yet considered in these evaluations and certifications (Tedesco et al., 2014; Jones et al., 2017). Thus, in most cases it remains open which Soft Skills are required for specific job positions. Despite several initiatives to collect this information, such as the all-European ESCO project, it is still a challenge to select and integrate it in the design of the university degrees. Alternatively, looking at the portfolios of 
courses on continuous education, Soft Skills have started to appear in them in the last few years. Again, there is no unified vision of what is understood as Soft Skills, and neither what are the most elementary and essential Soft Skills.

\subsubsection{Discussion}

As for Organizations, their performance and success depend on intelligence and, especially, how this intelligence is applied (Budhwar \& Bhatnagar, 2007; Azim, Gale, Lawlor-Wright, Kirkham, Khan \& Alam, 2010). The skills involved in these kinds of technical processes can be understood as hard skills. While technological advances were initially induced by individuals and 'geniuses', nowadays they are mainly created by teams. This is one reason why Soft Skills are becoming more and more important, as they are closely related to the performance of the team. Due to their transversal and general character, they can be adapted and modified according to the situation. Thus, they are broadly applicable in a variety of tasks, once acquired. This makes them different from many technical, 'hard' skills.

Undoubtedly, both types are needed, and a combination of hard and Soft Skills is generally considered necessary to provide a broader and better performance in the current labour market. To give a practical example, an IT professional with excellent technical skills will benefit remarkably from being able to communicate these skills within their team or to clients. Or, a skilled professional in culture production offers more value to the employing Organization, when possessing good team working skills.

Also, the working environments vary in different professional fields in terms of type of work, goal-setting, customerships and so on. In some fields (e.g., the healthcare and social sector) a 'soft' human approach may be highly appreciated and expected, whether in other fields, such as engineering, the focus has perhaps been in the process and its function. Thus, it must be noticed that the role and character of Soft Skills may vary in different professional fields. The following table demonstrates some of these differences.

\begin{tabular}{|l|l|l|}
\hline \multicolumn{1}{|c|}{ Point of View } & \multicolumn{1}{|c|}{ Hard skills } & \multicolumn{1}{c|}{ Soft Skills } \\
\hline Psychology & With Soft Skills, the hard skills grow. & $\begin{array}{l}\text { Soft Skills are necessary to enjoy Hard } \\
\text { Skills. }\end{array}$ \\
\hline Business & Hard skills give capacity to the person. & Soft Skills give value to the person. \\
\hline
\end{tabular}




\begin{tabular}{|l|l|}
\hline Engineering & $\begin{array}{l}\text { Symbiotic system (win-win): without software (Soft Skills), the hardware (hard skills) can't } \\
\text { be used, and without hardware (Hard Skills), software is useless. }\end{array}$ \\
\hline
\end{tabular}

Table 1 Hard and Soft Skills, as considered in different professional fields.

We can note that Soft Skills are perceived differently in varied professional fields. This can depend on the previously mentioned factors; moreover, also the culture in different Organizations may vary, depending on possession and management. To know the fieldspecific role of Soft Skills, this should be studied in detail.

To conclude, as not every competence is necessary for carrying out a particular job, not every Soft Skill will be necessary to be considered for each job position. Moreover, in some cases it will be counterproductive. As an example, 'oral communication' is needed for creating openness and trust, but excessive talking may harm team performance or even team spirit. Or 'empathy' will be appreciated in customer work, but it may make a project or customer relationship too costly when excessive or in the wrong context.

\subsection{Soft Skills Maps analysis}

\subsubsection{About Skills Maps}

If it is not clear what variety of Soft Skills are involved, it is difficult to establish the right Soft Skills for each job, and to determine to which level employees or graduates need them. As a first step, the variety of Soft Skills can be examined and detected in different registers and skills maps.

In Organizations, the new mainstream in management science, called "Talent management" has made it necessary to detect and assess a range of key competencies in the Organization at all levels (Budhwar \& Bhatnagar, 2007; Berdrow \& Evers, 2010). At the same time, customers, media and authorities are increasingly encouraging Organizations to perform according to sustainable and human values (Barrett, 2006; Hughes \& Rog, 2008). As a result of this, in many Organizations, at least in the bigger ones, managers and HR professionals have created skills maps to identify and develop the appropriate skills that match with the organizational culture and values (Paarlberg \& Perry, 2007).

However, managing skills profoundly involves more effort and goes beyond creating a list of skills, it is necessary to match skills with the Organization values, and to incorporate soft 
skills in the training processes. In addition, it is necessary to include these skills in the Organization strategy and manage the promotion of these skills (Budhwar \& Bhatnagar, 2007; Blazquez, 2014). Consequently, to create a skills map is only part of the solution to add skills as part of the Organization.

Consequently, for most Organizations, it is essential to know what Soft Skills their employees need, to perform in an optimal way. The skills maps and competence maps are a compendium of various competencies that seem appropriate to a specific job. For example, for business positions in sales and marketing, negotiation and communication skills are likely to be necessary, while, for an administrative position, order and quality or time management are more important.

Such maps are also useful for employment administration. According to Blazquez (2014), skills-based profiling tools in general serve to better diagnose individuals' strengths and weaknesses within the context of action planning and help target services more effectively for job entry. Thus, these kinds of tools can be expected to be highly useful in the matching process, enabling employers to include more detailed information on competence requirements, and the promotion of them.

\subsubsection{Existing skills maps and analysis}

The first operational phase of this research is to elucidate the Soft Skills titles that are used in educational, academic and organizational contexts. In addition, one map was included to represent graduates' skills, in particular, and finally one map to represent students' skills. I will study and analyze already existing skills maps, identify the most commonly used skills from various sources, and consecutively compare them and make a compilation of them. This phase enables to find the most relevant and appropriate titles, and thus reduce the number of skills. These Soft Skills must be relevant for both Higher Education and Organizations, as they will be used as an instrument in the further phases of the study (Framework).

The analysis of existing concepts and skills maps is carried out in following steps:

1. A desktop study research on concepts (skills/competences) to ensure coherence in the use of concepts 
2. Exploratory research on existing Soft Skills maps to detect the most used skills for the HEl-Organization context.

3. Analysis of graduates' skills map (MOSSA)

4. Analysis of students' skills map (UPV)

\section{Desktop study on concepts regarding skills/competencies}

Based on the thesaurus TESE, a list of titles that can be used to describe Soft Skills can be found by internet searches. To determine the adequate terms regarding skills/competences, a comparison has been made. For the comparison, all the terms used in the literature have been considered, using Google as a generic search engine, in addition scientific search engines (Scholar, Research Gate, Academia, Ref Seek) and professionals (LinkedIn and Eurostat) have been used. The results of this comparison can be found in annex 1 .

This search was conducted in June-July 2017. The most relevant result suggests that in the scientific field the title "skills framework" should be used for everything related to transversal competences. From a scientific point of view, also the titles "skills map" or "skills lists" are appropriate. Since from a professional point of view "skills map" seems more appropriate, this is the term used in the thesis. Obviously, the term "competence map" can also be used, although when it refers to a more general and less academic scope.

\subsubsection{Exploratory research on titles}

Given the high and blended variety of titles used, it would have been misleading to choose a certain existing skills map, without a broader examination. Exploratory research is well suitable for a situation where it is necessary to elucidate a field of research that is not yet clearly defined. In this case, we know that there is a big variety of titles used for certain types of skills, yet their frequency in use, mutual relationship and dimensions remain unstated. According to Stebbins (2001), this type of research is suitable to figure out the dimensions of a phenomenon and have a better understanding of the existing problem. In addition, it will normally give an indication on whether the research questions are properly set, or which variables are appropriate (Stebbins, 2001).

As the mission of this research is to facilitate the discussion between higher education and organizations and thus reduce the Soft Skills gap, it is essential to capture skills and titles 
that are appropriate for both parts. For this reason, the search is directed to different types of sources. It must cover educational, academic and organizational sources.

Given the large variety of titles and ambiguous categories referring to Soft Skills, noted by previous research (Cinque, 2015; Schleutker, 2017), it can be assumed that we can find a high number of skills in the existing skills maps. A very high number of skills would cause some problems, as it is necessary to compose a viable and compact Framework of skills to enable a discussion between education and working life. The number must be restricted also, as normally there is rather an excess of new skills than a lack of them, when planning curricula. A maximum number that we can think is $15-20$ skills, as this is a number that can be reasonably discussed and considered in organizational skills maps (Robles, 2012; Cinque, 2015).

The exploratory research was carried out in November-December 2017 by searches conducted in Google Scholar, Web of Science and Scopus, by using the following search words: 'Soft Skills categories', 'transversal skills categories', 'Soft Skills classification', 'transversal skills classification', '21. century skills categories', '21. century skills classification', 'employability skills categories' and 'employability skills classification'. Furthermore, only sources with clearly structured groups and titles of obvious Soft Skills were included. Although IT skills and other digital skills are sometimes counted as Soft Skills, they were excluded from the results, as their character is basically closer to hard skills, and they are commonly included in curricula already.

By applying these criteria, a total of 48 skills maps were detected. Of these, 18 were inadequate for various reasons (clusters rather than skills, too general-level, not academic skills, include other than Soft Skills). Hence, 30 relevant skills maps were selected in the analysis. They could be divided in four groups:

* Scientific articles, research reports (9)

* Educational development projects funded by the European Community (8)

* Other educational development projects by non-profit Organizations (6)

* Organizations in skills training and HRD (7) 
All these groups have a slightly different approach to the skills. As for scientific articles, they normally report research related to Soft Skills, wherefore they include typically a rather small number of previously acknowledged Soft Skills. In turn, various development projects and non-profit Organizations may have the aim to map out skills-in-use, their number of skills varies and can be large. They are often focused on vocational or higher education rather than the skills used in Organizations. The biggest variety and number of titles were found in the skills maps of Organizations, many of which may include novel skills not found in the two previous groups, e.g., 'assertiveness', 'innovativeness' or 'helicopter view'. The number of titles in each map reviewed varied from five skills up to 82 skills.

The skills titles found were structured and analyzed by means of Microsoft Excel by their quantities, whereby also their source was documented. The abstract presented in figure 6 shows in detail the sources found (horizontal direction) and the titles included in them (vertical). The entire excel sheet is annexed.

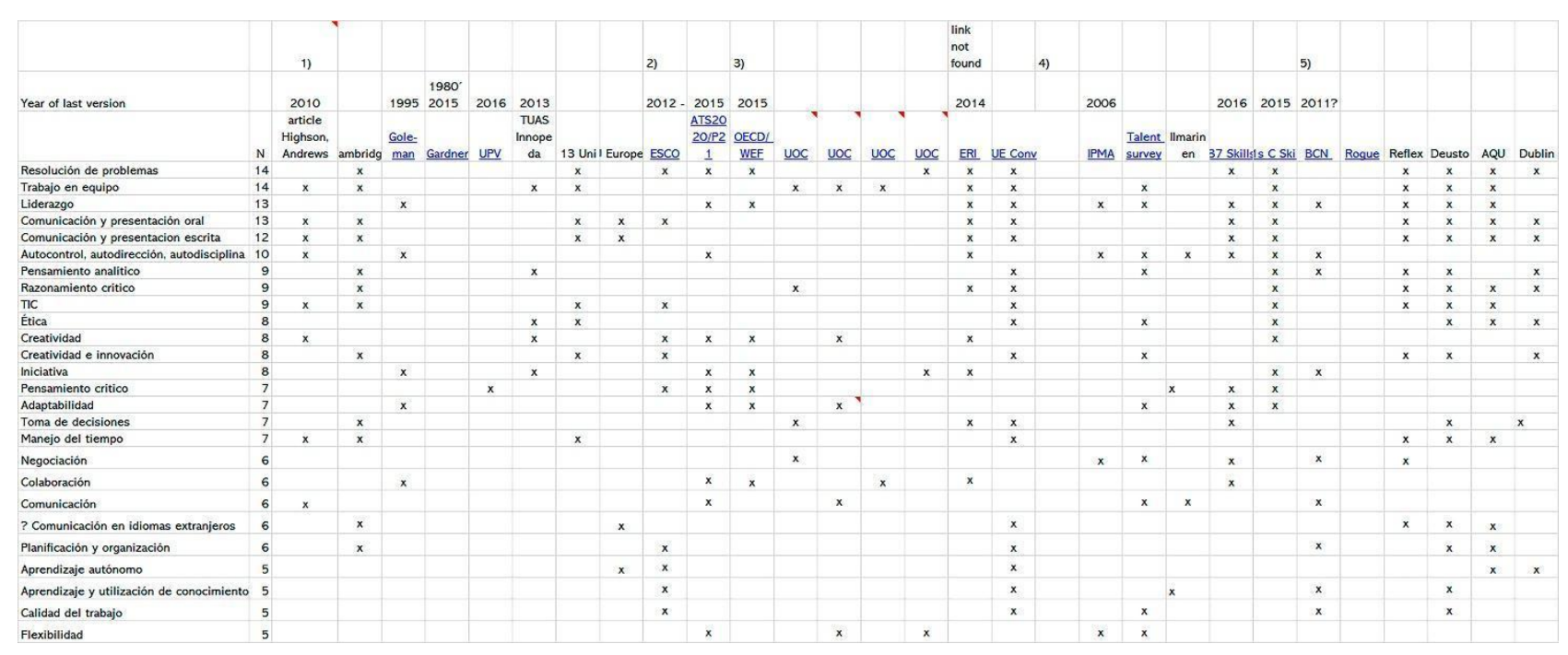

Figure 5 The spread sheet capture displays the used instrument. ${ }^{1}$

The research confirmed the assumed large number and diversity of titles in use. A total of 195 Soft Skills titles were detected from the sources. Among them, we can notice certain outstanding skills, getting over 10 hits among the 32 sources. The most mentioned Soft Skills are communication, creativity, critical thinking and problem solving. These findings are in line with previous studies mapping out skills in the organizational and business context 
(Andrews \& Highson, 2008; Mitchell et al., 2010; Robles, 2012; Anthony \& Garner, 2016). Evidently, all these skills are highly needed both in individual tasks, as well as in collective working environments.

Additional skills found in more than 10 sources were team working, leadership and selfmanagement. We can notice that these are typically needed in collaboration and team working, which are increasingly applied in Organizations. Moreover, we can state that also these skills have previously been subject to the Soft Skills discussion (e.g., Mourshed et al., 2014; Cinque, 2015). Among the most named titles we can also find analytic thinking, ethicality, initiative, adaptability and decision-making.

Most skills in the list of 195 titles are named only a few times. Thus, they are considered to have less importance when seeking the important Soft Skills appropriate for most Organizations, although they might be important in specific cases, Organizations, or projects. It must also be noted that some of the titles are very close to personal characteristics, for instance integrity, passion or tolerance. Yet, these titles were sporadic, they were mentioned only a few times.

The twelve most commonly used Soft Skills are listed below. The number of hits is announced within brackets. As we can see, communication stands out, yet it is worth noting that it consists of various elements and levels, for instance in oral and literal skills, or interpersonal and intrapersonal communication. In the educational context, these levels are very different. For this reason, communication is examined more in detail in 3.1.

* Communication (oral, literal) (25)

* Creativity and innovation (16)

* Critical reasoning (16)

* Problem solving (14)

* Team working (14)

* Leadership (13)

* Self-management, Self-control, Self-confidence (10)

* Analytic thinking (9)

* Ethicality (8)

* Initiative (8) 
* Adaptability (7)

* Decision making (7)

When examining these skills according to their relative appearance density among the 30 maps revised, communication appears in $83 \%$ of the maps. Creativity, critical reasoning, problem solving and team working can also be considered as highly essential Soft Skills, as they appear roughly in $50 \%$ of the maps. Furthermore, their importance is emphasized by the fact that they were found in all types of the reviewed skills maps.

The research was done to obtain an overall view of the titles used in different fields. It indicates clearly that there are certain Soft Skills that are significant in most contexts and thus widely used. 


\subsubsection{Map of graduates - MOSSA}

Additionally, it was decided to incorporate a Soft Skills map representing graduates on the border of entering working life. The MOSSA skills map was selected for closer study, as it is composed especially for graduates who aim to work in other countries. It is based on a survey on Soft Skills required by employers and recruiters and is statistically tested. MOSSA (2015) is a development project conducted in six European countries with the aim to detect relevant working life Soft Skills for young immigrants. This was carried out by interviewing 77 bodies that are involved with the employment of graduates, such as enterprises, employment agencies, career centers, employers' associations. MOSSA is especially interesting because it proposes a focus on Soft Skills in three groups. Table 2 demonstrates the Soft Skills selected in the MOSSA map:

\begin{tabular}{|l|l|}
\hline \multirow{5}{*}{ Group } & Soft Skill \\
\hline \multirow{5}{*}{ Social Skills } & Adaptability and flexibility \\
\cline { 2 - 3 } & Motivation \\
\cline { 2 - 3 } & Managing responsibility \\
\cline { 2 - 3 } & Time management \\
\hline \multirow{5}{*}{ Achieving results } & Communication skills \\
\hline \multirow{5}{*}{} & Team working \\
\hline & Conflict management \\
\cline { 2 - 3 } & Service skills \\
\hline & Decision making \\
\hline & Problem solving \\
\hline & Creativity and innovation \\
\hline & Critical and structured thinking \\
\hline
\end{tabular}

\section{Table 2 The MOSSA Map of Soft Skills.}

As we see, the MOSSA map includes 12 Soft Skills. They are divided in three groups, related to working life context and tasks ('Navigate the world of work'), communication and team working skills ('Social skills') and finally personal cognitive skills ('Achieving results'). The first group covers skills that are closely related to working contexts. In Organizations, their 
role is important within teams and departments as well as interaction with customers. These kinds of skills have also been called interpersonal skills (Schutte et al., 1997).

The third group is related to fulfilling tasks and future strategies. These more individual skills complete the basic working skills and social skills, as individuals need them for achieving results and performing well. They are essential as the modern way of working involves, besides team working, tasks and projects that are carried out individually, managing oneself. For this reason, it becomes understandable that the first and third cluster include 'selfmanagement' skills, which relate to an individual's ability to perceive situations, set strategies and act according to them. These kinds of skills are often called intrapersonal skills.

\subsubsection{University map - Universitat Politècnica de València}

As the context of the thesis is closely related to Higher Education and Organizations, it was decided to select a map of university level for closer study, to include the insight of higher education students. A HEI skills map, when equipped with sufficient descriptions and arguments for the skills included, provides an important contribution to the research. It expresses how the skills are perceived in a university and how they are described and motivated. The UPV map was selected as it offers a well-argued set of Soft Skills, with proper descriptions for each skill.

The UPV is one of the pioneering universities in the discussion of Soft Skills and their inclusion in curricula on an extensive multidisciplinary level. The UPV aims to integrate the transversal competencies in the curriculum of all its degrees. To do this, it proposes "competence dimensions" where one or more Soft Skills are grouped together to be worked by every subject. The Soft Skills considered by the UPV are detailed below (all details can be obtained at http://www.upv.es/contenidos/COMPTRAN/, the code CT means Transversal competence). The map of competencies shown above is used when evaluating the students at the University.

CT-01. Comprehension and integration. Understanding means "perceive and have a clear idea of what is said, done or happened or discover the deep meaning of something." To demonstrate that something has been understood, the person identifies and retrieves the 
information and explains it in their own words, interpreting and integrating the ideas from their own perspective.

CT-02. Application and practical thinking. The student, in real life, needs to be prepared to face situations in which it is not enough to apply recipes or formulas and in which the proposed decisions or solutions must be argued and accommodate the available resources. In this sense, this competence develops the way of thinking directed to the action, which allows to adapt to new situations and make decisions and consequently to act.

CT-03. Analysis and problem solving. Problems are new situations that require individuals to respond with new behaviours. Solving a problem involves performing tasks that require more or less complex reasoning processes and, in many cases, not simply associative and routine action. The objective of this competition is for the student to be able to apply structured procedures to solve problems, thus promoting their ability to learn, understand and apply knowledge autonomously

CT-04. Innovation, creativity, and entrepreneurship. Innovation is understood as the ability to respond satisfactorily to personal, Organizational and social needs, modifying processes and / or results to generate new value. In turn, the development of this competence requires both to think in a different way to provide different perspectives (creativity), and to commit certain resources at their own initiative, to explore an opportunity, assuming the risk that this entails (entrepreneurship).

CT-05. Design and project. A project is an effort that is carried out in a certain time to achieve the specific objective of designing and creating a unique service or product, by performing a series of tasks and an effective use of resources. The development of this competence enables the student to learn by making and integrating knowledge and skills from different disciplinary fields, developing high-level intellectual skills, promoting learning and autonomous work, team working and self-assessment.

CT-06. Team working and leadership. Team working involves creating and developing a climate of mutual trust between the components that allow working in a responsible and cooperative manner. The most appropriate term to describe this situation is to 'share': share 
knowledge, commitment and responsibility. It involves the distribution of tasks and roles and respect for the rules established by and for the group.

CT-07. Ethical, environmental and professional responsibility. This competence refers to the set of knowledge, skills, abilities and attitudes, useful for interacting with the environment in an ethical, responsible and sustainable way. This is to avoid or reduce the negative effects produced by inappropriate practices caused by human activity and to promote the benefits that professional activity can generate in the environmental field, considering its economic and social implications. Ethical responsibility refers to orienting human action in a rational sense, as it relates to actions and their moral value. Environmental responsibility is the capacity to define a positive or negative assessment for the ecological impact of a decision and generally refers to the damage caused to other species, to nature or to future generations, by the actions or non-actions of another individual or group. Professional responsibility arises at this point, as included within the moral responsibility, reaching within our conscience and with two primary objectives: to avoid any voluntary offense and to reduce, as far as possible, the number of involuntary offenses due to human weakness or negligence of others.

CT-08. Efficient communication. Communicating effectively means having the ability to transmit knowledge and express ideas and arguments in a clear, rigorous and convincing manner, both orally and in writing, using suitable resources appropriately and adapting to the circumstances and the type of audience. It is important to differentiate two dimensions within this competence: oral and written communication.

CT-09. Critical thinking. Critical thinking goes beyond the skills of logical analysis, since it involves questioning the underlying assumptions in our usual ways of thinking and acting, and based on that critical questioning, being prepared to think and do differently. Critical thinking is the thinking of the questions: Why are things like this? Why can't things be otherwise? Why do you think they are like that? etc. Consequently, we will say that a person has developed it to the extent that they question themselves about things and are interested in the foundations on which ideas, actions, valuations and judgments both their own and those of others are based. 
CT-10. Knowledge of contemporary problems. This competence refers to the need for students to understand contemporary political, social, legal and environmental issues and values, as well as the mechanisms for expanding and disseminating knowledge. It is about developing the ability to 'keep up' with current events in their field of knowledge and in society in general. To work on this competence, training scenarios must be sought in which students discuss this type of questions in depth, being able to summarize the most relevant aspects and defend a position on it. Similarly, it is very important that they learn to assess complex situations using different approaches, such as economic aspects, quality of life, and environmental impacts, local and national policies.

CT-11. Permanent learning. This competence is closely related to the idea of training reflective professionals, who do not settle for routinely reproducing known solutions, but rather seek to generate new solutions or solutions adapted to new situations. Reflective practice is based on three pillars: action or know-how, the knowledge we develop over our own knowledge and finally, the control we have over how we use our knowledge in a specific activity.

CT-12. Plan and time management. This competence implies being able to correctly organize and distribute the time we have and distribute it according to the activities necessary to achieve our objectives in the short, medium and long term.

\begin{tabular}{|l|l|}
\hline UPV Soft Skill Cluster & UPV Soft Skill \\
\hline Comprehension and integration & Structured thinking \\
\cline { 2 - 2 } & Integration capacity/thinking \\
\hline \multirow{2}{*}{ Application and practical thinking } & Customer orientation \\
\cline { 2 - 2 } & Practical thinking \\
\hline \multirow{2}{*}{ Analysis and problem solving } & Analytical thinking \\
\cline { 2 - 2 } & Synthesis thinking \\
\hline \multirow{2}{*}{ Innovation, creativity, and entrepreneurship } & Innovation capacity \\
\cline { 2 - 2 } & Creativity / Creative thinking \\
\cline { 2 - 2 } & Entrepreneurship \\
\hline
\end{tabular}




\begin{tabular}{|l|l|}
\hline Design and project & People management \\
\cline { 2 - 2 } Team working and leadership & Goal orientation (project) \\
\hline \multirow{2}{*}{$\begin{array}{l}\text { Ethical, environmental and professional } \\
\text { responsibility }\end{array}$} & Team working \\
\cline { 2 - 2 } Efficient communication & Seadership \\
\hline \multirow{2}{*}{ Critical thinking } & Commility \\
\hline Knowledge of contemporary problems & Empathy \\
\hline Permanent learning & Critical thinking \\
\hline Plan and time management & Motivation \\
\cline { 2 - 2 } & Strategic orientation \\
\hline
\end{tabular}

Table 3 UPV competence clusters and Soft Skills related with them.

As an observation from the UPV map, we can notice that the competence groups are quite broad and extensive descriptions, often covering various specific skills, presented in the right column.

Next, the MOSSA skills map and the UPV skills map are included in the compilation of skills, presented in the following chapter.

\section{Discussion on the Skills maps}


First, the desktop study and the exploratory research allow to draw some conclusions:

* New skills maps appear continuously. Organizations may prefer to generate a new map or modify an existing one. However, these maps do not usually have a solid foundation or justification.

* These new skills maps do not make obsolete those that already exist. Normally the new maps incorporate Soft Skills from the existing skills maps.

* Two kinds of new Soft Skills appear:

- New Soft Skills seem to be arising along with the evolution of an existing Soft Skill. For example, "helicopter view" can be associated with "analytical thinking".

- New Soft Skills can be considered part of several existing Soft Skills. For example, the ability to delegate can be seen as a form of leadership and time management. * Despite the high number of titles used, it seems that it is possible to distinguish specific clusters among the skills (for instance Self-management skills, Team working skills, Cognitive skills). The clusters will be discussed further in paragraphs 2.2.3. and 3.1.

* Communication is a specific Soft Skill with diverse connotations for self and intercourse with other people. Moreover, communication skills are needed for performing other skills. To understand the role of Communication, a special consideration and taxonomy is necessary. This consideration is done in paragraph 3.1.

\subsubsection{The proposed Soft Skills Framework}

To define a reduced number of Soft Skills to be used for detecting the ones with most significance and potential for educators and employers, the next phase will be to compose a Framework, representing the most appropriate skills.

The following conditions must be set on this Framework:

1. It must include skills that are significant in business organizations

2. The skills included should be potential and relevant even for HEls

3. The number of skills should be restricted to $15-20$, to be coherent. 
The skills maps analysis conducted in 2.2.2 provides us a comprehensive insight of Soft Skills titles. In total, more than 200 titles were reviewed and reduced into three skills maps. According to the criteria set, these maps are used in different areas of academic, educational and organizational contexts, especially in the European area. As a result, the exploratory research was able to distinguish a clear group of the most used titles that were used at least in $40 \%$ of all the skills maps reviewed. Consequently, it remains evident that the Top 12 skills include relevant and appropriate skills used in working life.

In addition, the results are relevant for higher education, as the educational and academic aspects were represented in the analysis by 14 of the 30 sources. Moreover, two specific sources were included to represent educational bodies. MOSSA represents graduates that head to work abroad and UPV for representing the students' view, with its comprehensive descriptions of competences.

In table 4, the compilation of these three sources is presented. The skills originating from the analysis in 2.2.2 are placed in successive columns. The skills with equal titles are named using this very title. In case of slight overlapping, an appropriate, most close-by name is selected. If a skill appears only in one of the maps, it will not be included in the Framework. After the completed process, a few completing skills, important especially in working life, were considered. The last column on the right presents these skills, suggested to the Soft Skills Framework.

\begin{tabular}{|l|l|l|l|}
\hline \multicolumn{1}{|c|}{$\begin{array}{c}\text { Skills maps } \\
\text { analysis }\end{array}$} & \multicolumn{1}{|c|}{ MOSSA } & UPV Soft Skill & \multicolumn{1}{|c|}{$\begin{array}{c}\text { Proposed } \\
\text { Framework }\end{array}$} \\
\hline $\begin{array}{l}\text { Spoken } \\
\text { communication } \\
\begin{array}{l}\text { Written } \\
\text { communication }\end{array}\end{array}$ & $\begin{array}{l}\text { Communication } \\
\text { skills }\end{array}$ & Communication & Communication \\
\cline { 3 - 4 } $\begin{array}{l}\text { Creativity and } \\
\text { innovation }\end{array}$ & $\begin{array}{l}\text { Creativity and } \\
\text { innovation }\end{array}$ & $\begin{array}{l}\text { Innovation } \\
\text { capacity }\end{array}$ & Empathy \\
\cline { 3 - 4 } & Creativity \\
\hline Critical reasoning & Creative thinking & \\
\hline
\end{tabular}




\begin{tabular}{|c|c|c|c|}
\hline & $\begin{array}{l}\text { Critical and } \\
\text { structured thinking }\end{array}$ & $\begin{array}{l}\text { Structured } \\
\text { thinking }\end{array}$ & Order and quality \\
\hline \multirow{3}{*}{$\begin{array}{l}\text { Problem solving } \\
\text { Analytical thinking }\end{array}$} & \multirow[t]{3}{*}{ Problem solving } & Analytical thinking & Analytical thinking \\
\hline & & Synthesis thinking & \multirow[t]{2}{*}{ Conceptual thinking } \\
\hline & & $\begin{array}{l}\text { Practical thinking } \\
\text { Integration } \\
\text { capacity/thinking }\end{array}$ & \\
\hline Team working & Team working & Team working & $\begin{array}{l}\text { Work in team and } \\
\text { cooperation }\end{array}$ \\
\hline Leadership & & Leadership & Leadership \\
\hline $\begin{array}{l}\text { Self-management } \\
\text { Self-confidence } \\
\text { Self-control }\end{array}$ & $\begin{array}{l}\text { Time management } \\
\text { Managing } \\
\text { responsibility }\end{array}$ & $\begin{array}{l}\text { Self-control } \\
\text { Goal orientation } \\
\text { (project) } \\
\text { Plan and time } \\
\text { management } \\
\text { Responsibility }\end{array}$ & $\begin{array}{l}\text { Self-control } \\
\text { Self-confidence } \\
\text { Goal orientation } \\
\text { Planning and } \\
\text { Organization }\end{array}$ \\
\hline \multirow[t]{3}{*}{$\begin{array}{l}\text { Initiative } \\
\text { Decision making }\end{array}$} & $\begin{array}{l}\text { Motivation } \\
\text { Decision making }\end{array}$ & Motivation & Initiative \\
\hline & Service skills & $\begin{array}{l}\text { Customer } \\
\text { Orientation }\end{array}$ & Customer Orientation \\
\hline & $\begin{array}{l}\text { Conflict } \\
\text { management }\end{array}$ & $\begin{array}{l}\text { People } \\
\text { management }\end{array}$ & People management \\
\hline \multirow[t]{4}{*}{ Adaptability } & $\begin{array}{l}\text { Adaptability and } \\
\text { flexibility }\end{array}$ & & $\begin{array}{l}\text { Flexibility and change } \\
\text { management }\end{array}$ \\
\hline & & $\begin{array}{l}\text { Permanent } \\
\text { learning }\end{array}$ & $\begin{array}{l}\text { Learning and use of } \\
\text { knowledge }\end{array}$ \\
\hline & & $\begin{array}{l}\text { Strategic } \\
\text { orientation }\end{array}$ & Strategic orientation \\
\hline & & & $\begin{array}{l}\text { Commitment to the } \\
\text { Organization }\end{array}$ \\
\hline
\end{tabular}




\begin{tabular}{|l|l|l|l|}
\hline Negotiation & & Negotiation \\
\hline & & Networking \\
\hline
\end{tabular}

Table 4 The Soft Skills framework proposed.

In addition to the three used skills maps, it is proposed to add the following Soft Skills not previously considered, as they are highly important in the Organizations of the 2020s, and thus essential for the context of this thesis, focusing on working environments in the fields of Business and ICT in particular.

Negotiation. This is one essential skill in the socio-economic environment of the 2020s, as the ability to find mutual understanding and reach agreements found a base for long-term customerships. Yet, this aspect is typically missing in the academic-based skills maps, however, reported essential in business and organizational contexts. (Robles, 2012; Cinque, 2015)

Commitment to the Organization. Along with increasing competition, employees in Organizations are expected to deeply apply values and working practices planned for reaching certain strategies. This aspect has essential value especially in business and ICT organizations (Lehtinen, 2006; Mitchell et al., 2010).

Networking. This last Soft Skill is one of the classical 'forgotten skills', needed especially to establish new relationships to advance business and find peer individuals and groups. In addition, the ability to obtain contacts and maintain them active through social media is one of the necessary Soft Skills (Mourshed et al., 2014; Jones et al., 2017).

Based on this procedure, the skills selected in the Framework column are expected to be the most appropriate 21 skills to be used in the discussion between higher education and employers, to select the right skills in curricula and promote them.

It is interesting that we can find very similar skills list in the Barcelona Activa Treball 'Mapa de Competencias transversales'. This map is used by employment officials in selfassessment and self-training of job-seekers. This is one more factor to confirm the validity of the Framework. 
The following presentation offers brief descriptions for the selected skills, partly adapted from the Barcelona map. The descriptions will be utilized in the questionnaire 3Si, needed in the main experiment (in 3.3).

1. Communication $(\mathrm{Cm})$ Ability to transmit something to someone in a clear and understandable way

2. Empathy $(E m)$ Sensitivity to correctly understand the thought, feelings and concerns of other people

3. Work in team and cooperation (WTC) Capacity and intent to work with others as part of a group

4. Planning and Organization (PO) Plan activities and lines of action, and optimize resources to reach expected results

5. Creativity $(\mathrm{Cr})$ Ability to solve emerging problems in divergent ways

6. Preoccupation for order and quality (POQ) Caring for work conditions and results for self and others

7. Analytic thinking (ATh) Ability to understand a situation by organizing its parts systematically

8. Conceptual thinking (CTh) Ability to identify key issues and patterns in situations or relationships

9. Goal orientation (GO) Ability to act with continuous improvement and set standards and goals to motivate self

10. Customer Orientation (COr) Desire and ability to help or serve customers and meet their needs

11. Initiative (In) Ability to react to opportunities and challenges proactively, make decisions and take actions

12. Learning and use of knowledge (LUK) Continuous development and acquirement of new knowledge to develop

13. People management (PM) To reason, persuade and convince others to act towards common goal

14. Flexibility and change management (FCM) Ability to adapt and work effectively in divergent situations and different people; accept changes in Organization or own duties. 
15. Leadership ( $L d)$ Lead, motivate and develop a team, communicate and promote visions and goals

16. Self-confidence (Scf) Belief that one can successfully perform a task or choose the right approach for a job or solve a problem

17. Self-control (SCt) Ability to keep own and team's emotions under control

18. Commitment to Organization (CtO) Ability and willingness to guide own interests and behaviours towards the needs and priorities of Organization

19. Networking (Nw) To establish win-win contacts with a wide range of people

20. Negotiation $(\mathrm{Ng})$ Ability to build consensus to reach an agreement and mutual benefits

21. Strategic orientation (StOr) Ability to link long-term visions and broad concepts into daily work

In the further step of the research, this Framework will be applied as a basic element in the Questionnaire 3Si and the method 3Si. They are presented in the next chapter. 


\section{Discussion}

The Framework set of Soft Skills is a result of a systematic procedure, thus it can be considered appropriate in the time where it was created. However, the analysis of skills maps indicate that these skills maps evolve over time and incorporate new skills or discard those that become obsolete. To recognize the evolution of these maps, in a longer run use, the framework should be updated to consider the evolution of the skills maps over time. At least the following parameters should be considered in the updates:

* The needs of the Organization. It should be considered that changes in the Organizational environment may imply different sets of competences, and thus result in a transformation in the skills map.

* The technical needs of the project in which the person participates. Changing the project, even in the same Organization, can mean a change of some Soft Skill. For example, if you work on databases in project 1, hard skill 2 (database programming) will be necessary. But if project 2 and project 3 are mobile application audit projects, hard skill 2 will no longer be necessary, but the need for hard skill 1 (systems analysis) will appear.

* The Soft Skills needed for the project in which the person participates. For example, if a person coordinates project 2, he will need "leadership" (Soft Skill 1), but if he is a programmer in projects 1 and 3, he will need "order and clarity" (Soft Skill 2), to write readable codes.

\subsection{Soft Skills Detection Methods}

Once the relevant Framework is created, we are one step closer to answer the main hypothesis "Based in the communication process, Soft Skills can be organized according to their significance to Organizations, universities and employees, and their development potential can be detected. “

In the context of this research, the profound mission is to exhibit and elucidate Soft Skills by means that enable assessing their significance in given working positions, their current level and their development potential. It is obvious that these questions cannot be answered merely from one part, for instance the educators, as they may lack the awareness of precise data on which skills are used in different positions, and how they are used. Similarly, a 
manager or HR person in an Organization is not likely to be able to state on their own, which skills can be promoted, or which specific skills should be included in their skills maps. As for the students, the ones who mainly need to master the skills, they have little experience from their future working environments and thus are hardly aware of the needed skills. For many reasons, it has become evident that business educators need this type of knowledge to provide graduates with skills that are relevant and needed by employers.

Consequently, it is necessary to create a research constellation, which can assess Soft Skills from different aspects.

- Which skills are significant in a given working position?

- Are there skills that are more significant than others?

- Are the skills considered possible to learn at HEls?

- What is the current level of graduates (is there a skills gap)?

For this aim, a variety of research methods could be applied. I will briefly present some research methods and their advantages and disadvantages, thus (facilitating to assess) considering their appropriateness for the current research.

\subsubsection{Methods to detect skills}

In behavioural sciences in particular, enough attention should be paid to the choice of the research methods, whereby it is recommended to use mixed methods (Gravetter \& Forzano, 2018). In essence, their appropriateness depends on the circumstances. For instance, in research on competences and skills, sometimes it could be necessary to obtain a very precise view of the skills needed, whether in other cases it can be more important to have an overall picture of the dimensions and skills that form a competence.

Basically, researchers can apply appropriate qualitative or quantitative surveys, depending on the type of answers and data they need. The first type is normally used in the case where elements and variables need specification and there is a need to find deeper insight on a phenomenon. In these cases, the size of the sample is relatively low, whereas the outcome received from each respondent can be broad, for instance in an interview or video session. 
The quantitative method, on the contrary, needs the acquisition of numeric data from larger samples. As a result, it can state set hypotheses and allows even statistical testing. Yet, in this research type, the questions must be uncontradictory and easily perceived. In addition, they must be operationalized in a form allowing rating by scales. (e.g., Research Methods Guide, 2018).

In the following, some of the most common research methods are presented, whereafter they are compared to justify the choices made in the research.

\section{Observation}

Observation is taking place when participants do some activities (role playing, genuine work, etc.) and an experienced person participates in the process as a watcher. Observation can be structured or unstructured, whereby the former produces information only on pre-selected issues, whereas the latter can change according to the situation. This method gives direct access to the phenomena, but the arrangements may take much effort and time (Research Methodology).

\section{Interview}

Interview is a qualitative research technique that is used when there is a need to highlight new phenomena or obtain deeper understanding on already familiar phenomena. It is conducted by interviews with a small number of respondents assumed to possess knowledge and understanding of the phenomena. An interview is a method to explore their perspectives on particular ideas or phenomena, often based on a situation, where the interviewer poses questions to the interviewee.

Often the topics discussed may be open, and thus an interview helps to explain and better understand research subjects' opinions, behaviour and experiences, even revealing unforeseen issues. An interview is appropriate to use when profound information is sought from a small group of people. Normally, interviews are saved by recording or other documentation, and opened afterwards in detail. (Research Methods Guide)

\section{Focus Groups}

A focus group is a research method used to gather data through group interaction. A focus group comprises a small number of carefully selected people, expected to discuss a given 
topic. Focus groups are used to identify and explore the thoughts and behaviour of people, and they throw light on questions like 'why, what and how' (Parker \& Tritter, 2006). The sessions can be supervised by an instructor, or alternatively, they can have a freer form (Focus Group). Normally the sessions are saved for further specific analysis.

\section{Survey by questionnaire}

Survey is a typical quantitative research method, conducted by launching a questionnaire to a sample that represents the target population of the research. Questionnaires are often considered as a kind of a written interview, although the questions are mostly structured. They can be easily shared to a big number of respondents, and thus they are appropriate when precise numeric data is expected from a larger group. They allow statistical analysis and testing. (Research Methods Guide).

\section{Method comparison}

In the following table some advantages and disadvantages of the different research methods are compared. The comparison exhibits the major characteristics of the research methods.

\begin{tabular}{|l|l|l|l|}
\hline \multicolumn{1}{|c|}{ Type } & $\begin{array}{c}\text { Method and } \\
\text { tool }\end{array}$ & \multicolumn{1}{|c|}{ Advantages } & \multicolumn{1}{|c|}{ Disadvantages } \\
\hline Qualitative & Observation & $\begin{array}{l}\text { Participants learn skills while the skills are evaluated. } \\
\text { Good detection in the case that observers have } \\
\text { experience. }\end{array}$ & $\begin{array}{l}\text { Expensive in cost and time } \\
\text { Observer subjectivity effect. } \\
\text { Participants can change their behaviour } \\
\text { if they know that they are observed. }\end{array}$ \\
\hline Qualitative & Interview & $\begin{array}{l}\text { Can be directed to selected people with valuable } \\
\text { information or experiences. } \\
\text { Gives precise information on the phenomena, also } \\
\text { unforeseen details. }\end{array}$ & $\begin{array}{l}\text { The role of the interviewer may affect } \\
\text { the responses. } \\
\text { Expensive in cost and time. Not } \\
\text { appropriated to bigger samples }\end{array}$ \\
\hline Qualitative & $\begin{array}{l}\text { Focus } \\
\text { groups }\end{array}$ & $\begin{array}{l}\text { Allows following genuine discussions. } \\
\text { Reveals motives and intentions of the participants. } \\
\text { Can raise up unforeseen factors. }\end{array}$ & $\begin{array}{l}\text { Less appropriate for surveying large } \\
\text { groups. } \\
\text { Sessions may not be reproducible. } \\
\text { Expensive in cost as it takes experts' } \\
\text { personal time. }\end{array}$ \\
\hline Quantitative & Survey & $\begin{array}{l}\text { San be passed to a big sample. } \\
\text { Crovides objective, numeric data. } \\
\text { Allows to compare results scientifically }\end{array}$ & $\begin{array}{l}\text { 'Cold' in the sense that human contact } \\
\text { is missing. } \\
\text { Able to provide data that represents } \\
\text { larger groups. }\end{array}$ \\
\hline
\end{tabular}

Table 5 Comparison of research methods.

First, if we want to obtain new, perhaps unforeseen knowledge of a phenomenon, qualitative methods will be appropriate. The disadvantage with these methods is that they are timeconsuming and are only able to cover small groups. As for quantitative methods, they typically need a relatively large sample, thus allowing statistical analysis. They are good for affirming or testing a hypothesis or assumption. 
As for the current research, it is quite obvious that observation as a method would bring some advantages. We could imagine observing one or a few Soft Skills and their use in action, which would undoubtedly provide new understanding on the use of the skills. Yet, the disadvantage is that this method would not provide enough data to conclude any answers to the question asked in the hypothesis in a reliable way.

As for interview and focus group methods, the advantage is that they can be directed to selected people with valuable information or experiences. In the context of this research, they could be used for affirming certain presumptions or proposed research measures. Also, they would probably lead to interesting discussions, creating new understanding of Soft Skills in various situations. Yet, these methods would not provide enough data to answer exclusively on the question set in the hypothesis. However, the interview and focus group are applied for experimenting the survey questionnaire of this research (in 4.1).

As for the survey, it suits well when the purpose of the study is to measure differences and correlations between groups, and often, to confirm the previously set hypothesis instead of providing new information. In this case, the analysis provides quantitative data that is typically able to indicate 'How much?', 'How many?' and 'How big shares?'.

In a survey, it is important that the questionnaire is pre-tested and equal for all respondents. In addition, these must be selected so that they represent the target population. The number of samples needed for quantitative research is quite high, to obtain reliable results. The data can be collected either by printed questionnaires, or with modern online techniques, increasingly by digital surveys.

As the main objective of the thesis is to create a systematic method for classifying Soft Skills, it will need experimenting and validation. Hence, it is obvious that we need to apply a quantitative survey for this purpose.

Table 6 displays the research methods applied in the current research, and their purposes and target groups in detail. 


\begin{tabular}{|c|c|c|}
\hline Research phase and form & Purpose & Group/Sample \\
\hline $\begin{array}{l}\text { Experiment } 1 \\
\text { Qualitative research } \\
\text { (Interviews, Focus groups) }\end{array}$ & $\begin{array}{l}\text { Test the proposed 3Si Framework } \\
\text { (presented in 2.2.3.) } \\
\text { Prove the usability of the } 3 \mathrm{Si} \\
\text { Questionnaire (3.2) } \\
\text { Get complementary insight of the validity } \\
\text { of the research }\end{array}$ & $\begin{array}{l}\text { Managers and } \mathrm{HR} \\
\text { professionals } \\
\text { experience of } \\
\text { maps anills } \\
\text { development. }\end{array}$ \\
\hline $\begin{array}{l}\text { Experiment } 2 \\
\text { Quantitative research } \\
\text { (Online survey) }\end{array}$ & $\begin{array}{l}\text { Examine the } 21 \text { Soft Skills by means of a } \\
\text { three-dimensional approach } \\
\text { Test the Method } 3 \mathrm{Si}\end{array}$ & $\begin{array}{lr}\text { People with } & \text { sufficient } \\
\text { experience } & \text { in } \\
\text { respective } & \text { working } \\
\text { positions } & \text { (Business, } \\
\text { ICT) } & \end{array}$ \\
\hline
\end{tabular}

Table 6 Research methods to be applied in the current research.

The design of the 3Si survey and the 3Si Questionnaire used in this research is presented in 3.2 .

\subsection{Conditions for Matching Soft Skills}

This thesis focuses on detecting Soft Skills that are significant for employers and potential to promote and include in the curricula of HEls. This process can be called 'matching of Soft Skills', to reduce the existing skills gaps between Higher Education and Organizations.

This raises several questions. As we have stated in 2.1.2, higher education institutions and organizations are steered by different kinds of intentions and goals, and thus they choose skills and competences with slightly differing bases. Here we end up at the question: how can these differences be considered and matched?

Furthermore, it is two totally different things to name a skill and assess its significance, and consequently, create learning in these skills and raise their performance level. It is far from evident that every skill can be learned, or taught, equally. Obviously, this concerns Soft Skills in particular.

A third question comes from the fact that each employee in an Organization has different kinds of skills profiles. While mastering certain skills, a graduate or employee needs training 
in other skills, whereas a colleague may have a different type of profile. The situation is equal with students or graduates, as well.

Traditionally, the definition of necessary skills and the composition of skills maps are based on existing maps that are updated in the course of time (Kaplan \& Norton, 2004). In the cases where needs for new skills are detected, they are often based on vertical analysis in situations that involve changes. As a result, a trainer-learner constellation will often remain, meaning that one of the actors is ruling the learning process and the other actors are perhaps in a more passive role.

Unfortunately, we have seen that in many cases updating of skills, training projects and learning at HEls has failed, at least to a part, due to these kinds of faults (Eurydice, 2014; Cinque, 2015).

For this reason, and for the special character of Soft Skills as well, I consider it extremely necessary to figure out the acquisition process of skills, especially Soft Skills. According to my 15 years' personal experience as business teacher, I believe that competences and skills must be continuously updated, even in the role of an experienced professional. Also, I think that learning happens best in an atmosphere where each learner is motivated and feels responsible for their learning process.

The consideration will be done applying the modern learning paradigm called lifelong learning, which allows us to distinguish the specific 'stakeholders' of the process.

\subsubsection{The acquisition process of Soft Skills}

To perceive the formation procedure of professional competence, it is necessary to examine the whole process by which individuals obtain skills. This examination comprehends various important issues. First, according to the paradigm of lifelong learning (Steffe \& Gale, 1995; Field, 2000), the process continues throughout the whole life, as a sequence where individual and professional competences meet new challenges and will be updated accordingly. This is due to two main factors. First, the rapidly changing environments in working and private life create a need for adapting or learning new. Second, the accelerating supply of new information creates in itself a need for updating, yet also a source for each individual to learn new. In figure 9 , this process is visualized. 
In respect to the skills acquisition process, this means that obtaining of skills should not merely be considered - as it traditionally often has been - as a vertical, unique occurrence in a given time space, but rather as a continuous sequence that involves various stakeholders with their own specific interests.

When examining individual skills in the light of lifelong learning, many skills and competences are acquired through social and everyday life experiences, as well as nurtured at home. Most evidently, this is the case with many Soft Skills, as well. However, many professional skills are learned later, during formal education. In the modern European society, people have quite extensive options to choose individual learning paths and head for professions that they find interesting and convenient. Consecutively, the school system provides general education in the initiating period, then focusing on professional knowledge in the later part of the studies. This means that many of the field-specific skills are learned during higher or vocational education. Thus, in respect to professional competence and its gaps, the last years and the role of higher education are essential.

As seen in 2.1.3., for Organizations, a qualified workforce is one of the main issues, directly influencing their performance. Hence, they invest considerably in successful recruitment and training of staff. As it is reported that there are skills gaps (Mourshed et al., 2014; EC, 2015) and recruitment times become longer (Bughin et al., 2018), it is obvious that Organizations are increasingly interested in actions that guarantee the availability of graduates with appropriate skills.

As for HEls, basically, they are expected to provide their students with adequate skills expected by their socio-economic environment, i.e., Organizations that recruit and employ them. In ideal cases, most graduates would possess a high level of essential skills, matching with the needs of employers. In 2.1.5, we have stated that the employment rate of graduates is essential to HEls for many reasons, primarily because of their funding is often related to these rates, and because their good fame means that it becomes easier to recruit students.

Accordingly, it is obvious that it is not sufficient to inspect the learning of skills and competences as a responsibility of a particular actor (Learner, HEl, Organization). It is also evident that all of them have remarkable interests involved in the learning process. 
Therefore, the skills acquisition process must be considered as a joint venture of these three stakeholders.

Figure 6 presents the process of skills acquisition in the aspect of lifelong learning ('timeline'), with the three stakeholders and their roles described. In a later phase of the research, the three stakeholders will be transformed to statistical dimensions in the method described in detail in 3.2 .

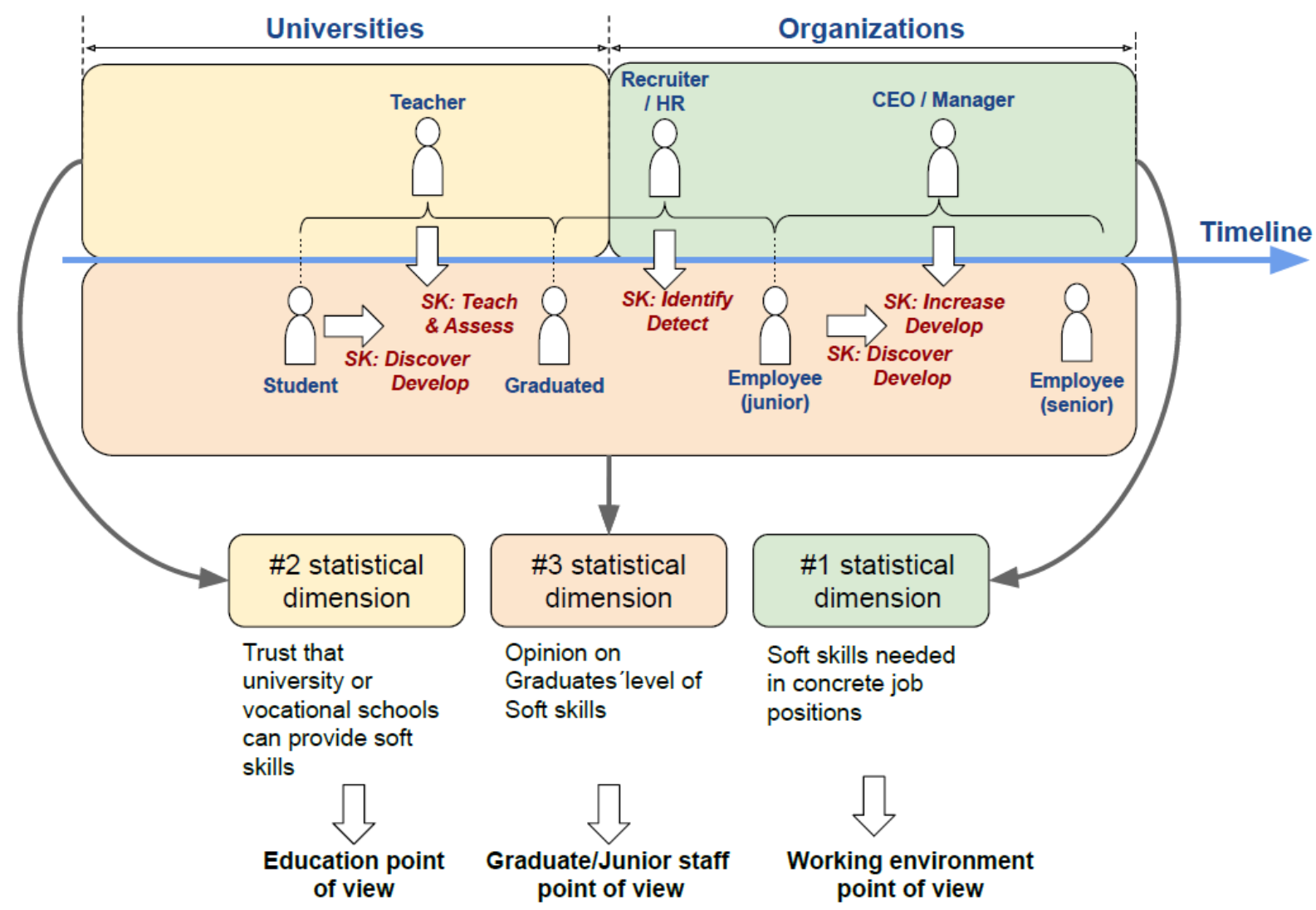

Figure 6 The roles and interest of the stakeholders in the acquisition of skills.

In the start of their career, as students, people obtain a professional degree through studies at HEls or other educational institutions. During the studies, each one will choose a skills profile they find most convenient. Consequently, a set of subject-related skills is taught and assessed, with the presumption that they are significant in working life.

After graduation, young professionals seek employment and subsequently get hired, at a rate that depends on their Hard and Soft Skills (Mason et al., 2009; Redomero et al., 2019). Obviously, the competence and skills obtained by an individual student depend on the 
curricula and teaching methods in the HEls, and finally their own effort. Especially for Soft Skills, this aspect is crucial, as they are considered difficult to define and teach/learn.

In Organizations, the appropriateness of the graduate is identified by recruiters or managers, applying a set of assessments, measuring competence and level of skills, especially in the skills that are significant for the employer. Later, professional competence is increased by in service training, in skills that are considered significant.

The figure also presents the evolution of the role of the learner, from student to graduate, and further to junior and senior employee or professional. It is obvious that the role of own effort and motivation of the learner has increased over the past 20 years. The paradigm of lifelong learning raises the individual in a position that has dramatically changed from the passive role that was usual in learning contexts over time. The learner has a central role in the skills acquisition process. Thus, the new paradigm turns the learner from a mere receiver to an active agent of their life and formation (Steffe \& Gale, 1995; Field, 2000).

\subsubsection{The Dimensions of the Process}

To build a research constellation and statistical dimensions that enable examining Soft Skills and classifying them in a meaningful way, it is necessary to elucidate the dimensions, why they are important and what data they can provide on Soft Skills. The dimensions will be used in the survey and subsequently in the method designed, described in 3.2.

The three dimensions are presented briefly in table 7 , and subsequently described in detail.

\begin{tabular}{|l|l|l|}
\hline Stakeholder & Aspect & Dimension \\
\hline Organization & $\begin{array}{l}\text { What is the significance of the skill } \\
\text { in our working positions? }\end{array}$ & Significance \\
\hline $\begin{array}{l}\text { HEls } \\
\text { (Higher Education Institutions) }\end{array}$ & $\begin{array}{l}\text { Is there trust that a given skill can } \\
\text { be learned and taught (at HEls)? }\end{array}$ & 'Learnability' \\
\hline $\begin{array}{l}\text { Learner } \\
\text { (student/graduate/employee) }\end{array}$ & $\begin{array}{l}\text { What is the current level of the } \\
\text { skill? }\end{array}$ & 'Level’ \\
\hline
\end{tabular}

Table 7 The aspects of the stakeholders presented in statistical dimensions. 


\section{Significance}

The role of the Organizations bases on their role in recruiting the graduates from HEls and other workforce and employing them along their working career. It has been said that companies fall or rise according to the performance of their staff, this is to say that they need a skilled workforce. The role of competences and skills is decisive regarding competitiveness and progress of any Organizations.

Detection, evaluation, improvement, and accreditation of these core skills are among the most important tasks of HRD professionals. Finally, the definition of the core skills required by each job position is the conclusive step needed. To reach this, several initiatives have been conducted recently in Europe. Within the EU, the ESCO project has tried to classify, identify, and categorize information regarding the three cornerstones for describing the labour market: (i) types of occupations (2942), (ii) skills and competences required to conduct any of these occupations (13485), and (iii) what are the qualifications that assured an optimal level of competence to conduct an occupation (9458). This kind of information is used mostly by employment authorities and HR professionals to facilitate their recruiting functions and employees training within the company (ESCO).

Accordingly, the recruitment bodies seek to hire graduates and professionals who possess appropriate skills, the most significant skills for the Organizations. Organizational performance relies essentially on identifying first the key tasks, and then defining the key competences that are needed for carrying them out successfully (Kaplan \& Norton, 2004). This issue was argued previously in 2.1.3. and 2.2, when discussing skills maps and skills gap. It was also stated that often organizational skills maps include skills that are common for all employees. Yet, specific skills might be necessary in some functions of the Organizations.

A viable way to detect them is asking people who work in the given positions to rate their skills by their significance. Accordingly, this will be the first statistical dimension in the survey tool.

\section{Learnability}


One question, especially interesting for HEls, is to what extent is it possible to teach and learn Soft Skills? Previously this aspect has been scarcely studied, and consequently many Soft Skills are still considered to have an ambiguous character, often rather inborn abilities rather than skills (Gilbert et. al., 2004; Grugulis \& Vincent, 2009; Cinque, 2015). With respect to education, they have been described as hard-to-teach (Bereiter \& Scardamalia, 2006; Tulgan, 2015), indicating that new methods are needed to learn them. An additional reason for this is that Soft Skills are said to be adjusted according to context and situation (Mitchell et al., 2010; Cimatti, 2016)

It has been suggested that Soft Skills are promoted along with individual experiences rather than classroom methods (Schultz, 2008; Cinque, 2015), which can easily be understood by the transversal character that Soft Skills have. On the one hand, they are often applied in social contexts (e.g., team working, leadership, communication), where the promotion of skills typically happens through regulating personal activities (e.g., Zimmerman, 2000) and adapting behaviour according to context (Schunk \& Zimmerman, 1998; Pintrich, 2000). On the other hand, being rather broadly applicable in a variety of situations and contexts, rather than narrow-focused field-specific skills, it can be assumed that they develop along with facing new situations. Consequently, it has been suggested that Soft Skills are developed in practical contexts along working careers (Muir, 2004; Tulgan, 2015; Silber-Varod \& EshetAlkalai, 2019).

Obviously, given the character of Soft Skills, it is impossible to assess precisely to what extent a skill can be fostered and developed, also because there are only a few previous attempts and experiments. Yet, this question provides essential aspects for all stakeholders. The organizations can take this aspect in account and adjust their in service training. Also, this aspect is interesting for learners, as they may be better motivated to learn a skill that has high trust in learning, than one with low trust in learning.

In addition, this aspect is most interesting for educators and HEls, for various reasons. It may motivate teachers to choose new Soft Skills in their study units. As a result, this may steer and impact how easily Soft Skills will be included in curricula. 
As for the statistical dimension and the survey, the question remains, who are the best respondents to assess 'learnability' in this research? As previous reports indicate that Soft Skills are most typically learned through practice and professional experience, the most appropriate ones to assess their learnability will probably be done by people with remarkable working experience in respective fields.

\section{Level}

The assessment of the level of skills is a key factor for Organizations, not only regarding graduates and applicants in the recruitment process, but also employees and staff in connection to HRD activities in Organizations. For these purposes, Organizations increasingly use the assessment method mentioned in the previous paragraph, e.g., peer evaluation and 360 degrees evaluation (Kaplan \& Norton, 2004). These assessments, combined with skills maps, provide several types of results that are used in HRD activities and training of staff; for instance, they indicate the skills where a person or department has a sufficient level (and thus do not necessarily need to be promoted) and the ones where skills gaps can be seen. This is useful to select and focus on certain skills in sequence, instead of setting effort on the entire skills map that may include 15-20 skills. In addition, they can be used for finding the most appropriate people for certain projects or positions. Here it must be added that, when discussing Soft Skills, many of them are considered to appear in personal behaviour and manners, even more trustworthy than in certificates (Schultz, 2008; Cimatti, 2016).

For higher education, the dimension 'level' has been traditionally important in various aspects. The level of a given skill, for instance 1-5, is incorporated in any curriculum, often combined with a verbal description of the objectives of a study unit. This kind of procedure allows educational institutions to design standardized study units that are uniform in their degree of demands. This is needed to have conform the curricula, justified for all students independent of their background and previous studies.

Also, for students, the assessed level of their performance is essential for several reasons. It is a form of external feedback on the level where they are currently, giving reason to plan further learning goals and strategies. Moreover, the grades can form an important source of motivation. For many students, achievement of high grades is a factor that drives them to better learning results (Evers et al., 1998). Also, for employees, the experience of 
continuous improvement in their level of professional competences and skills has been reported as a main motivational factor (Pintrich, 2000; Ruohotie, 2002).

\subsection{Summary}

The presented examination of the skills acquisition process was carried out to distinguish the key elements and actors in the process or lifelong learning of professional skills. This consideration is an essential step when seeking to find solutions for reducing the skills gap between HEls and Organizations, which is the main objective of the thesis.

The presented examination affirmed that this process should not be considered only from the point of view of the HEls or Organizations. Instead, it must be viewed as a process with three important, independent stakeholders. Along with the paradigm of lifelong learning and the new concepts of learning introduced subsequently, it seems evident that the individual learner - the student, the graduate, the employee - must be considered as an equally important actor in the process. The dimensions presented in this paragraph will be used as elements of the Soft Skills Status indicator (3Si) method that will be presented in chapter 3.

Obviously, a widening set of hard and soft skills is needed in the working environments. Many recent studies suggest that the role of Soft Skills will increase. Consequently, there is a need to update the HEls' curricula to provide students with these skills. However, for educators the promotion of these skills has turned to be challenging, leading to evident gaps in Soft Skills. A reason for this is that the character of Soft Skills is different from Hard Skills, and thus it has been a problem to define them coherently enough. Another reason is that the mind-set and culture of HEls differs from that in working life and Organizations.

When intending to reduce the Soft Skills gap between HEls and working life, a first step is to define the most appropriate skills, relevant both for Organizations and educators. As a result of an extensive skills maps analysis conducted (2.2.6), it was possible to define 21 Soft Skills, called 'the Framework'.

Regarding the main mission of this research project, i.e., to reduce the gap of Soft Skills between HEls and Organizations, it is not enough to detect the most used and needed Soft Skills. Without increased efforts to provide graduates with these skills, the situation will 
remain unchanged, with the skills gaps continuing to exist. Obviously, the HEls have a crucial role in bridging these gaps, as they are key actors in promoting professional competence. One problem has been the ambiguity in the character and learnability of Soft Skills. For this reason, more knowledge regarding these is inevitably needed.

Currently, any further examinations regarding learning and skills acquisition cannot be made without considering the paradigm of lifelong learning, which includes two essential principles. First, both personal and professional learning is needed - and is happening - not only in the school years, but all the way through an individual's life. Second, it emphasizes the role of the individual, being responsible for creating their choices and strategies to maintain personal competence and competitiveness in life and in the labour market.

Consecutively, the acquisition process of professional skills and Soft Skills cannot be considered as a responsibility of merely the HEls or Organizations, but rather as a process with the three stakeholders involved, also the learners to an increasing extent. Based on the paradigm of lifelong learning and the aspects of these three stakeholders, the skills acquisition was presented and illustrated as a process that involves three dimensions, each of them involving specific interests towards the skills.

The next phase of the research seeks to create a systematic method to assess Soft Skills, responding these conditions. The suggested method for detecting the most potential Soft Skills is presented in 3.2 . 
3 


\section{Practical Implications}

After presenting the State of the Art and proposing some tools (the Soft Skills Framework) and procedures (the Soft Skills acquisition process) based on the analysis done in 2.2, the next phase is to suggest some practical implications. First, I will do a closer examination on the different levels and contexts of communication and suggest a Taxonomy based on it. Second, as a more extensive measure, I try to apply the three-dimensional approach (in 2.4) for creating a method for assessing and classifying Soft Skills.

Among all the reviewed skills maps (in 2.2), it could be noticed that communication is an outstanding soft skill. This skill is evidently composed of various subskills (e.g., oral, literal, non-verbal communication) and several levels (interpersonal, intrapersonal). Due to its assessed importance and its intermediating character (Schulz, 2008; Jones, Baldi, Phillips \& Waikar, 2017), it deserves closer examination. Furthermore, communication has been considered as a crucial parameter in the exploitation of other professional skills (Mitchell et al., 2010; Cinque, 2016). For this reason, I will include the 21 Soft Skills from the Framework in the consideration and consequently, suggest a communication based Taxonomy of Soft Skills.

\subsection{Communication based Taxonomy}

The exploratory research of Soft Skills maps that was conducted earlier (2.2.2.) displayed the outstanding role of communication. The specific character of this skill is basically because it is necessary to connect us to other people and societies. Thus, it is necessary in fulfilling basic needs in private life and working life, such as closing relationships and creating trust. Evidently, for people with more responsibility, such as managers and leaders, or working with customers, they need even more diversified skills in communication. In addition, it is important to note that our way of communication is different depending on the context in which it is carried out. For example, communicating with one person individually is probably a different compared to communicating in a group of people. Likewise, in working contexts, group communication with familiar people of the team daily is probably different from communicating as a leader to distribute tasks or speak to an unknown audience. 


\subsubsection{Guidelines for Skills Clusters}

It is common to categorize skills in dimensions or clusters. The practice of clustering essential skills has initially been applied in nursing education (Childs, Coles \& Marjoram, 2009; Jones, 2019). This has various benefits: First, it enables educators, trainers and managers to conclude the most appropriate skills in their respective fields. Second, when starting skills selection from the dimensions, or clusters, clusterization is a way to ensure that all important dimensions are kept within scope. As an example, an artist should be able, in addition to creating marvelous and compelling pieces of art, able to calculate costs and market their products. For these reasons, skill maps are commonly organized in clusters, categories, or other blocks that include skills with similar characteristics.

For HEls, obviously one of the most complicated aspects is to organize the teaching/learning of soft skills, due to their ambiguous character (Cinque, 2015). Therefore, a syllabus is the starting point to organize the teaching. Teachers should know which blocks are those that link similar skills. These blocks are usually called thematic blocks, units or simply themes. When the content to be organized is based on hard skills, the thematic blocks are simpler to obtain and sequence. For example, it is easy to place the sum in a thematic block of operations. Or alternatively, it is easy to determine that for learning multiplication, one must first know how to add. Consequently, multiplication will be a content to be learned after the sum.

Unlike hard skills, it is possible that Soft Skills do not necessarily depend on each other sequentially (Schultz, 2008; Heckmann \& Kautz, 2012), or at least, these sequences are more difficult to define. However, there are cases in which a 'personal' soft skill is necessary to develop social skills. For example, empathy is probably needed in order to develop communication in an assertive way. Time management may be more related to self-control, but it also requires certain hard skills, such as knowledge of agenda tools. Although the sequencing and grouping of Soft Skills is obviously more complex than in the case of hard skills, it is expected that some interdependence can be found. 
To create some additional insight on the possible interdependence of Soft Skills, I will shortly review some of previously presented models.

In 2.2, we found out that communication has intrapersonal and interpersonal levels. In this respect, it is interesting that Daniel Goleman, when presenting 'Emotional intelligence', divided it into 'intrapersonal' and 'interpersonal' areas (in Schutte et al., 1998). In his model, intrapersonal skills refer to self-awareness and the ability to regulate one's thoughts and actions, such as self-image, determination and assertiveness. Intrapersonal skills allow one to adapt oneself in different environments and develop own performance. Interpersonal skills are needed to interact with other people, to communicate appropriately, and to build stronger and more meaningful relationships. In working contexts, they are used as a tool for conveying messages to achieve objectives, (as,) for example, a manager is likely to try to influence their staff members. (Schutte et al., 1998)

A similar kind of division was stated by the National Research Council in the USA. They have structured the $21^{\text {st }}$ century Skills in three main groups: Intrapersonal, Interpersonal and Cognitive skills. Intrapersonal skills include skills such as adaptability, self-management, time management, self-regulation, self-development and executive functioning. Interpersonal skills consist of communication skills, team work, cultural sensitivity and dealing with diversity. As for cognitive skills, they include problem solving, critical thinking and analytic thinking. (Koenig, 2011).

Third, the Business-focused Inventory of Personality (BIP), a scientifically developed assessment procedure, used in various European countries, will be reviewed. BIP includes a systematical assessment of job-relevant personality character traits. The BIP questionnaire measures 14 personality characteristics in respect to behaviour at work, displaying the following clusters:

* Psychological constitution, Occupational orientation (Intrapersonal area)

* Social competences, Occupational behaviour (Interpersonal area) 
The three clusters reviewed demonstrate that Soft Skills can in a coherent way be divided in intrapersonal and interpersonal skills, depending on whether they are practiced more internally, utilizing cognitive operations, or externally, by utilizing social abilities.

These levels allow interesting insights on the Soft Skills regarding their communicational dimension. As a following step, I will examine the 21 Soft Skills from the Framework (2.2.3), focusing on the type and level of communication that is involved in them.

\subsubsection{Communication based Taxonomy of Soft Skills}

The proposed Taxonomy builds on the type of communication (intrapersonal, interpersonal) that is needed in working environments. As internal cognitive processes are necessary for each of us to adapt in varying environments (Schutte et al., 1998), we can assume that the intrapersonal level of communication is always present. In fact, it seems that it is relevant for many different purposes, and that intrapersonal communication is involved in the application of many Soft Skills.

In this review, it is meaningful to consider communication according to the context where it is used. Communication with one person is undoubtedly different from communication that is practiced among various people or in working groups. Furthermore, leaders or managers will likely need a broader variety of communication, when attempting to persuade other people for performance and development. Last, the era of internet and globalization has introduced a totally new sphere for communication, meaning an open network and social media, where communication is typically directed (at least partly) to unknown people.

A visual description of the Taxonomy is presented in figure 7 . The five levels are in the left column. The core of the figure is that each arrow in the "Visual description" column refers to a communication process, intrapersonal or interpersonal. The right column displays Soft Skills (the 21 skills in the Framework), placed according to their interdependence with the communication levels. 
The suggested Taxonomy aims to facilitate understanding how the different levels and contexts of communication are involved with the application of soft skills, and furthermore, to state appropriate methods and measures for promoting these skills.

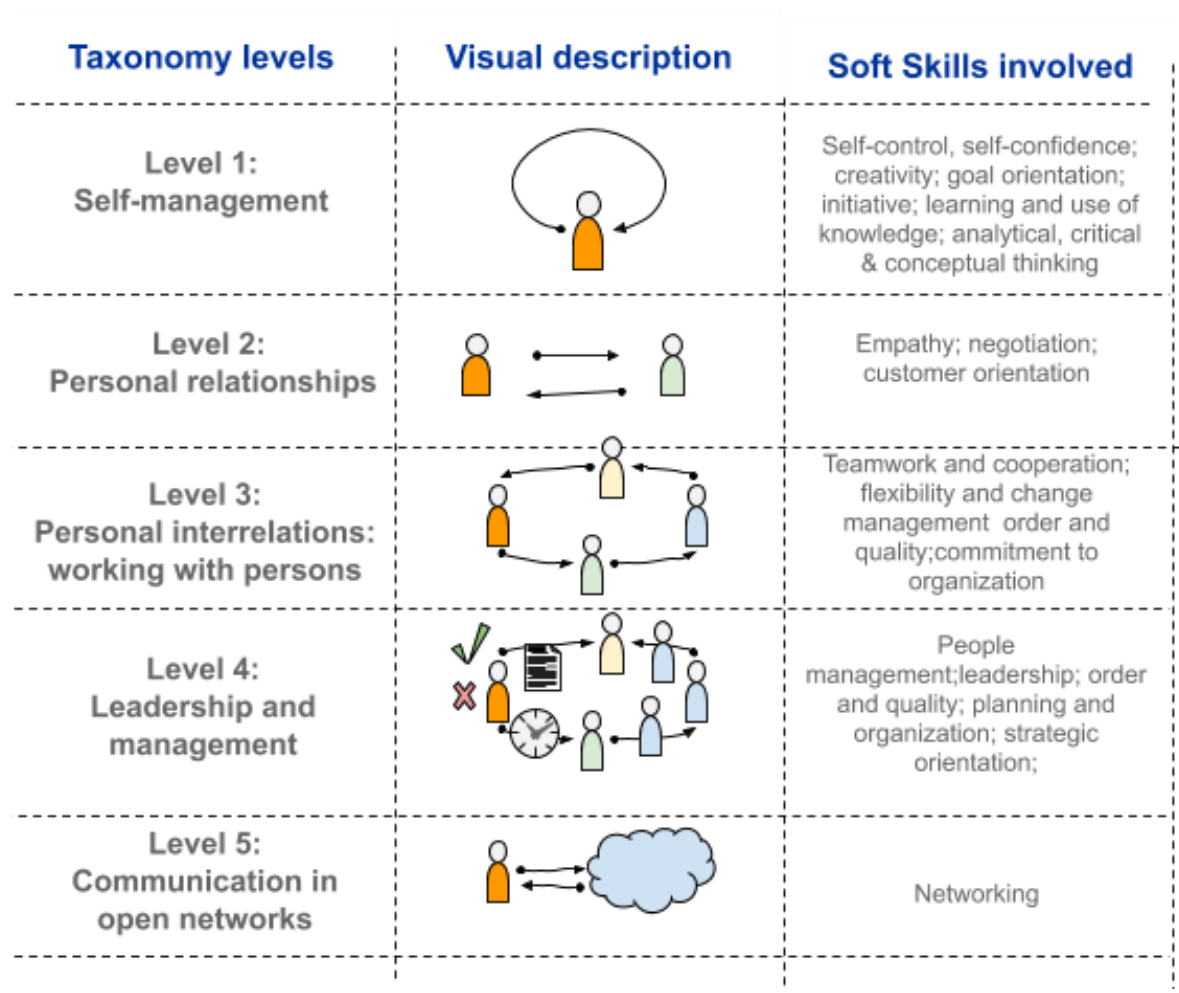

Figure 7 Communication based Taxonomy of Soft Skills.

It must be noted that the purpose of the Taxonomy is not to build a categorization with strict, definite borderlines between classes. In addition, the Taxonomy is not suggesting that a given skill is used merely on a given level, quite the opposite, most skills are connected to various levels. For instance, self-confidence is probably an essential skill at any level. It is located on level 1 as maintaining and developing selfconfidence is essentially dependent on internal communication.

Next, I will describe in more depth the five levels and how different levels of communication are involved when practicing the Soft Skills.

\section{Level 1:Self-management}

The first level, self-management, involves internal communication, covering a wide range of cognitive activities with oneself, enabling one to regulate individual actions 
(Zimmerman, 2000). The results of applying these competencies enable us to maintain a personal life management by reflecting on situations we meet and create strategies to proceed (for instance in studies or working life). The clearest examples, and possibly the most important Soft Skills of level 1 are self-confidence and self-control. The role of self-confidence is essential as it allows us to be open to the world, to other people and to new possibilities. It has a special role in business contexts and Organizations, as business is basically about finding potential ideas and options and exploiting them, as well as opening new contacts.

Hence, self-confidence is generally considered a useful and desired skill, thus important to be developed. It is well known that the best way to develop self-confidence is through exposing oneself to authentic situations and challenges (Zimmermann, 2000), for instance meeting unknown people if one is shy. What happens during these actions is that the person is talking with themself, possibly assessing details of the situation, in a way that can be discouraging or encouraging. Thus, the tone of voice of this internal communication is decisive when regarding the results of the action, whether successful or not. This again has an impact on the total level of self-confidence and how it develops.

As a control system, self-control requires hard skills to "sensor" situations and to "act". In this case, the sensors are the knowledge of oneself as an individual self-knowledge. This is where internal communication is applied. In the case of action, it implies making strategies of action and creating the capacity to do what must be done (Baumeister, Vohs \& Tice, 2007; Redomero et al., 2019). The latter is related to will and motivation (Schunk \& Zimmerman, 1998). The processing part between sensing and acting implies a special cognitive reasoning.

"Effective communication is $20 \%$ what you know and $80 \%$ how you feel about what you know." Jim Rohn

It is remarkable that the majority of our 21 Soft Skills can be located in this category. Order and quality involves a desire and need to have things under control, thus affected and steered more by internal than external communication, being closely 
related to self-control. Again, flexibility and change management points to other types of people with a lower need of control. However, it is well known that most people basically possess quite a conservative mindset, and they do not like changes. This means that a huge number of people have had to, to cope with changes, develop a flexible mindset by internal reasoning and communication, perhaps telling themselves 'you cannot affect the change anyway, it's better to adapt' or on the other hand, 'it can be cool to try new things'. As the conservative tone is very profound inside us, most of us need continuous internal communication when facing all the numerous changes that affect us daily. Nevertheless, these two skills are obviously strongly involved in the third level, in situations when working with other people.

Goal orientation, too, is undoubtedly a characteristic that is combined with such traits as ambition or need to achieve and fulfill things. What we know from achieving, for instance in business, sports or career development, is that at the point of problems and challenges, a lot of internal speech and encouragement is needed, like 'you can do it, others did as well' or 'remember the goal you will reach by achieving this', etc. These are examples of the type of communication involved.

As for initiative and creativity, they can be considered to be somewhat related to each other. Both involve processes where a person reacts to situations where something is not working well, and solutions are needed. Typically, these signals come from the external world, but the reactions to them are created mostly internally. This may take place by comparing similar situations met earlier. Also, taking an initiative or being creative may be related to motivation and an internal desire to fulfill things or to see something happen, encouraging one to act.

Furthermore, there are additional Soft Skills that involve cognitive activities and internal communication. Evidently, learning and use of knowledge consists of processes where former learning and previously obtained knowledge is assessed and applied in new situations. In most cases, the outcomes provide signals of new skills that must be learnt to do well, these cases are often named as triggers or gaps for learning. This kind of state also induces motivation to learn, and leads to a process, often called 'double loop learning' (Argyris, 2002) where learning is continuous and the loops increase the 
knowledge, as practical experiences direct the goals of learning. This process is enabled by internal reflection, consisting of assessment of the knowledge needed to solve problems or manage situations, obtaining new knowledge and finally, assessing the outcomes. It is obvious that a notable amount of internal communication is involved in these processes.

Additionally, there are three Soft Skills that can be included in the first level of the Taxonomy, self-management. They are analytical, critical and conceptual thinking. According to Robbins (2011), analytical thinking is necessary when an ambiguous situation requires the learner to identify or create a problem to solve. Reasoning, an essential element of both problem solving and analytical thinking, involves the manipulation of verbal stimuli to restrict response alternatives in accordance with a problem's outcome.

\section{Level 2: Personal relationships}

This level focuses on the skills that facilitate direct person-to-person communication. It includes both received communication, knowing how to listen, and produced communication, knowing how to communicate to a person, not to a team or to a bigger audience. This level is a key to the employment relationship since it enters the territory of personal relationships. In one-to-one communication there are only two parts, which means that all the observation and communication is directed fully to the opposite person. Two skilled professionals, for instance colleagues, may have conflicts because of lacking Soft Skills at this level.

To create a mutually well-working communication and trust with someone, empathy is likely to be a key skill. It refers to an ability to correctly understand another person's thoughts, feelings and concerns. The ability to understand another person is a condition for forming the right messages. It is also key to communicate in a way that is understandable and meaningful to the other person.

Further Soft Skills affiliated to this level are negotiation and customer orientation. By definition, they both imply individual action in a way that enables serving others and creating mutual benefits. Negotiation, in particular, can be a demanding process of 
communication where efforts are needed to find agreeable solutions for both parts. Obviously, such agreements cannot be created on a one-way basis, hence all levels of communication are needed (vocal, literal, listening, physical behaviour). Hence, communication skills are employed to a wide extent when applying the skill of negotiation.

Regarding customer orientation, it may be argued that it is closer to a mindset than to active behaviour, however it has a very concrete role in personal customer relationships. A customer will immediately be aware whether the counterpart is customer oriented or not. This pinpoints that customer orientation is strongly connected with communication, the things we speak out and express, perhaps without words, unintentionally.

\section{Level 3: Personal interrelations: working with people}

The third level is about how to communicate with a number of other people, for instance colleagues in a working team. It is necessary to distinguish this level from the previous, as the type of communication applied here is less focused on a person, instead, more focused on the discussion and atmosphere of the group. Also, the time span of the communication is different from the previous level. In this case, communication is continuous, often involved with carrying out shared tasks and/or reaching common goals.

Like in most taxonomies and hierarchies, it must be noted that the skills of the two previous levels are likely to be needed even on this level. Yet, one of the key Soft Skills in working contexts is team working and cooperation. Doubtless, the ability and intention to collaborate with others as a part of a group is desirable in most working places. It is evident that team working involves a big variety of communication skills. In addition, it is necessary to consider other people in an equal way, respect them and their manners to work, and be aware of hierarchies and relationships in the working groups. Thus, it is obvious that team working and cooperation consist not only of expressive and operative skills, but it includes also internal communication, for instance reflection on impacts of own behaviour and communication and interpreting and assessing them. 
Another essential Soft Skill related to communication in working contexts is flexibility and change management. It implies the ability to work effectively in changing situations and with a variety of people. In modern working contexts, changes happen more often and more unpredictably (Bughin et al., 2019). In addition, this skill enables one to assess and manage changes in their own role. This, again, is necessary to maintain a positive and balanced mode of communication towards other people and thus foster the atmosphere in the Organization (Kaplan \& Norton, 2004). Also, order and quality is a skill needed in working contexts, for instance when carrying out individual task, or following internal quality rules.

There is one more Soft Skill that is in most working contexts related to communication but is not always observed at the first glance. It reminds customer orientation, perhaps closer to an attitude or mindset than a skill. This skill is commitment to organization, involving the ability and willingness to direct own behaviour towards the needs of Organization. With a closer glance we can notice that at any working place it is possible to detect those who 'do not care' or 'are just working here', and those who are more deeply dedicated to the Organization they work for. Obviously, it can be expressed partly internally and partly externally. This trait can derive from loyalty, or it can be determination for promoting one's professional career. The reasons for this may obviously vary, but the important point is that the presence or absence of this skill affects the group spirit and the culture. For this reason, many organizations have raised commitment to organization among their most prominent values and goals.

\section{Level 4: Leadership and management}

The fourth level associates the special skills that are needed by leaders and managers in charge of working groups and bigger units, expected to fulfill certain tasks and objectives continuously. Their task is very much about being informed, taking decisions and sharing this information to subordinates. Principally, it is apparent that communication itself is a very important skill in these contexts, as its main purpose is to transmit something to others in a clear and understandable way.

Obviously, the Soft Skill of leadership is essentially involved with managerial and leadership communication. Leaders are expected to promote visions and goals in a 
clear and motivating way. This is usually expressed by communication that is encouraging, trustworthy and professionally relevant. Leaders are also supposed to act as examples and role models. In certain situations, communication can be of the type one-to-one, however mostly it concerns several people, for instance the whole team or working group. In a team or department with great diversity, this task is far from easy. Thus, very many different abilities are probably needed, for instance understanding and respecting people, knowing their differing traits and features and being able to read and regulate the atmosphere in a team.

Again, it must be noticed that leaders need several skills from the intrapersonal level (1). To communicate clearly and answer uprising questions, they must process and assess information, have good self-control and self-confidence and goal orientation. Furthermore, modern management theories encourage managers to create autonomous learning and working and aspire to mutual communication with their subordinates (Budhwar, P. S., \& Bhatnagar, J., 2007), instead of the traditional oneway communication. This means that managers need to include more communicational aspects in their work than they historically have needed. For this reason, the previously mentioned leadership skills are necessary to be combined with communication of all those who work as managers. In our Skills framework, also people management covers essential elements of communication, as it is about reasoning and convincing towards a common goal.

Finally, planning and organization and strategic orientation skills are additional important skills related to the performance of managers and leaders, even though they are not as visible and evident. The first named skill includes the ability to prioritize lines of action and optimize resources for reaching expected results. Doubtless, these kinds of activities involve essentially also internal communication (level 1). Strategic orientation has apparently similar traits, it refers to the ability of linking long-term visions and goals to daily operations. Also, here, internal communication (level 1) is undoubtedly applied since it is about assessing and comparing various daily tasks and comprehending their significance and role in a holistic view. 


\section{Level 5: Communicating in open networks}

This level of communication has gained increased relevance in the time of internet and globalization, whereby the world is connected to an extent previously never seen (Bughin et al., 2019). These sequences have been essential especially for business Organizations, as they have offered new possibilities for their core operations. It has become habitual to search for customerships, material and human resources in online environments, either open platforms or websites of other Organizations.

Concurrently, in the era of social media, a variety of worldwide platforms have been opened for publishing individual profiles, for communication between individuals and for sharing experiences with followers and within groups. The different social media applications are available for private purposes, for more informal relations, but also for professional purposes, for creating a personal presence and improving personal branding (McDonald, 2019).

As a crucial difference to the previous types of communication, these open, worldwide platforms involve communication with a partly undefined audience, i.e., people who are previously unknown to us. They may be the followers of our followers, members of a group we belong to, or even totally unknown, depending on our profile and account settings.

As for our Soft Skills, the skill networking can be located on this level. Networking is about the ability of establishing win-win contacts with a wide range of people. It is easy to see that this skill has a special importance in business Organizations, where many of activities are carried out either in the social media or outsourced to partners in networks of autonomous companies (Kaplan \& Norton, 2004). Consequently, networking has always been widely used in marketing and sales activities in search of new customerships and extending markets, and this has gained ever more importance in internet-based communication and social media. Doubtless, these activities involve different kinds of communication, partly similar to that in leadership, for instance transmitting things in an understandable way and being persuasive and convincing. In addition, a type of interest, empathy and understanding of other people's feelings is obviously needed. Even when communicating with unknown people it is necessary to understand the other person's situations and concerns, as this is probably the best 
way to offer solutions and help and thus establish relationships of mutual win-win, even in digital networks and social media.

\subsubsection{Applications of the Taxonomy}

The suggested Taxonomy is based on the different levels and types of communication that are needed in working contexts. Applying the Framework created in 2.2.3., it seems possible to connect these Soft Skills with internal and external communication in the five presented contexts. The definition was facilitated by applying the verbal definitions of the skills, previously presented in 2.2.3. Although some of the skills (such as self-confidence or analytic thinking) have multiple roles and could thus be located on several levels, most of the skills have a clear affiliation with the communication types and context in question.

The suggested Taxonomy affirms the central role of communication, as it is respectively involved in the practice of most other Soft Skills. For instance, leadership, networking, or people management doubtless involve a considerable number of communication. Via the Taxonomy, the interdependence between the intrapersonal level (1) and interpersonal levels $(2,3,4,5)$ can be recognized. As an outcome, it becomes evident that the practice of most interpersonal skills essentially needs intrapersonal cognitions and communication. As an example, a person who is expected to lead teams, build networks, or manage a department, is likely to apply self-confidence, self-control or goal orientation.

This finding allows us to state that, in respect to the development and promotion of Soft Skills, introspection should be encouraged much more in aspects of business studies, to promote skills of level 1. Furthermore, concerning self-confidence and selfcontrol in particular, educators and trainers should encourage learners to attend authentic procedures and actions, where they face the need of these skills.

Due to their importance, communication skills appear in some form in most HEl curricula, also in business HEls (Grugulis \& Vincent, 2009; Mason et al., 2009). However, it has often been considered a challenge to promote communication skills and to apply appropriate teaching/learning methods respectively (e.g., Maguire \& Pitceathly, 2002; Malhotra et al., 2009). In particular, this seems to be the case in 
business education. To operate successfully, business professionals, especially managers, apparently need diversified communication skills. However, many business educators still utilize a superficial set of skills, dividing communication according to the media used (Bovée, Thill \& Raina, 2016) rather than the deeper approach, covering the necessary skills.

Thus, one of the main contributions of the Taxonomy is in facilitating teaching and learning of communication skills. As it clearly exhibits skills that constitute communication skills in given contexts, educators and trainers can choose some of these specific skills and develop them, instead of merely training 'communication' without a specific focus. Evidently, this is useful for people working in Organizations in tasks of customer relations and managers, but also for students in business higher education.

Generally, the Taxonomy allows educators and trainers to take new approaches in the promotion of communication skills, as it defines not only certain skills but also the contexts where they are typically needed. Hence, training can be conducted based on concrete environments and levels of interaction, for instance training can be focused on two-person communication, working group communication or leadership communication, whereby the Taxonomy provides relevant skills that are involved on each level. Especially in the role of leader or manager, it is evident that more types of skills are needed than in the role of a regular employee.

One of the main outcomes of the Taxonomy is that it exhibits the central role of internal communication in the practice of Soft Skills. Almost a half of the skills in the Framework (21 skills) have an affiliation with internal communication, level 1. This suggests that internal communication and cognitive processes should be raised to curricula, as they seem to be a base in the practicing of many Soft Skills that are professionally important.

\subsection{The proposed method: Soft Skills Status indicator (3Si)}

Next, I will take on the major task of the research project by creating and suggesting a method that is able to assess Soft Skills in a way that enables selecting the most 
important and potential ones, to reduce the skills gap between HEls and Organizations. For this purpose, I propose a method that bases on previous elements of this research, first, the Soft Skills Framework (2.2.3) and second, the skills acquisition process involving three stakeholders (2.4.1 and 2.4.2). The proposed method, hereafter called Soft Skills Status indicator (3Si), seeks to classify Soft Skills in terms of their perceived importance, level and learnability.

Subsequently, the method will be tested by two experiments, applying research methods presented in 2.3.1. The experiments are reported in chapter 4.

The method and the experiments are expected to answer the sub-hypothesis 2 "Certain Soft Skills are more significant in working context than others", sub-hypothesis 3 "At least some of these skills can be detected" and sub-hypothesis 4 "and developed".

\subsubsection{The Soft Skills Match - the process of defining and detecting Core Soft Skills}

In paragraph 2.3, the conditions of matching education, skills and employment were discussed. The process of skills acquisition was designed, inferring that there are different stakeholders involved in the process. This examination has made it possible to structure the process into a sequence with three stakeholders, the Educators, the Learners and the Organizations. The next step is to design the research constellation and design a corresponding survey tool. This is made by a closer examination of the match of skills between HEls and Organizations (figure 11).

In addition, the design of the method and its expected outcomes are presented in this paragraph. The outcoming method (3Si) is expected to provide new insights on the Soft Skills acquisition process and thus be useful for higher education and trainers, learners and Organizations.

The phases of the process, discussed previously in 2.4., are demonstrated in the figure below. In the run of the process, a large set of general Soft Skills (a) is reduced to a viable skills framework (b), covering skills that are appropriate for educators as well as Organizations and their teams, wherein the aim is to detect the core skills (c) that are 
important and essential for the stakeholders (d). Being able to detect these skills is a step towards reducing the skills gap.

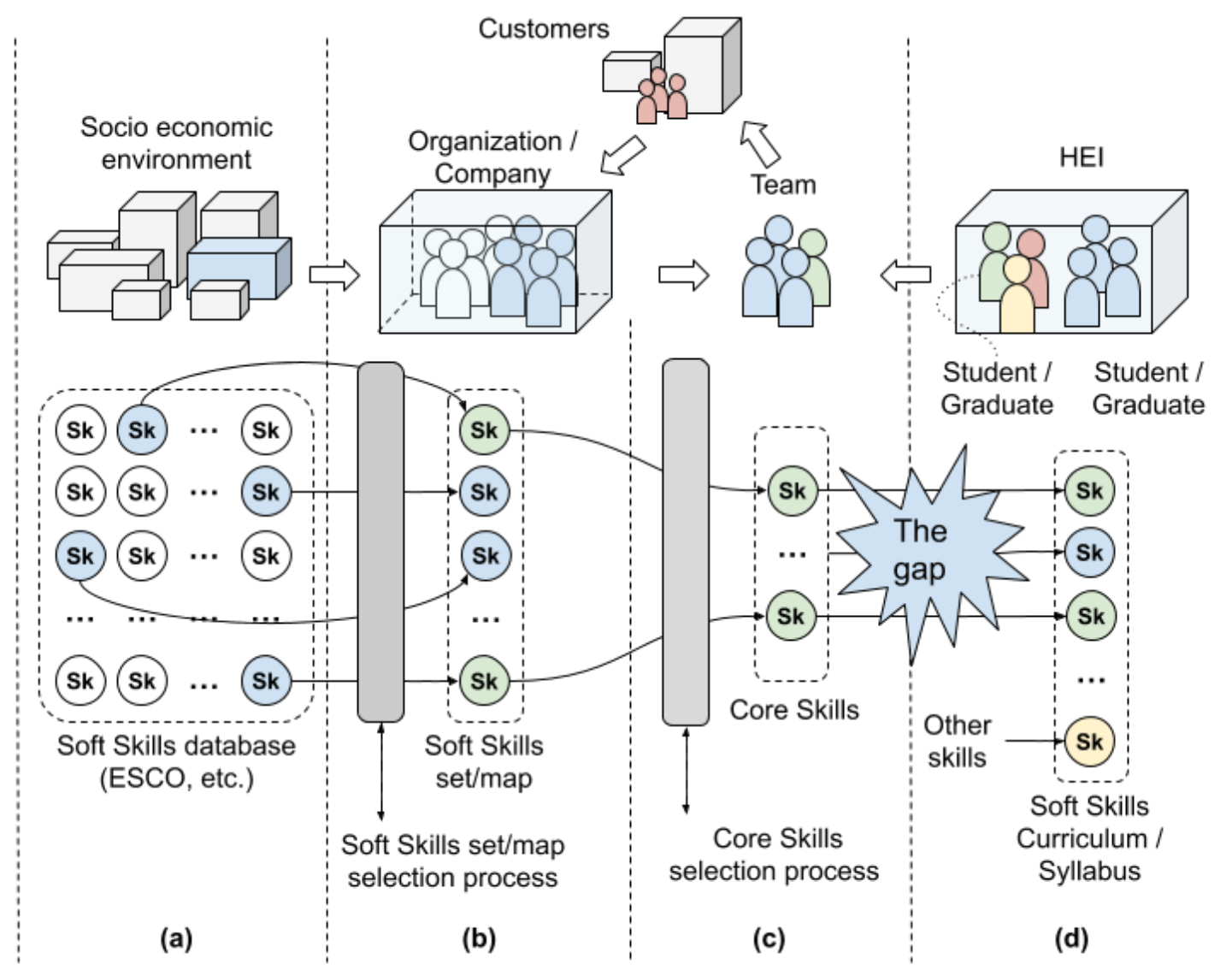

Figure 8 "The Soft Skills match": the process of defining and detecting Core Soft Skills.

In this research, 'core skills' are defined as a limited number of Soft Skills that have more relevance in the attempt of reducing the skills gaps. They are skills that are considered significant in working positions and, in addition, they are considered possible to learn and develop at HEls. It can be assumed that these kinds of skills are essential for all stakeholders.

The first stage of the process (column 'a' in the figure) has already been conducted in this research by the skills maps analysis (2.2). So has the phase (b), by defining the viable Framework for this research (2.2.3). In Organizations, these stages are normally entered by the initiative of the researcher, or because Organizations consider that the Soft Skills obtained from the previous stages should be reviewed. Here researchers must collect the Soft Skills, check if new ones have appeared or even generate the Soft Skills (Sanghi, 2016). 
Obviously, the step (a) is still on a general level and thus not sufficient to enable a mutual understanding and development activities to be carried out by HEls and Organizations. The following needed step (b) is necessary to select those that are relevant to the Organization or working environment in question. In the current research, this process was carried out as described in 2.2., resulting in a well-argued framework of skills, viable for working life and Business organizations (in 2.2.3).

However, the method 3Si strives for a more specific consideration, as it aims to detect Soft Skills with common interest for education and working life, and possibly classify the skills accordingly. The question arises, can these aspects be combined? How could it be done? For this purpose, in this research, I will use the previously suggested Soft Skills acquisition process (2.3), the insight of the stakeholders and the dimensions originating from considering their aspects, discussed in 2.4. This stage is expected to detect the most essential Soft Skills (c). Relying on the dimensions, we can distinguish three dimensions:

1) The significance of the skill (dimension Organization)

2) Trust that a skill be learned and taught at HEls (dimension $\mathrm{HEI}$ )

3) The level of the learner (dimension Student/Graduate/Employee)

The first dimension is justified, as most graduates get employed in Organizations, and these will recruit people equipped with significant skills. Thus, HEls are expected to do their best to provide their students and graduates with skills that are needed by the Organizations and the modern working life. As I have stated previously in chapter 2.1.3, one profound reason for the skills gap is that academics and education often lack updated information of the working contexts of their respective fields. Thus, the first dimension will essentially convey the needs of working life to the HEls, their curricula planners and teachers.

The second dimension aims to assess, or indicate, the learning potential of Soft Skills. This is necessary as methods for hard skills are well known, but measures for promoting Soft Skills are widely needed (Tulgan, 2015; Succi \& Canovi, 2019; Silber- 
Varod, Eshet-Alkalai \& Geri, 2019). Relying on the ambiguity of the skills, it is probable that there are differences in the perceived learning potentials of the different skills, as some Soft Skills are perhaps considered more as inborn abilities than others, or for other reasons. This dimension aims to provide indications for educators and trainers in particular

Of course, it must be noticed that there is hardly a definitive answer to the last dimension, 'How possible is it to promote skill $n$ ?' At least it would need a long sequential study, which is not in the scope of this thesis. In the presented method, this will be considered by asking professionals to rate the development potential of certain Soft Skills, based on their own judgment and experience. This is considered relevant, as the development of Soft Skills has been reported to take place mostly through practical application and experience (Mitchell et al., 2010; Anthony \& Garner, 2016; Redomero et al., 2019; Silber-Varod et al., 2019).

The third dimension 'graduate level' reflects the current status and level of skills by the learner. It might be a graduate, recently recruited or employee. From the learners' point of view, 'Level' includes a goal dimension, as it enables to rank the skills in the order according to the level the learner currently has. For many students and employees, a concrete rise in a grade or level is a key factor for improvement and self-development. Thus, this dimension covers a motivational factor for learners, whether students or employees.

In particular, this dimension reveals skills gaps. If it turns out that the level of staff is exceptionally low, or lower than a predicted rate, it means that training is needed in this skill, whereas high and acceptable levels indicate that there is a sufficient level of this skill in the Organization. If high level, the need to develop this skill at HEls is not as urgent as if the skill shows a deficit.

In many of the recent studies (e.g., Robles, 2012; WEF, 2016; Bughin et al., 2018) the first dimension has been included, and recently some of them also include insights on the third dimension (e.g., Mourshed et. al, 2014; OECD, 2016). The second dimension 
provides novelty and can be considered especially interesting for educational bodies and HR professionals and trainers.

Finally, the question 'which type of research should we use here?' remains. Relying on the review made on research methods (2.3.1), a survey was decided to be used. A quantitative survey enables us to gather sufficient data for statistical testing and conclusions (e.g., Bradburn, Sudman, Blair, Locander, Miles, Singer, Stocking, 1979; Broadbent, Cooper, FitzGerald \& Parkes, 1982).

As for the target group and sample, in addition that it represents the total target population, it should be reachable and possible to define. In this research, the starting point is in higher education; thus, one of the main purposes is to obtain complementary information and insights from working life, especially business organizations. For these reasons, it was decided to focus on professionals who work in positions of business. 'Business' covers basically the fields of marketing \& sales, administrative tasks and accounting. Furthermore, it was decided to select people with at least three years of working experience, as they can be expected to possess sufficient insight to assess the significance and learnability dimensions of skills. Moreover, with several years of working experience, most likely in various organization, they are in the position to assess their younger colleagues, representing the recently graduated.

The next step was to design the questionnaire to be used in the survey. This is presented in 3.2.2. Before launching to the target group, the questionnaire was tested by interviewing experienced focus people in the fields of management and human relationships (HR). This experiment is reported in paragraph 4.1.

\subsubsection{The 3Si Survey Questionnaire}

To obtain research data to test the sub-hypotheses 2, 3 and 4, a questionnaire was designed. In essence, the main purpose is to create a survey that represents the aspects of the three stakeholders, described in the previous paragraph. Hence, the respondents are asked to assess the 21 soft skills (Framework) in three statistical dimensions. 
The questionnaire consists of three parts, as presented in figure 12. The first and third block cover background data and specific opinions regarding skills maps. The second block is the main part, covering the respondents' assessments of the 21 skills, from the three dimensions. According to its focus, this research instrument is called the Soft Skills Status indicator (3Si) Questionnaire.

\section{Background data}

The focus of this research is on the Soft Skills that are needed especially in business and ICT environments. These fields include different types of positions such as marketing and sales, accounting and administrative work (business), or programmer, software specialist, project manager (ICT). Therefore, to identify the respondents' tasks and roles, they were asked to indicate their working position, according to the ESCO (2013) system. In addition, they were asked to indicate their working experience, as it was assumed that this would affect their assessment. Furthermore, the field and branch of business were asked, in accordance with the NACE code classification. Finally, the company possession type and size (private/public, small/medium/large) were asked.
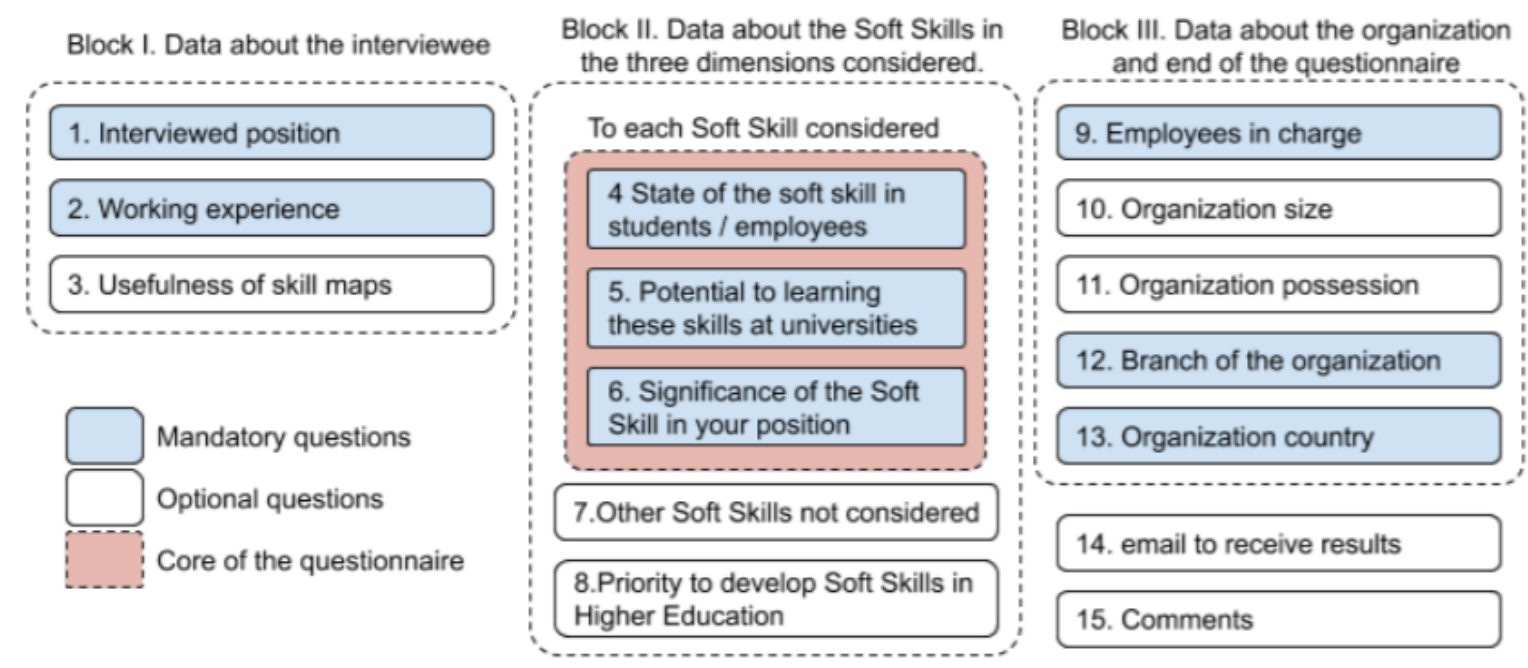

Figure 9 The structure of the 3Si questionnaire.

Regarding the background data, the following questions were set as obligatory: the interviewee's position and working experience, employees in charge, branch of the organization and the country represented. 
In addition, some questions were added to be responded optionally: Usefulness of skills maps, possible skills to add in the Framework, organization size and possession, personal email address to receive results and finally, comments.

\section{Main block of the questionnaire}

In the main block a matrix of 21 Soft Skills (table 8), originating from the framework compiled previously in 2.2.3, was asked to be rated by the Likert scale 1-5 in three dimensions.

\begin{tabular}{|c|c|c|}
\hline Class & Category & Soft Skill \\
\hline \multirow[t]{3}{*}{ Intrapersonal } & Cognitive & $\begin{array}{l}\text { Learning and use of Knowledge } \\
\text { Creativity } \\
\text { Strategic Orientation } \\
\text { Analytic Thinking } \\
\text { Conceptual Thinking }\end{array}$ \\
\hline & $\begin{array}{l}\text { Goal } \\
\text { Orientation }\end{array}$ & $\begin{array}{l}\text { Initiative } \\
\text { Goal Orientation } \\
\text { Planning \& Organization } \\
\text { Preoccupation with Order and Quality }\end{array}$ \\
\hline & $\begin{array}{l}\text { Personal } \\
\text { Management }\end{array}$ & $\begin{array}{l}\text { Self-Confidence } \\
\text { Self-Control } \\
\text { Commitment to Organization } \\
\text { Flexibility and change management }\end{array}$ \\
\hline \multirow[t]{2}{*}{ Interpersonal } & $\begin{array}{l}\text { Team } \\
\text { Management }\end{array}$ & $\begin{array}{l}\text { People Management } \\
\text { Leadership } \\
\text { Work in team and Cooperation }\end{array}$ \\
\hline & Influence & $\begin{array}{l}\text { Communication } \\
\text { Empathy } \\
\text { Negotiation } \\
\text { Networking } \\
\text { Customer Orientation }\end{array}$ \\
\hline
\end{tabular}

Table 7 The Soft Skills matrix used in the questionnaire, result of the Framework presented in chapter 2.4.

The first dimension, the significance of a given skill in a certain working position, was asked by the question 'How significant do you consider this skill in your work position?', on the scale $1-5$ (1=not significant, $\ldots, 5=$ highly significant). This question enables to measure how significant a skill is considered in a certain working position. 


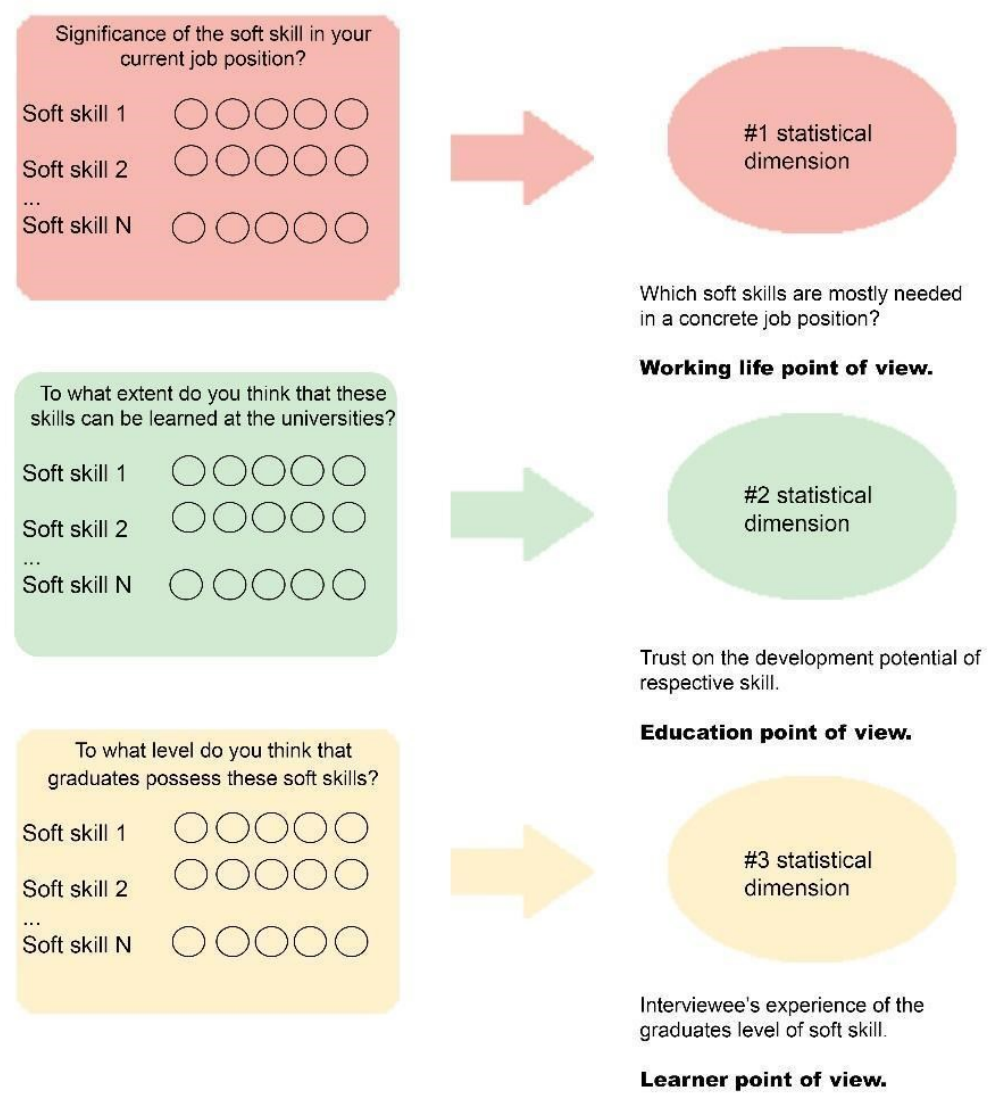

Figure 10 The main block of the Questionnaire with three statistical dimensions.

The following dimension aims to provide an indication to both trust in higher education institutions and similarly, in the learning potential of a given Soft Skill in general. For this purpose, the question 'To what extent do you think that these skills can be learned at universities?' was asked. This is expected to give important indications to educators and trainers, as methods and measures to promote Soft Skills are widely needed. Although the responses and the outcomes cannot be considered as definite, they are based on the experience of business professionals, and thus they include much value, specifically as Soft Skills are said to develop along with personal work career and experiences.

As for the third dimension, the question 'To what extent do you think that graduates possess these skills?' was set. In this target group, it seeks to highlight primarily the level of graduates. This data is important for the graduates themselves, reflecting what their competence in the labour market in terms of Soft Skills is. Moreover, this question can reveal possible skills gaps, as well as differences in individuals regarding these levels. Obviously, this question could as well measure the level of peer employees. In 
addition, in a different kind of research constellation, with slight changes to the question, we could measure in this dimension, the attractiveness of mastering a skill, for a learner.

To avoid confusion regarding the perception of these definitions, the online questionnaire was provided with a concise definition for each of the 21 skills (figure 11).

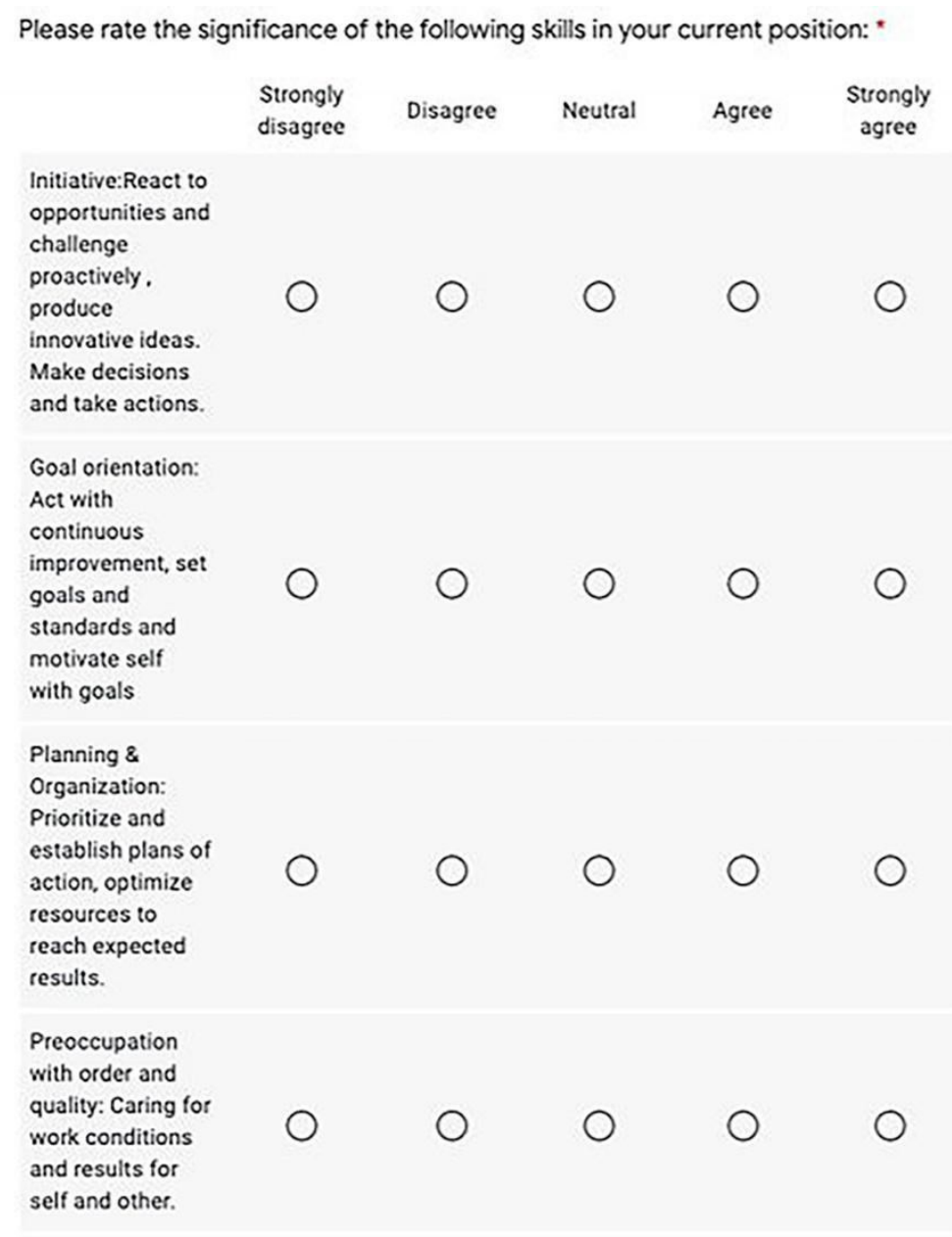

Figure 11 Each skill was supplied with a short description.

Finally, the respondents were left the option to add any important Soft Skill, in case they did not find it in the matrix.

\section{The influence of the interviewee}

The other important aspect of the questionnaire is the personal opinion, and possible predisposition, of the interviewee about skills maps. Generally, it is agreed that skills 
maps are necessary and should be considered for the success of companies. To know the percentage of respondents who might disagree, a question was raised about the point of view of the interviewee. As this aspect is subjective, the question was posed at the beginning of the questionnaire.

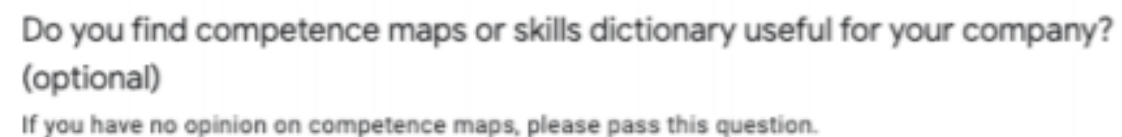

If you have no opinion on competence maps, please pass this question.

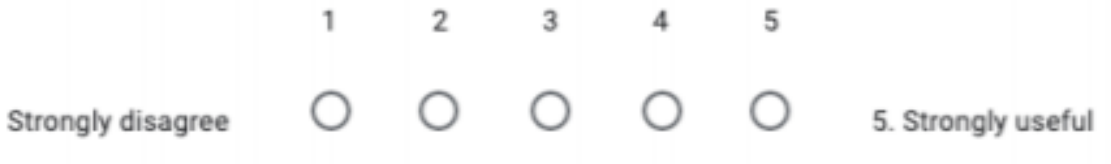

Figure 12 Respondent's opinion of the utility of skills maps in general.

Finally, the survey also had a pedagogical utility. After answering the questions, the respondent was given an additional choice to respond whether they find skills maps useful or not. It was assumed that the opinion might have changed along with rating the skills.

\section{Summary}

To sum up, the created survey tool is designed for measuring the state of skills, in this case especially Soft Skills, with the purpose of detecting the most crucial ones by rating their importance in working life positions and moreover, indicating their current or desired status and potential of learning. This type of knowledge is essential for the actors who are expected to promote Soft Skills; with this, we refer to higher education, vocational education, organizational HR bodies and private training companies.

As for its usability, the survey could be launched in most professional fields, as it covers Soft Skills that are generally used and relevant in both academic and working contexts. The Framework was composed as a result of an extensive exploratory research (2.3), affirming that it includes the most relevant Soft Skills. Regarding the dimensions of the 3 Si survey, they are justified by considering the skills acquisition as a process that has several stakeholders. As such, it includes novelty in its approach. 


\subsubsection{The 3Si Method}

\section{Description of the Method 3Si}

Basically, quantitative surveys provide distributions of values, exhibiting the respondents' experiences, opinions and assessments towards the variables. This data enables to compare the variables and set them in order. In addition, it can indicate volumes and frequencies of certain variables and thus, their relative importance. Also, quantitative surveys allow to examine influences between different variables and background data. Moreover, due to the precise data provided, quantitative analysis can confirm or discard a preset hypothesis. (e.g., Bradburn, Sudman, Blair, Locander, Miles, Singer, Stocking, 1979; Broadbent, Cooper, FitzGerald \& Parkes, 1982).

As for the 3Si survey, the 21 skills will likely get varying scores from each three dimensions. Most interesting in this research are the scores for 'significance' as they indicate skills that are evidently important in the respective areas of work. In addition, also the 'learnability' scores are interesting for all of us who work in the field of education, as they indicate the likeliness to promote and foster the Soft Skill. In this research, the 'level' scores are interesting as they demonstrate the potential skills gaps, or alternatively skills that are mastered well. Also, this information is important for educators.

The scores from these dimensions would be informative as such; however, this research aims to classify Soft Skills by means that make it possible to reason and select skills by certain arguments. In addition, my aim is to find possible 'core soft skills' that are more interesting and potential than others, in the educational aspect. For these reasons, the three dimensions must be associated in a unified consideration, which is the basic idea of the $3 \mathrm{Si}$ method. In the following, I present its foundations:

Combination of the three dimensions would basically result in numeral configurations, for instance 3-4-2. However, the use of the entire Likert 5-scale would give in total a very high number of combinations (125), which would not yet allow any classifications. Consequently, it was decided to classify each skill value simply two-way as 'High' or 'Low', according to whether it exceeds a specific given threshold that could be, for 
instance, the average of each dimension. Basically, the average of the 21 skills will be used as threshold value. This division will provide eight classes of Soft Skills. They will be presented in detail in the next paragraph.

Accordingly, the following essential questions can be placed:

- How should the scores and values be interpreted?

- Which further indications do the high $(\mathrm{H})$ and low $(\mathrm{L})$ values offer in each dimension?

- Which of the values are essential for each stakeholder?

- What kind of information is obtained for educational purposes when associating the three dimensions?

- What is the role of the threshold?

Regarding the values, a high $(\mathrm{H})$ value for a given skill in dimension 'Significance' means that the respondent considers this skill higher than average in their working position, whereas low (L) would mean less significance for the skill. As the questionnaire is launched to professionals, this value reflects opinions of people who work in the respective fields and therefore are assumed to know best the skills needed in the positions concerned. The 'significance' score has two important implications. First, within Organizations, it gives managers and HR professionals an indication on which skills are important in different positions. Second, for HEls, the skills and their ranking deliver a clear hierarchy for skills to be included in curricula. This reference is essential for reducing the skills gaps between HEls and Organizations.

However, it is to note that the questionnaire allows the respondent to score all skills high, which would cause a sort of 'inflation' in the values. This makes it necessary to use a threshold value when dividing scores between high and low $(\mathrm{H} / \mathrm{L})$. For instance, using the average value as threshold would mean that $50 \%$ of the skills will be rated low $(\mathrm{L})$ and $50 \%$ high $(\mathrm{H})$. The determination of the threshold value mainly depends on the needs of the Organization. This subject will be discussed in more detail in paragraph 4.4 . 
As for the second dimension 'Learnability', high scores imply that this skill is perceived as rather likely to learn, whereas lower scores indicate less learning potential, or uncertainty towards this. Although a subjective opinion, these assessments are valuable as they are based on the respondent's own experience and perception of obtaining this skill. Their assessments can be considered justified and realistic, as Soft Skills have been reported to develop most likely in authentic working environments (Muir, 2004) and through personal experience (Gilbert et al., 2004).

Primarily, high scores in 'Learnability' are a positive sign for the HEls or trainers within Organizations to reinforce their training in respective skills. This is especially useful in cases where the level of skills needs improvement, and of course, if the skill has high significance. On the other hand, low scores in this dimension are a potential challenge for educators, especially in the case that the skill has high significance. The scores of this second dimension can be considered important especially for the HEIs, as there is usually an 'overflow' of skills that should be promoted and included in curricula, and only a few can be chosen. The results of the statistical dimension 'Learnability' will facilitate the selection of the appropriate Soft Skills in the curricula.

Regarding the third dimension 'Level of graduates', in this research it exhibits the actual status of graduates, as perceived by their co-workers. Although it is a subjective assessment, it reflects graduates' performance in daily working contexts, thus providing authentic judgment on the graduates' Soft Skills 'in action'. The values in this dimension highlight two important aspects. First, they reveal skills that are rated low, thus offering both Organizations and HEls important information about existing gaps in Soft Skills. To enable detecting such gaps, it is common that Organizations use threshold values, whereby they state a minimum level of a skill. Second, it may be the case that graduates possess high levels in some skills, learned either at school or through other activities (in hobbies or at home), meaning that they possess the level that is needed by their employers. In the case of these kinds of skills, HEls may consider whether it is necessary to include these skills in the curricula, and to what extent. 
The association of the high $(\mathrm{H})$ or low $(\mathrm{L})$ values from each dimension, provides a comprehensive view on Soft Skills, useful for Organizations, Higher Education and students/graduates in their career planning. The proposed method Soft Skills Status indicator (3Si), is expected to answer the main hypothesis of the thesis, "Soft Skills can be organized according to their significance to Organizations, universities and employees, and their development potential can be detected. “

\section{Description of the 3Si Classification}

As a result of dividing skills in High or Low in the three dimensions, we obtain combinations that enable us to view each skill in a three-dimensional perspective. For HEls, to reduce skill gaps, the most interesting skills are those that have scored High in the dimension significance. This conveys to the HEls the skills that their students and graduates should master sufficiently when seeking recruitment. These classes and their scenarios are described in the following presentation (table 9).

\begin{tabular}{|l|l|l|l|l|}
\hline Class & $\begin{array}{l}\text { Significan } \\
\text { ce } \\
\text { (Organiza } \\
\text { tion) }\end{array}$ & $\begin{array}{l}\text { Learning } \\
\text { potential } \\
\text { (HEI) }\end{array}$ & $\begin{array}{l}\text { Graduate } \\
\text { level } \\
\text { (Learner) }\end{array}$ & Scenario for Skills included \\
\hline 1 & High & High & High & $\begin{array}{l}\text { 'Core Soft Skills' } \\
\text { Organizations need, can be learned, } \\
\text { and high graduate/staff level }\end{array}$ \\
\hline 2 & High & High & Low & $\begin{array}{l}\text { 'Ignored skills' } \\
\text { Organizations need, can be } \\
\text { learned, but low graduate/staff level }\end{array}$ \\
\hline 3 & High & Low & High & $\begin{array}{l}\text { 'External skills' } \\
\text { Organizations need, low trust in } \\
\text { learning, high graduate/staff level }\end{array}$ \\
\hline 4 & High & Low & Low & $\begin{array}{l}\text { 'Neglected skills' } \\
\text { Organizations need, low trust in } \\
\text { learning, low graduate/staff level }\end{array}$ \\
\hline
\end{tabular}

Table 8 Description of the Soft Skills classes with High significance.

In the case of $\mathrm{H}-\mathrm{H}-\mathrm{H}$ (class 1), it includes skills that are highly significant in the working context, have a high trust in learning and in addition, high level of graduates. This indicates that graduates' level is matching with Organizations' needs, and furthermore, 
the skill is judged to be quite easily obtained. This would be a good situation also for HEls, as there seems to be learning potential for the skill, if needed. Therefore, the skills in class 1 are called 'Core Soft Skills'. Considering the skills provided by HEls and the skills needed by Organizations, this situation has the least problems, and there would not be any clear skills gap. However, it must be remembered that HEls do not necessarily have these skills in their curricula.

The skills positioned in the class 2 deserve attention. They are assessed highly significant, yet not mastered especially well by the graduates. Thus, they are kind of 'ignored skills', implying a potential skills gap for the Organizations. It would be in their interest to promote these skills if they had the resources and possibilities. Anyhow, as these skills are assessed to have high learning potential, it could be recommended that HEls invest in promoting these very skills. To sum up, classes 1 and 2 are the most interesting for educators, as they include skills that are rated high both in terms of significance and learning potential, yet not mastered especially well by graduates (class 2).

Regarding the Soft Skills in classes 1 and 2, valued high both in significance in learnability, a possible suggestion is that their acquisition should be facilitated in alternative, more cost-effective ways, instead of universities. In addition, their real need in working life should be checked between universities and companies. In the case of the skill scoring high in graduates' level, it is advisable to check if they are appropriate for the type of company where they wish to develop their work.

Class $3(\mathrm{H}-\mathrm{L}-\mathrm{H})$ refers to skills that are important for Organizations and mastered by graduates, yet trust in learning them at higher education institutions is low. Obviously, for Organizations and graduates these skills are mainly not a problem. Students/graduates could have obtained these skills in some non-academic way, giving reason to call them 'external skills'. For educators, this class is somewhat confusing, as they are expected to provide these skills for their significance, however, their learning potential in academic environments seems low. Probably it would take some effort of the HEls to invent appropriate learning methods. Alternatively, these 
skills could provide an opportunity to reduce the number of skills in curricula, as there is indication that they are mastered by the graduates.

The skills in the fourth class (H-L-L) are interesting in the sense that they are scored high in significance, yet both graduate level and learnability are rated relatively low. Thus, they can be called 'neglected skills'. These skills can also be seen as somewhat alarming, as too low levels can cause problems to both Organizations and graduates, if lacking these skills. Naturally, here the role of the threshold becomes essential, as it determines the border between High and Low. Anyhow, for educators these kinds of skills emphasize the importance of being aware of the needs of Organizations.

To conclude, the four first classes are the most interesting outcomes of the method, as the scope of the research is primarily in reducing skills gaps. This discussion essentially begins from the skills that are important for Organizations.

However, the method 3Si also enables to define those kinds of Soft Skills that may have less significance for Organizations but are important for either HEls or graduates. The following presentation (table 10) describes these skills (classes 5-8).

\begin{tabular}{|l|l|l|l|l|}
\hline Class & $\begin{array}{l}\text { Significance } \\
\text { (Organizatio } \\
\text { n) }\end{array}$ & $\begin{array}{l}\text { Learning } \\
\text { potential } \\
\text { (HEI) }\end{array}$ & $\begin{array}{l}\text { Graduate } \\
\text { level } \\
\text { (Learner) }\end{array}$ & Scenario for Skills included \\
\hline 5 & Low & High & High & $\begin{array}{l}\text { 'Unvalued skills' } \\
\text { Not currently valued by } \\
\text { Organizations; high trust in learning } \\
\text { and high level by graduates }\end{array}$ \\
\hline 6 & Low & High & Low & $\begin{array}{l}\text { 'Redundant skills' } \\
\text { No longer required by Organizations } \\
\text { or mastered by individuals; yet high } \\
\text { learning potential }\end{array}$ \\
\hline 7 & Low & Low & High & $\begin{array}{l}\text { 'Personal skills' } \\
\text { Individually needed skills, developed } \\
\text { personally }\end{array}$ \\
\hline 8 & Low & Low & Low & $\begin{array}{l}\text { 'Low } \\
\text { Low trust in learning, nor needed by }\end{array}$ \\
\hline
\end{tabular}


\begin{tabular}{|l|l|l|l|}
\hline & & $\begin{array}{l}\text { Organizations or mastered by } \\
\text { individuals }\end{array}$ \\
\hline
\end{tabular}

Table 9 Soft Skills with less import in the HEI - Organization context.

Classes 5, 6, 7 and 8 are supposed to be less interesting at least from the Organizations' point of view, as their Organizational significance is rated low, i.e., under average. Class 5 includes skills that show high learning potential and high graduate level; they may be skills that are learnt traditionally at homes and at schools, but not necessarily among the top-ranked skills in the recruitment context, thus called 'Unvalued skills'. Class 6 represents skills that have high learning potential but not needed nor mastered by graduates, as an example among hard skills we can imagine 'statistical skills' or other redundant skills which used to be important and appreciated but not anymore. 'Personal skills' (class 7) consist of skills, which are mastered by graduates, yet not needed nor given high trust in learning at HEls. As examples here we can imagine for instance certain presenting skills, social media skills or role playing skills. The last class L-L-L includes skills that are 'Unnecessary', as they are not rated high in any of the dimensions.

In all the classes 5-8, the significance in working positions is low, yet there is a high level of learning potential or high level by graduates' skills (or both). Although they are not rated generally high in significance, it must be remembered that they may be important in some working tasks or special occasions in Organizations. Hence it is important for them to identify these types of skills.

\section{Summary}

To sum up, in chapter 3 I have presented two major initiatives to answer the hypothesis

"Based on the communication process, Soft Skills can be organized according to their significance to Organizations, universities and employees, and their development potential can be detected. "

In 3.1, the key soft skill communication was examined in detail in respect to the other 20 Soft Skills in the Framework. The examination is carried out by applying the precise descriptions of each skill. Accordingly, it was possible to propose a communication 
based Soft Skills Taxonomy, displaying the functional relationships between communication and each of the 21 Soft Skills used in the framework of this research project. The Taxonomy is highly appropriate for all educators who want to improve communication skills in working life, especially in the business and ICT contexts.

Next, in 3.2, I have proposed a method that enables the detection of Soft Skills that have more importance and potential in a certain context than others, in the discussion of reducing the Soft Skills gap. The foundation of the methods lies in the modern learning theory with the paradigm of lifelong learning, which allows to examine the process of learning and obtaining skills as a sequence with three stakeholders (Organizations, HEls and Learners). These stakeholders and their aspects form the main body of the method Soft Skills Status indicator (3Si), allowing to research Soft Skills in three dimensions, all of them essential for the discussion between HEls and companies. The presented 3Si survey tool enables gathering data from appropriate people, and the results can be structured in eight classes.

As a further step, the proposed method and the survey tool were tested, first by focus groups and interviews, and subsequently by comprehensive surveys, passed to business professionals in four countries. These experiments are reported in chapter 4 . 


\section{Experiments and Results}

An experiment is a procedure where the veracity of a preset methodic or scientific hypothesis can be tested. Also, certain parts of the research procedure, and their relevance, can be tested by experimenting them. Often, an experiment is an empirical procedure where elements of the research are tested and assessed in circumstances that are in some respects related to the original hypothesis. Experiments are also expected to give outcomes that allow to assess and improve the method (e.g., Gauch \& Gauch, 2003; ThoughtCo, 2020).

Various methods can be used for experimentation. I have presented the most important of them shortly in 2.3.1, whereby I preferred two of the methods to carry out the current experiments needed.

To test the method 3Si and the survey tool presented in the previous section, two experiments were conducted.

The first experiment was carried out for testing the usability and relevance of the 3Si survey questionnaire (presented in the previous section), to be sure that the questions are understood in the way that is intended. In addition, the time of responding must be reasonable, to keep the response rate high enough.

For this purpose, it was decided to apply a qualitative method. Qualitative research is used in situations where we want to obtain deeper insight on a phenomenon or its parts. It was considered important to have opinions from a relatively big number of people in different positions in Organizations. For these reasons, I selected individuals and focus groups of people with long experience in either management or Human Resource Development, and knowledge of skills maps, to test the survey tool. The experiment is described in 4.1 .

The second experiment was conducted for assessing and improving the method 3Si, by launching the pre-tested (4.1) questionnaire, and thus answering the subhypothesis 2, 3 and 4 . This experiment was carried out by a quantitative research 
method, as the aim is to prove hypothesis. Quantitative research produces data that can be tested and analyzed statistically, thus providing results that allow us to assess distributions and correlations within the sample, as well as their significance (e.g., Bradburn, Sudman, Blair, Locander, Miles, Singer, Stocking, 1979; Broadbent, Cooper, FitzGerald \& Parkes, 1982).

The survey was launched in Finland, Spain, Portugal and Netherlands between May and October 2018. The conduct of the survey and the results are described in paragraph 4.2 .

\subsection{Interview with experts}

To receive adequate feedback on the survey questionnaire $3 \mathrm{Si}$, it was tested by interviews and focus groups of experienced professionals in business and human relations management. The selection of the interviewees was made on the basis of their educational background, working experience and current position. They were expected to have a higher education degree (academic or applied sciences university), a position as manager or expert in HR (Human relationships), and a considerable working experience (minimum five years) in these kinds of positions, likely in various organizations.

I searched appropriate persons using my professional and Linkedln networks. 30 managers and HR experts in Southwestern Finland and Helsinki area were selected for a personal one-to-one interview or focus groups discussions with 3-4 people. The interviews and focus groups were carried out in August-September 2017. Their average working experience was 27.5 years, and they had close to 16 years in a managerial position by average. 12 of them were male and 18 female.

I carried out 18 interviews one-to-one, mostly in the working places of the respondents. In addition, four focus group interviews were held with three people participating in each one, in addition to me. The interviews were conducted with 'the first version' of the questionnaire that was presented in 3.2.2.

In the interviews, the respondents were asked to assess the three dimensions (significance, development potential, graduate level) for each skill. Also, they were 
asked to describe 'In which working contexts do you need this particular skill, and how do you use it?' The interviews lasted between 45 minutes and 150 minutes.

In the focus groups, the procedure was different, the people in each focus group received the questionnaire in advance and were asked to answer the questions prior to the meeting of the focus group. In the groups, the topics were discussed in a sequence (each dimension apart). In addition, the background questions and their relevance were discussed.

The interviews and the discussion in the focus groups provided important feedback to the research and the questionnaire.

In general, the interviewees considered the research topic important, whereby $84 \%$ of them assessed competence maps important or very important.

The big majority of the interviewed experts (94\%) considered it important to research the significance of the given skills and their development potential (88\%). The dimension 'level of graduates'/junior staff' appeared to be a bit more ambiguous, as some experts might normally not work with recently hired staff, or also if they have recently changed jobs and are not fully aware of competencies and skills needed in the environment of their new Organization.

The composition of the proposed skills map and the 3Si questionnaire were mainly considered relevant. Although the character of a few skills raised some discussion, the short descriptions were helpful, and the skills were understood properly. To the question 'Are there some other skills that have not been considered in this skills map?' only a few 'new' titles were raised ('Problem solving' 3 times, 'Resilience' 1 time, 'Persistence" 1 time). Out of these, 'problem solving' can be linked closely to 'analytic thinking' present in the skills map chosen to this study.

The interviewees and the focus groups were also asked to describe the contexts where they used the Soft Skills, and how they were applied. Here, they described some of the Soft Skills, most familiar to them from their working context. This question was asked for knowing more about the different ways of applying soft skills. For instance, 
self-control, communication or goal orientation are likely to have many different modes of application in different working contexts. However, this point was quite timeconsuming. Although these questions did give very interesting new light on the character of Soft Skills in working environments, it became obvious that it could not be included in the main survey (next step), as this would have been too time-consuming.

To sum up, the interviews and focus group discussions confirmed the managers' and HR experts' interest towards Soft Skills, justifying the research project and the survey to be conducted. They also stated the relevance of the three dimensions (Significance, Learnability, Level) to be included in the study, and consequently in the 3Si method.

\subsection{Launching the Survey $3 \mathrm{Si}$ to Business professionals}

In the previous experiment (4.1), the first version of the 3Si questionnaire had been tested by managers and HR experts, to ensure its usability. Based on the results, some changes were made: the most noticeable was leaving out the qualitative part, to keep the responding time reasonable.

In the current experiment, the questionnaire $3 \mathrm{Si}$ is launched as a survey, to gather appropriate and sufficient data to test the Method 3Si, to answer the sub hypotheses:

O2: Certain Soft Skills are more significant in given working contexts than others O3: At least some of these skills can be detected in any Organizational environment O4: and developed

Quantitative research will be used as it provides data that can be analyzed statistically, providing results that allow to assess distributions and correlations within the sample. In addition, it allows statistical testing, indicating the statistical significance of the results and correlations. Accordingly, given that the sample is representative and extensive enough, these tests allow to confirm or discard the hypothesis. (e.g., Bradburn, Sudman, Blair, Locander, Miles, Singer, Stocking, 1979; Broadbent, Cooper, FitzGerald \& Parkes, 1982).

As the research project focuses on the skills gap between higher education and Organizations, especially in the field of business and ICT, it was decided to direct the 
survey to people in relevant working positions in business and ICT environments. This condition is necessary for the assessment of Soft Skills in all the dimensions of the survey (Significance, Learnability, Level). A further goal was to have various branches and working positions in business and ICT represented in the sample, as well as different types of organizations (small, medium, large; private, public).

The survey was launched over May-October 2018 in four European countries: Finland, Spain, Portugal and the Netherlands. The network of partners in the European project CoSki21 (Core Skills for 21. Century Professionals), was utilized in gathering the sample.

\subsubsection{Background data}

The questionnaire was created by Google Forms. The original version was in English, consecutively translated into the languages of the partnering countries (Finnish, Spanish, Portuguese, Dutch). The questions were implemented as a classical format (short text, long text, one-option, etc.). The composition of the questionnaire was described in detail in 3.2.2. The questionnaire can be found in the annex, and the original version can be obtained at this address: https://forms.gle/FyErM7X4bcFwr5436 .

The questionnaire was spread as an online link during May-October in 2018 to associations of entrepreneurs, in managers' and HR professionals' events and to adult students in business and ICT higher education, with a minimum of three years of working experience.

In total, 381 responses were collected, of which Portugal counted for 173, Finland 159, Spain 23 and the Netherlands 26. Due to the small samples in Spain and the Netherlands, these samples are reported in the distribution part, but not included in the correlation analysis.

As for the background of the respondents, $39 \%$ of them belong to technicians and operatives (sales, administrative, programmer), $23 \%$ to higher level operatives, $19 \%$ to managers and superiors. $12 \%$ were currently adult students in business or ICT, with working experience in these fields. The rest, $7 \%$, work in other positions than the named. In Portugal the share of adult students was somewhat higher than in the other 
countries. Regarding the organizations of the respondents, $29 \%$ were small, $22 \%$ medium-sized and $49 \%$ big organizations. This distribution can be considered representative, as well as the share of private (56\%) and public bodies (44\%). A large variety of business branches were represented, the most occurring were 'Wholesale and retail trade' (18\%), 'Public administration' (9\%), 'Information and communication technologies' (8\%) and 'Professional, scientific and technical activities' (6\%).

As for the question 'How useful do you find the Skills maps', the average scores by country varied between 2.39 and 4.45. Finnish respondents consider the usefulness clearly lower than the other nations, and the highest ratings are from Spain. This difference is interesting as it is also statistically significant. As the attitude towards skills maps generally can be seen to reflect trust in learning and systematic development of skills, the result indicates that this kind of trust is lower in Finland than in the other countries.

Skills map utility, means by country

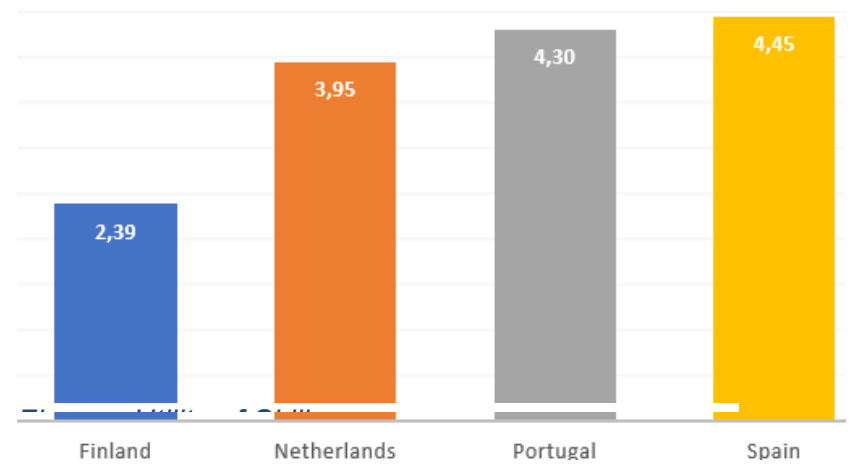

Figure 13 The perceived utility of skills maps. 


\subsubsection{The Results of the 3Si Survey}

In the main part of the questionnaire, the respondents assessed the 21 Soft Skills, in three dimensions. The dimensions present the three stakeholders (HEls, Organizations and graduates/employees), being titled as 'Significance', 'Learnability' and 'Level' of graduate/employee'. In the assessment, the Likert scale (1-5) was used.

\section{Significance}

This dimension was measured with the question "How significant do you consider this skill in your work position?' (1=not significant, .., 5=highly significant). The primary aim of this question was to find out whether Soft Skills can be classified according to their importance in a particular working position. The secondary aim is to provide knowledge to the HEls about Soft Skills in particular working positions in business and ICT, as these have been reported to be short of this knowledge (Garcia Aracil \& van der Velden, 2008; Mason et al., 2009; Eurydice 2014, 2019).

The average scores in this dimension reached close to 4 in the whole sample, yet there were significant differences between the countries. The five highest rated skills in the total sample were communication (4.59), work in team and cooperation (4.52), initiative (4.47), learning and use of knowledge (4.40) and self-confidence (4.38).

This is in line with previous research, where especially communication and team working skills have prevailed (Andrews \& Highson, 2008; Mourshed et al., 2014; Mitchell et al., 2010), as well as initiative (Mitchell et al., 2010; Cinque, 2015; Keinänen \& Oksanen, 2017). As for the fourth skill, the idea of continuing learning has been emphasized in recent years, which may be one explanation for the high scores of this skill. The high scores of self-confidence are interesting, as this skill has appeared rarely in business and ICT Soft Skills maps. It is noticeable that business and ICT professionals rate this skill high, indicating that self-confidence is highly involved in their work performance.

The five lowest rated skills were networking, conceptual thinking, strategic orientation, leadership and analytic thinking. This may indicate that some of them are deemed as 
'academic skills' that are less used at work. However, it is somewhat surprising that networking and leadership are among the less rated, as the former is likely to be needed at least in some business working positions (sales, marketing), and the latter has been prevailing in previous studies regarding important business skills (Mitchell et al., 2010; Robles, 2012). One reason may be that the share of managers is quite low $(19 \%)$ in the sample.

In all, the dimension Significance received the highest average values of the three dimensions, which indicates a high perceived importance of Soft Skills in these working environments. In figure 14 , the results are presented by country. ${ }^{2}$

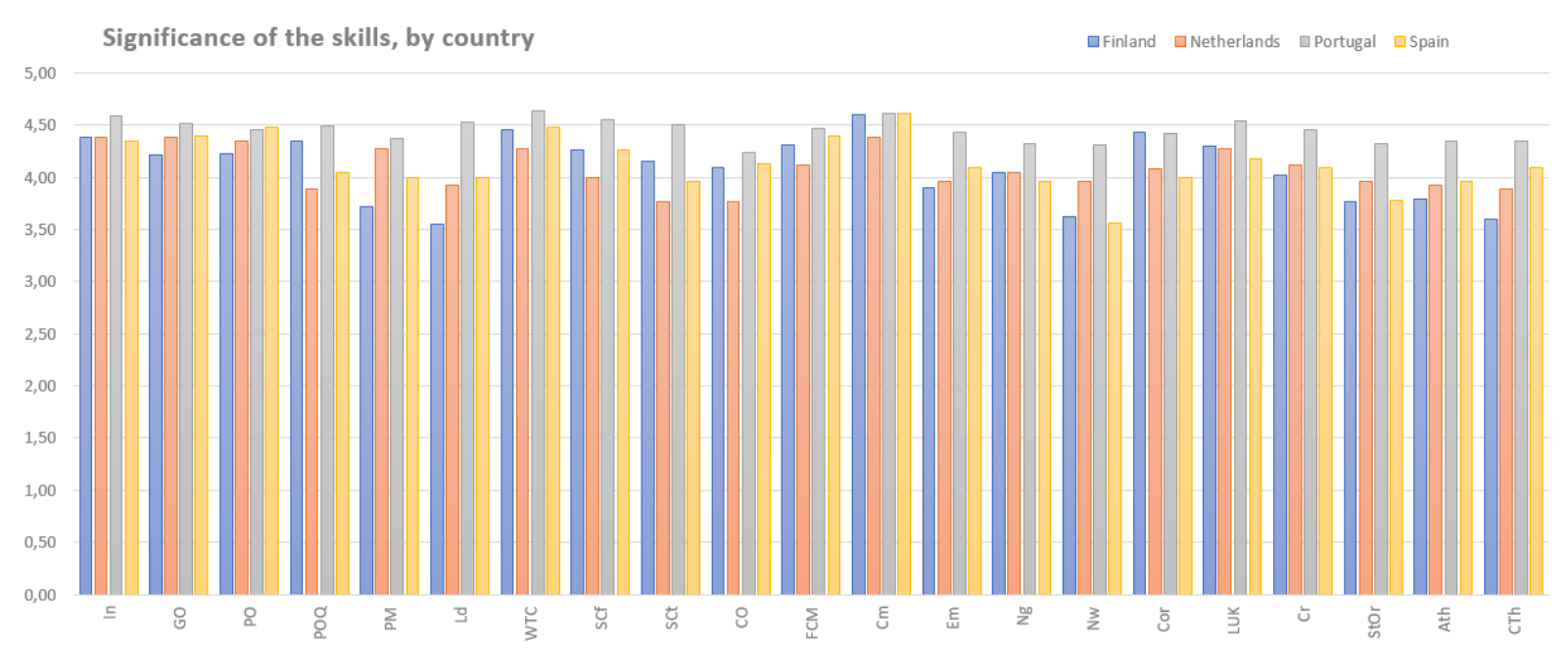

Figure 14 The evaluated significance of Soft Skills in work positions, by country.

The average scores of all respondents $(\mathrm{N}=381)$ are distributed between 3,50 and 4,57. Moreover, the figure displays quite clear differences in the results by country. 'Significance' is rated especially high in Portugal compared to Finland. This difference is statistically significant in many skills (POQ, PM, Ld, Scf, Sct, Em, Nw, StOr, ATh, Cth). It must be noted that Spain and the Netherlands were not included in the correlation analysis due to small samples.

When searching the reasons for the high scores given in Portugal, one explanation may be that the Portuguese sample included a higher share of people currently doing adult studies in business. Another reason may be found in cultural considerations, this will be reasoned more detailed in the Discussion part.

\footnotetext{
2 Abbreviations: In=Initiative $\mathrm{GO}=$ Goal Orientation $\mathrm{PO}=$ Planning and Organization $\mathrm{POQ}=\mathrm{Preoccupation}$ of order and quality $\mathrm{PM}=\mathrm{People}$ management $L d=L$ eadership WTC=Work in team and cooperation SCf=Self-Confidence SCt=Self-Control CO=Commitment to Organization $\mathrm{FCM}=$ Flexibility and change management $\mathrm{Cm}=$ Communication $\mathrm{Em}=$ Empathy $\mathrm{Ng}=$ Negotiation Nw=Networking COr=Customer orientation LUK=Learning and use of knowledge $\mathrm{Cr}=$ Creativity StOr=Strategic Orientation ATh=Analytic thinking CTh=Conceptual thinking
} 


\section{Learnability}

This dimension was formulated into the question 'To what extent do you think that these skills can be learned at universities?', seeking to state whether Soft Skills can be learned, more specifically at universities. This dimension is important especially for Higher Education, as Soft Skills have often been considered inborn abilities (Gilbert et al., 2004; Cimatti, 2016) and not-easy-to-teach (Bereiter \& Scardamalia, 2006). Although the outcomes cannot be considered as definitive, they are based on insights of professionals, and thus with experience of learning these skills during their career. This justifies the question, as Soft Skills are said to be promoted and developed mainly through working experience (Muir, 2004; Cinque, 2015), and their learning potential has been poorly researched so far.

In the whole sample, the highest averages were given to work in team and cooperation $(4,24)$, learning and use of knowledge $(4,21)$, planning and organization $(4,17)$, communication $(4,13)$ and analytical thinking $(3,89)$. Yet, there were significant differences between countries, also in this dimension. Overall, the scores in this dimension were lower than in the previous dimension Significance. This implies primarily that Learnability of Soft Skills is not considered as evident as their Significance.

The values of the skills in this dimension varied between 3.23 and 4.24. The lowest learning potential was assessed to empathy, commitment to organization, self-control, customer orientation and self-confidence. As a possible explanation, we can assume that these skills are perceived among the most ambiguous and inborn among Soft Skills, and hence not perceived as highly potential to learn at universities. Figure 15 demonstrates the distribution by country in this dimension. 


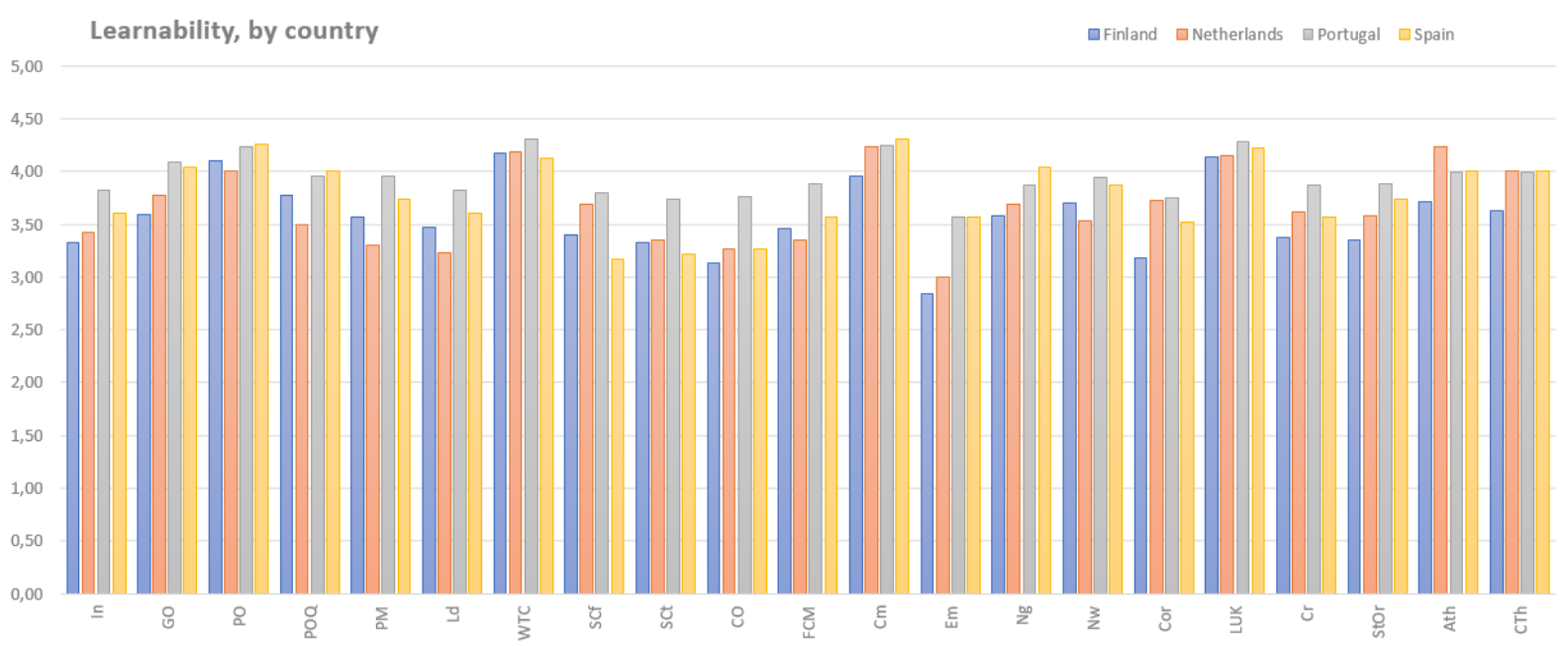

Figure 15 Assessed trust in learning of Soft Skills, by country.

Reviewing the results, we can recognize that the highest rated skills seem to be skills that are typical 'university skills', or closely related to them. This may indicate that the assessment of Learnability is difficult. For this reason, it is possible that the question mode 'trust in learning at university' leads the respondents to associate with universities, more than the skills themselves. Subsequently skills that are familiar from existing curricula may likely be associated with this question.

The figure exhibits clear differences between countries also in this dimension. Portugal shows higher trust in learning of Soft Skills at HEIS than other countries. The difference to Finland is significant in several skills (In, GO, PM, SCt, CO, Em, COr, Cr, StOr). This outcome is interesting, yet the reason for it is not evident. To some extent, it may be due to the relatively bigger share of people doing part-time studies in the Portuguese sample, making them more aware and motivated in learning and developing their skills. Additional explanations for this 'learning optimism' could be found in cultural attitudes towards education and conformity; this aspect is reasoned in the Discussion part. 


\section{Level of graduates}

To measure this dimension, the respondents were presented the question 'To what level do you think that graduates in your working environment possess these Soft Skills?' In this survey, its purpose is to give data on the current level of a person in the given skills. This information may be useful for the persons themselves, or working team, HR staff or superior. It also gives indication on possible skills gaps, which is essential as it has been repeatedly reported that graduates lack essential Soft Skills (e.g., Cappelli, 2012; Mourshed et al., 2014; Cinque, 2015; Succi \& Canovi, 2019).

The highest assessments in 'Level' were found in learning and use of knowledge (3.69), work in team and cooperation (3.63), communication (3.48), customer orientation (3.38) and flexibility and change management (3.37). The first can be considered obvious, as recently graduated are likely to master this skill, for instance in searching information on the internet. In addition, the result may indicate that their peers believe they are skilled at learning and use of knowledge.

As for work in team and cooperation and communication, their position among the five highest rated skills is unexpected, as previous research (Mourshed et al., 2014; Cinque, 2015) has indicated lacks in these skills. For all the stakeholders (educators, organizations, graduates), this result is, thus, encouraging.

The high rated levels of customer orientation and flexibility and change management are standing out, partly as these skills (especially FCM) have been reported as missing skills (Mourshed et al., 2014). One explanation for their assessed high level may be due to increased part-time working by business students all over Europe. Typically, they work in sales and customer service, whereby they gain experience in customer orientation.

The lowest ranked in 'level' were leadership (2.88), people management (2.97), negotiation (3.20), self-control (3.21) and empathy (3.22). From these, at least the three first mentioned can be explained with the obvious fact that they develop along with working experience and manager positions, and therefore they cannot be well mastered by graduates. The distribution of the whole sample can be seen in figure 16 . 


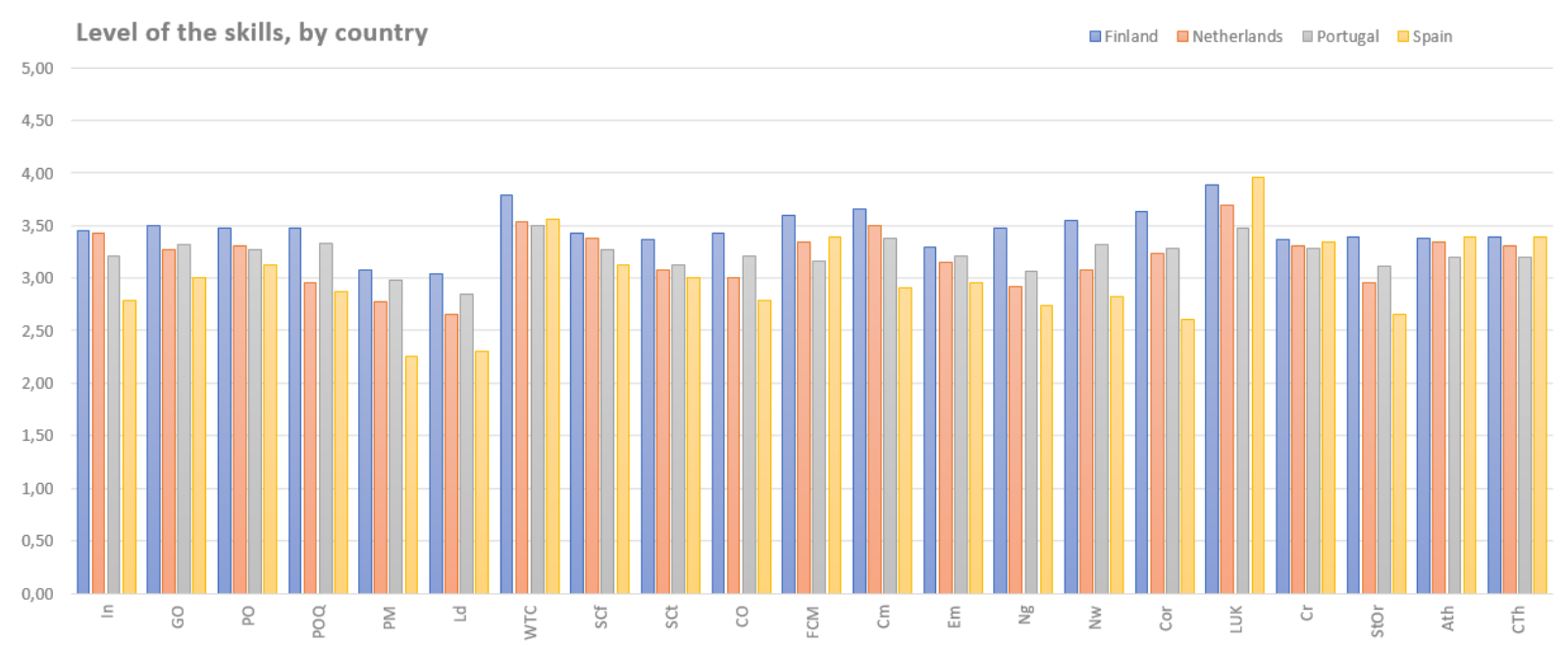

Figure 16 Assessed Level of graduates' Soft Skills, by country.

We can see that the overall scores in the dimension 'Level' were considerably lower than in 'Significance' and 'Learning'. Also, in this dimension, some differences between the countries can be noticed, although the other way round. One interesting outcome is that the Finns rate the level of graduates higher than other countries. This difference is statistically significant in several skills (FCM, Ng, COr, StOr). It can be explained in two ways. Either the business people's attitude in Finland is more positive towards the 'newcomers' in the workplace, or the graduates are de facto more skilled in some skills than their peers in other countries. The second argument is possible as in Finland it is very common that business students work part-time as salespeople etc. This may provide them with better skills in certain skills.

To sum up, the three dimensions showed a clear tendency in the assessments. The first dimension (Significance) scored the highest averages, the second (Learning potential) had lower values and the third dimension (Level) received the lowest values. This becomes evident in a presentation of all the 21 skills that shows the values for each dimension by skill (figure 17). 


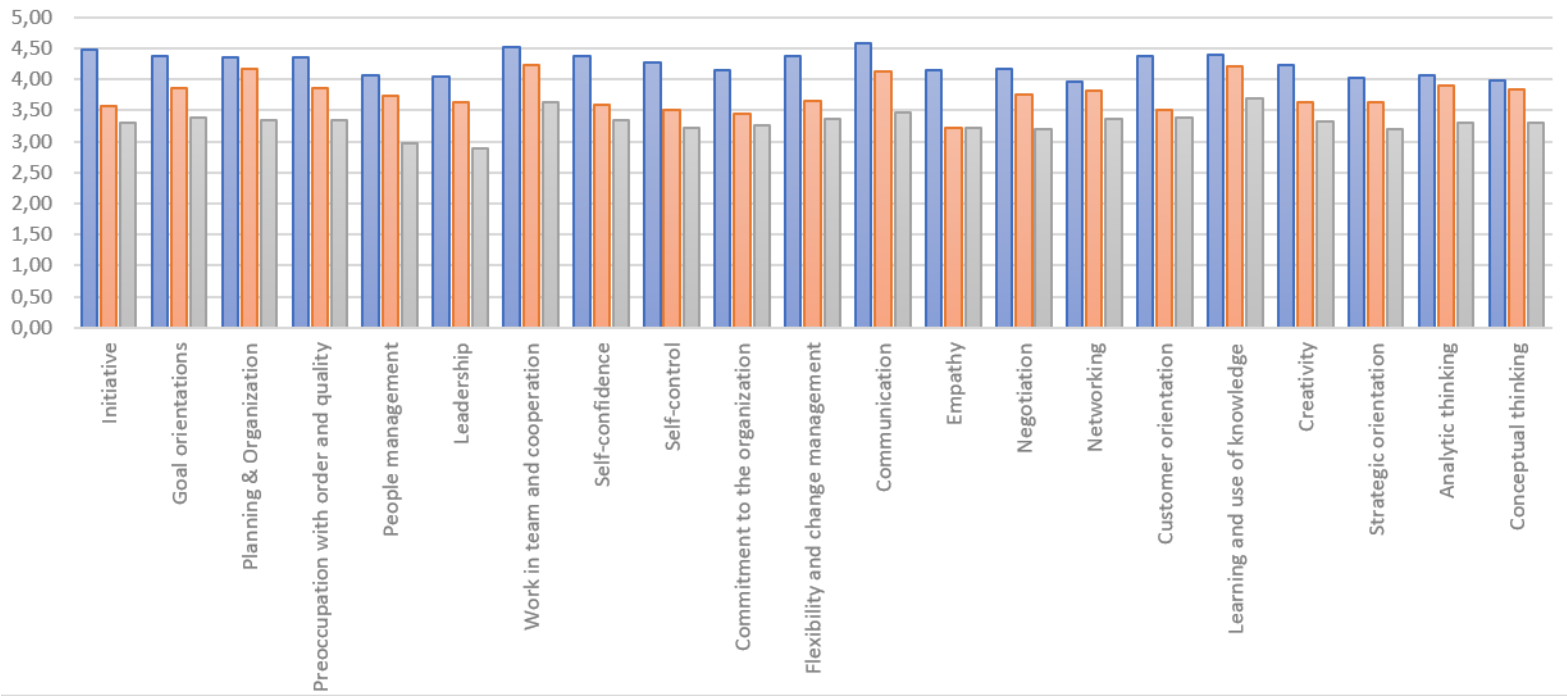

Figure 17 Three-dimensional evaluations of the skills.

In all the 21 skills the sequence is the same: they get highest values in dimension 1 , then dimension 2 and lowest in dimension 3.

\section{Additional outcomes and findings}

In addition, the data allows to examine correlations between the background data and the dimensions. The following variables were included in the correlation analysis: the respondents' working experience, position (student/technicians, middle level/professional/managers), manager position, opinion of the utility of skills maps. In addition, the potential correlation with the size, possession and branch of the respondents' organizations were analyzed. In the following, the most outstanding results are presented by dimension.

\section{Significance}

As for Significance, people with a long working experience seem to rate the Significance dimension higher than people with less years at work. This correlation is significant in 13 skills, i.e., the majority of the 21 skills. Furthermore, people in a managerial or leader position rate some skills higher than the rest of the sample, this concerns the skills leadership, people management, negotiation and conceptual thinking in especial. This correlation is predominant, as people in operative positions assess almost all the 21 skills significantly lower than the two higher position groups do. 
Furthermore, a significant correlation was found between the assessed utility of skills maps and assessed Significance of skill. The higher the skills maps are considered in importance, the more likely Significance is rated high. This question may reflect the respondents' attitudes towards education and promotion of skills in general, affirming the belief in formal and organized education (Southerland, Sinatra \& Matthews, 2001).

As for the organizational background variables, in general, they did not produce remarkable correlations. However, people working in bigger Organizations rate negotiation, learning and use of knowledge and strategic orientation more significant than in medium-sized or small organizations. These correlations are statistically significant. There is no evident explanation for this; this result would need additional research. Moreover, in the public sector some skills (people management, leadership, empathy, negotiation and conceptual thinking) are rated more significant than in the private organizations. A suggested explanation for this, at least regarding the four first skills, would be that 'smoother' management styles are appreciated in the public sector, and thus managers and leaders are expected to put effort especially in their style of people management and empathy.

Some correlation was also found between the branch of the Organization and Significance; however, it is not adequate to report these as the number of branches was high (19) and the sample is too small to affirm any correlations in this aspect.

\section{Learnability}

Regarding the dimension Learnability, the clearest correlation was found with the perceived utility of skills maps. The higher the utility was rated, the higher the trust in learning of skills. This correlation could be found in all the 21 skills; in addition, it was statistically significant in all the cases. It seems that these respondents have higher belief in learning skills overall. Again, this may be due to the respondents' attitudes towards the nature of knowledge and the role of education in obtaining skills and knowledge (Southerland et al., 2001). 
Moreover, the working experience of the respondents shows a positive correlation with their assessment of learning potential. The longer experience, the higher trust in learning. This concerns 11 skills (initiative, self-confidence, customer orientation, empathy, negotiation, customer orientation, learning and use of knowledge, creativity, strategic orientation, analytical thinking and critical thinking. When looking at these skills, many of them are characteristics and abilities that are typically considered to develop by experience, for instance initiative, self-confidence, empathy and creativity. Thus, it can be considered logical that experienced people have it easier to see development potential in them, as they have probably learned these skills themselves along with their working career.

Regarding the respondents' working position, an interesting negative correlation was found. Managers have a significantly smaller trust in learning of certain skills ( $L d, W T C$, $\mathrm{Cm}, \mathrm{Ng}$, StOr) than the other groups of respondents. This finding is interesting, as it refers also to skills that are especially important for managers. It is possible that it reflects a kind of 'nobody can substitute me' phenomenon. If real, this phenomenon can be considered somewhat concerning, as managers have remarkable responsibility in training their staff.

As for public and private organizations, it is interesting that trust in learning is overall higher in public Organizations. This correlation is statistically significant in 11 skills (In, POQ, PM, SCf, SCt, CO, FCM, Nw, COr, Cr, StOr, CTh). Regarding this correlation, it is difficult to suggest explanations in a coherent way. It is possible that public Organizations in general offer more training for their staff, and thus the general attitude towards improving and developing skills is more positive. In addition, there may be other reasons that would need more research.

Finally, respondents in bigger Organizations have higher trust in learning of communication than in smaller organizations. For this correlation, there is not any evident and coherent explanation. However, bigger organizations usually have special staff in communicational functions and thus the daily communication in big organizations may have better results and appear more structured to the employees. 


\section{Level}

As for the dimension Level, there was some correlation; the most evident was the negative correlation with working experience. The respondents with a longer working experience and/or in managerial positions assessed the level of graduates lower. This correlation was significant in 17 of the 21 skills, and this raises several questions. It can be harmful for an organization if the more experienced part of the staff considers graduates' level systematically low. Possibly, this phenomenon can be interpreted in various ways. First, it can originate from a hectic working life where young colleagues are seen as burdens during the time they keep on learning the work. Yet, it is possible to think that managers and experienced people have a more extensive insight on the requirements of the tasks than less experienced employees, which gives reason for a more comprehensive assessment than what people with less experience could give. However, this result may reflect a negative attitude towards younger workers and colleagues, which would include a concerning factor for the organizations. This correlation seems to exist in both private and public Organizations, regardless if they are small or big. Due to its importance for organizational performance, this phenomenon deserves additional research.

\subsection{Statistical Analysis of the Survey Results}

\subsubsection{Implementation of the 3Si Classification}

Next, the survey results will be considered in respect to the suggested 3Si Method (3.2.2), to detect skills that have more importance and potential in the discussion between HEls and Organizations. This aspect is essential in answering the subhypotheses 2, 3 and 4 of the thesis.

The process is initiated by defining each of the 21 skills as High or Low, according to their survey average score in each dimension, as described in 3.2.3. Skills exceeding the average (AVG/AVG) are defined high $(H)$ and those under the average are low $(L)$. By this means all skills are set either high or low, offering indication to their Significance, Learnability and Level of performance. 
First, table 11 demonstrates the 21 skills in alphabetical order, their average values in the dimensions, deriving from the survey, and finally the class they get positioned in. The AVG/AVG refers to the medium value of the dimension in question; it is calculated by counting the average value of the averages of the 21 skills in each dimension. According to the purpose, we can change the threshold, which makes the skill to be up- or downgraded between the classes. This issue is described in the next paragraph, 'the role of the threshold'.

\begin{tabular}{|c|c|c|c|c|}
\hline Skill & $\begin{array}{l}\text { Significance } \\
\text { (AVG/AVG } \\
4,25)\end{array}$ & $\begin{array}{l}\text { Learning } \\
\text { potential } \\
\text { (AVG/AVG } \\
3,76)\end{array}$ & $\begin{array}{l}\text { Level of } \\
\text { graduates } \\
\text { (AVG/AVG } \\
3,31 \text { ) }\end{array}$ & $\begin{array}{l}\text { Skill } \\
\text { class }\end{array}$ \\
\hline Analytical Thinking (ATh) & L & $\mathrm{H}$ & L & 6 \\
\hline Commitment to Organization (CtO) & L & L & L & 8 \\
\hline Communication $(\mathrm{Cm})$ & $\mathrm{H}$ & $\mathrm{H}$ & $\mathrm{H}$ & 1 \\
\hline Conceptual Thinking (CTh) & L & $\mathrm{H}$ & L & 6 \\
\hline Creativity (Cr) & L & $\mathrm{L}$ & $\mathrm{H}$ & 7 \\
\hline Customer orientation (CO) & $\mathrm{H}$ & L & $\mathrm{H}$ & 3 \\
\hline Empathy (Em) & L & L & L & 8 \\
\hline $\begin{array}{l}\text { Flexibility \& Change Management } \\
\text { (FCM) }\end{array}$ & $\mathrm{H}$ & $\mathrm{H}$ & $\mathrm{H}$ & 1 \\
\hline Goal Orientation (GO) & $\mathrm{H}$ & $\mathrm{H}$ & $\mathrm{H}$ & 1 \\
\hline Initiative (In) & $\mathrm{H}$ & L & L & 4 \\
\hline Leadership (Ld) & L & L & L & 8 \\
\hline Learning and Use of Knowledge (LUK) & $\mathrm{H}$ & $\mathrm{H}$ & $\mathrm{H}$ & 1 \\
\hline Negotiation $(\mathrm{Ng})$ & $\mathrm{L}$ & $\mathrm{L}$ & $\mathrm{L}$ & 8 \\
\hline Networking (Nw) & L & $\mathrm{H}$ & $\mathrm{H}$ & 5 \\
\hline People Management (PM) & L & L & $\mathrm{L}$ & 8 \\
\hline Planning and Organization (PO) & $\mathrm{H}$ & $\mathrm{H}$ & $\mathrm{H}$ & 1 \\
\hline $\begin{array}{l}\text { Preoccupation for Order and Quality } \\
\text { (POQ) }\end{array}$ & $\mathrm{H}$ & $\mathrm{H}$ & $\mathrm{H}$ & 1 \\
\hline Self-Confidence (SCf) & $\mathrm{H}$ & L & $\mathrm{H}$ & 3 \\
\hline Self-Control (SCt) & $\mathrm{H}$ & L & $\mathrm{L}$ & 4 \\
\hline Strategic Orientation (StO) & L & L & L & 8 \\
\hline
\end{tabular}




\begin{tabular}{|l|l|l|l|l|}
\hline $\begin{array}{l}\text { Team Working and Cooperation } \\
\text { (TWC) }\end{array}$ & $\mathrm{H}$ & $\mathrm{H}$ & $\mathrm{H}$ & 1 \\
\hline
\end{tabular}

Table 10 The 21 Soft Skills defined in classes (H/L) according to survey results.

It can be noticed that the 21 Soft Skills are distributed to all classes, except for the class $2(\mathrm{H}-\mathrm{H}-\mathrm{L})$. Two classes, class 1 (seven skills) and class 8 (six skills) included a remarkable number of skills, whereas the rest of the skills were distributed quite equally.

Next, we will position the 21 skills in the proposed Soft Skills Status indicator (3Si) classification frame (table 12), to consider their importance and potential, as seen from the aspects of Organizations and Higher Education.

\begin{tabular}{|c|c|c|}
\hline Class & Scenario for Skills included & $\begin{array}{l}\text { Skills positioned in class } \\
\text { (using AVG/AVG as threshold) }\end{array}$ \\
\hline 1 & $\begin{array}{l}\text { 'Core Soft Skills' } \\
\text { Organizations need, trust in learning, } \\
\text { high graduate level }\end{array}$ & $\begin{array}{l}\text { communication } \\
\text { flexibility and change management } \\
\text { team working and cooperation } \\
\text { goal orientation } \\
\text { learning and use of knowledge } \\
\text { preoccupation for order and quality } \\
\text { planning and organization }\end{array}$ \\
\hline 2 & $\begin{array}{l}\text { 'Ignored skills' } \\
\text { Organizations need, trust in learning, } \\
\text { low graduate level }\end{array}$ & none \\
\hline 3 & $\begin{array}{l}\text { 'External skills' } \\
\text { Organizations need, low trust in } \\
\text { learning, high graduate level }\end{array}$ & $\begin{array}{l}\text { customer orientation } \\
\text { self-confidence }\end{array}$ \\
\hline 4 & $\begin{array}{l}\text { 'Neglected skills' } \\
\text { Organizations need, low trust in } \\
\text { learning, low graduate level }\end{array}$ & $\begin{array}{l}\text { initiative } \\
\text { self-control }\end{array}$ \\
\hline 5 & $\begin{array}{l}\text { 'Unvalued skills' } \\
\text { Not currently valued by } \\
\text { Organizations; high trust in learning } \\
\text { and high graduate level }\end{array}$ & networking \\
\hline 6 & $\begin{array}{l}\text { 'Redundant skills' } \\
\text { No longer required by Organizations } \\
\text { or mastered by individuals; yet high } \\
\text { assessed learning potential }\end{array}$ & $\begin{array}{l}\text { analytical thinking } \\
\text { conceptual thinking }\end{array}$ \\
\hline
\end{tabular}




\begin{tabular}{|l|l|l|}
\hline 7 & $\begin{array}{l}\text { 'Personal skills' } \\
\text { Low need in Organizations, low trust } \\
\text { in learning, yet high graduate level }\end{array}$ & creativity \\
\hline 8 & $\begin{array}{l}\text { 'Low profile skills' } \\
\text { Low trust in learning, nor needed by } \\
\text { Organizations or mastered by } \\
\text { graduates }\end{array}$ & $\begin{array}{l}\text { commitment to organization } \\
\text { empathy } \\
\text { leadership } \\
\text { negotiation } \\
\text { people management } \\
\text { strategic orientation }\end{array}$ \\
\hline
\end{tabular}

Table 11 The 21 Soft Skills presented in the 3Si Classification.

The following skills are included in class 1: communication, flexibility and change management, team working and cooperation, goal orientation, learning and use of knowledge, preoccupation for order and quality, and planning and organization. This means that they have been assessed higher-than-average in all dimensions (Significance, Learnability and Level), indicating that they are interesting for all the stakeholders of the learning process. For this reason, these skills are called the Core Soft Skills in the 3Si classification. Their position in the 3Si classification implies that they are both necessary to learn, and further, there is trust in learning them. In addition, they seem to be valued by graduates, as their level is assessed high.

As an observation, we can notice that the class includes several skills that have been considered important in working contexts, in previous research (communication; flexibility and change management; team working and cooperation; goal orientation in especial), which is encouraging from the educator point of view. Yet, it must be noted that the status of a skill, exhibited in the classification, merely refers to a current situation, related to the period of the survey.

Regarding class 2, it includes skills with high significance, high trust in learning, yet low level of graduates, hence named the Ignored Skills. This would mean a sort of problematic situation for both educators and organizations. It would strongly indicate that the promotion of these types of skills have been ignored, either by educators or by the students. This can be explained either by unawareness of the importance of the skill, or for lacking learning methods for promoting the skills. The data of this survey (and the normal threshold) did not place any skills in this class. This outcome is positive to educators, as it means that most of the potential skills are mastered by graduates, at least in the sample presented. 
Class 3 is characterized as External Skills, assessed high in significance and graduate level, yet rated quite low in their learnability. Overall, these skills can be considered essential for educators, as they are obviously essential in working contexts. The fact that their graduate level is assessed high, although their learning potential is rated low, provokes the question where these skills have been learnt or should be learnt. In this study, customer orientation and self-confidence can be found in this class. We can find a potential explanation for them by the increased part-time working; at least business students work commonly in sales work beside their studies. By this means, it is likely that they will learn some Soft Skills along with their own experience. For educators, it is a relief that there are skills that are learned outside school, as it offers more resources for other necessary skills. Yet, educators must at least make sure these skills are mastered by graduates.

Most concerning for educators, perhaps, are the skills in class 4, Neglected Skills, as they are clearly needed in working contexts, yet rated low in both in learnability and graduate level. In this class we have initiative and self-control. Initiative has been rated among the most wanted skills by employers previously (e.g., Mitchell et al., Mourshed et al., 2014; Vieira \& Marques, 2014; Keinänen \& Oksanen, 2017). A direct outcome is that these skills should be fostered at HEls more than what is currently done. Undoubtedly, this would make it necessary for educators to create and apply appropriate novel learning methods, as in most universities, these skills have not appeared in curricula.

In all, the classes 1-4, rated High in the dimension Organization, include clear indications regarding 'working life Soft Skills'. Hence, they should be observed carefully, in particular by HEls, as these skills are likely to be those that the HEls may lack awareness of (Mason et al., 2009; Cappelli, 2012; Succi \& Canovi, 2019; paragraph 2.1.5 in this research).

As for the remaining classes, 5-8, they are less interesting in the scope of this research, as my thesis focuses on the skills gap in the area between HEls and organizations. Yet, they must be shortly interpreted and commented, as they may offer 
unforeseen findings. In addition, they include a remarkable number of the Soft Skills. Again, the role of the threshold in each dimension must be pointed out here, as it decides the class where each skill is placed. By lowering the threshold, several of the skills would be raised in upper classes. Also, it must be remembered that the results and the classification provide average values from the whole sample. Hence, they do not necessarily represent the assessments and needs of each organization.

In class 5, we find the Unvalued Skills, rated high in learnability and graduate level, yet quite low in significance. This kind of situation can be interpreted in various ways. First, we can figure out that there are skills that are still learned at educational institutions, although they are not used or needed as much as they used to. Second, it is possible that we have skills that are learned generally by students because they are needed in some special branches, though not in all organizations. In this research, networking ended in this class. Although it was rated low by Significance, it is evident that this skill is essential at least in some positions (sales, marketing) and therefore likely needed in some organizations more than others. The high graduate level is beneficial for graduates, it may possibly originate from the increased use of social media by graduates born in the 1990s.

Class 6 refers to skills with low Significance and graduate Level, yet high trust in Learning. It might be skills that have traditionally prevailed in curricula, however not currently (or anymore) needed in working contexts, nor mastered by graduates. The reason for the latter may be that the skill is not considered important or attractive during studies. In this class, named Redundant Skills, two skills are placed in this study, they are analytic thinking and conceptual thinking. Regarding these skills, we have evidence that they are needed at least in some organizations (Bughin et al., 2018), but perhaps not in most of them. For educators, it is therefore important to check their needs and act consecutively, especially if the graduate level remains low.

Class 7 is interesting in the sense that it includes skills that are assessed low in significance and learnability, yet mastered well by graduates, named Personal Skills for this reason. One skill ended in this class, creativity. The result might indicate that creativity is a skill that is generally fostered by self-improvement, in the context of each 
person's private life. In addition, it is worth remembering that creativity has also been mentioned in some research (Cinque, 2015; Keinänen \& Oksanen, 2017) as one of the essential Soft Skills.

Class 8, characterized as Low Profile Skills, includes skills rated lower than average in each of the three dimensions. The skills are commitment to organization, negotiation, leadership, people management, strategic orientation and empathy. Given that the respondents were working in the business context, it is somewhat unexpected to find some of these skills in this class. Perhaps the low rating of empathy is most easy to understand, as being close to an inherent trait, although it is a necessary element in good communication, and thus probably needed in business, for instance in customer relationships. Again, we come to the role of the threshold, and the needs of individual organizations. In addition, the result may be explained by the emphasis of operative level people in the sample: only $19 \%$ were working in a manager position, and $81 \%$ in more operative positions. It is evident that people in lower positions are likely to rate 'managerial skills' lower as they may not yet have any own experience of using these skills in the position they work in.

As we can notice, the criterion of the threshold is a key question, because depending on the threshold criteria selected, the class can change, and the interpretation accordingly. In the following chapter the role of the threshold will be considered more in detail.

\subsubsection{The role of the threshold}

To determine the threshold value, it was initially decided to use the average of the valuations in each dimension (AVG(Dm). However, the educator or manager can decide a minimum value for the skills in each dimension to be set as the threshold, according to the needs and emphasis in their discipline or organizations.

The average of the 'significance' dimension is 4.08 which leaves a total of 14 soft skills (64\% of the map) above this threshold. The average of the dimension Learnability is 3.56, which leaves a total of 11 Soft Skills (52\% of the map) above this threshold. Finally, the average of the dimension Level of graduates is 3.46 , which leaves a total 
of only eight Soft Skills (38\%) above this threshold. Applying these thresholds to the classification method previously presented, there are six Soft Skills in the classes 1 or 2 , two of class 3 , and two in the class 4 , with eleven remaining low-interest Soft Skills. If we want to have a more general vision, instead of using the average of each dimension as a threshold, it is possible to use the average of all the three dimensions $(A \vee G(A \vee G(D m)))(3.72)$. Applying this critical case, in the dimension Significance, 18 Soft Skills (86\%) exceed the threshold. In the dimension Learnability seven Soft Skills $(30 \%)$ are obtained above this threshold. However, in the case of the dimension Graduate level, there are only two Soft Skills above the threshold (10\%).

With these criteria, only two of the skills would belong to class 1 , whereas four skills in class 2, none of class 3, and 12 Soft Skills of class 4 . The amount of low interest Soft Skills would remain at 3 . With this criterion, apparently less restrictive, only two Soft Skills are classified as class 1 (Core skills): work in team and cooperation (4.45) and learning and use of knowledge (4.30). Figure 18 shows the class distribution of the skills analyzed using the two different thresholds discussed above.

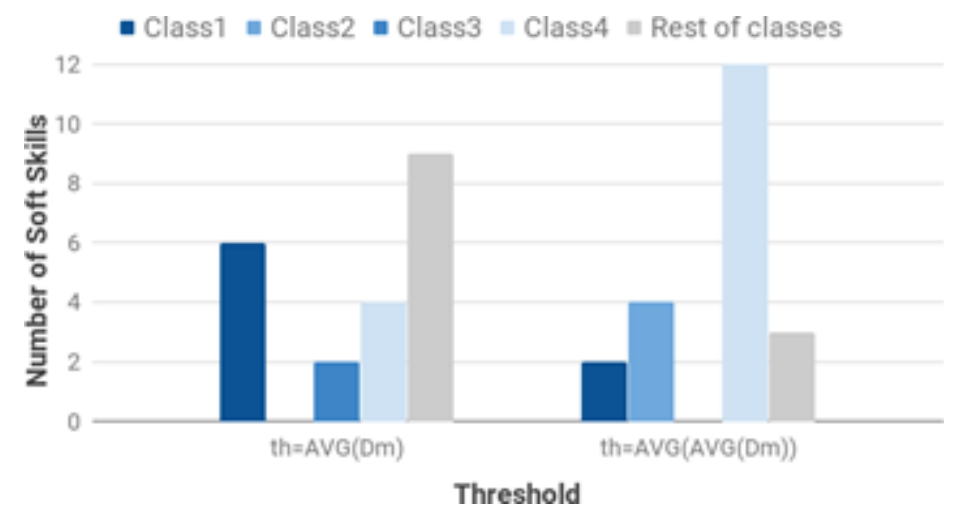

Figure 18 The impact of the threshold on the distribution of skills classes.

Table 13 demonstrates the specific class assigned to every Soft Skill, using both the thresholds presented above. The skills are presented in alphabetical order, to make their location easier.

\begin{tabular}{|l|l|l|l|}
\hline Analytical thinking $(\mathrm{ATh})$ & Class 6 & Class 2 \\
\hline Commitment to the Organization (CO) & Class 4 & Class 4 \\
\hline Communication $(\mathrm{Cm})$ & Class 1 & Class 2 \\
\hline Conceptual thinking (CTh) & Class 6 & Class 8 \\
\hline
\end{tabular}




\begin{tabular}{|c|c|c|}
\hline Creativity $(\mathrm{Cr})$ & Class 8 & Class 4 \\
\hline Customer orientation (CO) & Class 3 & Class 4 \\
\hline Empathy (Em) & Class 8 & Class 4 \\
\hline Flexibility and change management (FCM) & Class 3 & Class 4 \\
\hline Goal orientation (GO) & Class 1 & Class 4 \\
\hline Initiative (In) & Class 4 & Class 4 \\
\hline Leadership (Ld) & Class 8 & Class 8 \\
\hline Learning and use of knowledge (LUK) & Class 1 & Class 1 \\
\hline Negotiation ( $\mathrm{Ng})$ & Class 5 & Class 4 \\
\hline Networking (Nw) & Class 5 & Class 8 \\
\hline People management (PM) & Class 6 & Class 4 \\
\hline Planning and Organization (PO) & Class 1 & Class 2 \\
\hline Preoccupation with order and quality (POQ) & Class 1 & Class 2 \\
\hline Self-Confidence (SCf) & Class 4 & Class 4 \\
\hline Self-control (SCt) & Class 4 & Class 4 \\
\hline Strategic orientation (StO) & Class 8 & Class 4 \\
\hline Work in Team and Cooperation (WTC) & Class 1 & Class 1 \\
\hline
\end{tabular}

A highly restrictive threshold will not allow to select only Soft Skills useful for employers (the company) (classes from 1 to 4), and therefore strategic decisions cannot be made, especially regarding the selection of employees and the training of students.

\subsection{Results analysis}

\subsubsection{Regarding the 3Si survey}

The survey was expected to provide data on the significance and potential of Soft Skills; hence the main body of the questionnaire were the three dimensions highlighting the selected 21 skills.

In the dimension Significance, the results essentially support earlier results, affirming the high importance of certain skills (e.g., communication, initiative, work in team and cooperation) in working positions. Nevertheless, some skills in the top 5 (e.g., learning and use of knowledge, self-confidence) have previously appeared rarely in business 
skills maps. As for this part, the results suggest that these skills should be considered in the curricula, especially self-confidence.

Regarding the lowest valued skills, many of them (networking, conceptual thinking, strategic orientation, analytic thinking) can be considered quite expected, especially as most of the samples worked in mid-level positions (only $8 \%$ were managers). This share explains also the surprisingly low scores for leadership in 'significance'. It can be assumed that in a sample with a higher share of managers, the managerial skills (leadership, people management) would be assessed higher.

As an interesting finding we did note that both managers and people with long working experience tend to assess 'Significance' higher than those with less experience. This could possibly be explained with their larger number of situations where Soft Skills have been necessary, which has made them see their variety. Alternatively, it is possible that they have become aware of their own Soft Skills, and hence they opine that all employees should possess these skills. The latter would be in line with previous reports, indicating that Soft Skills grow along with working experience (Muir, 2004; Cinque, 2015).

As a remarkable outcome, the dimension 'Significance' demonstrated clear differences between the four countries. Portugal tends to give higher values than other countries. The reason for this may originate from different factors, it can be because the Portuguese sample was more student-emphasized than the other samples. Also, it may depend on cultural factors and belief in education (Southerland, Sinatra \& Matthews, 2001). In any case, this finding may have importance for multicultural Organizations and cooperation as well as trainers and educators working across borders. For this reason, this phenomenon would deserve further examination.

As for the second dimension, measuring trust in 'Learning', some of the highest rated skills were typically academic Soft Skills (e.g., learning and use of knowledge, analytic thinking), which may suggest that skills that are familiar from the academic environment are considered evident to be learned and taught at HEls. Nevertheless, the fact that two skills reported essential in previous research (work in team and cooperation, communication) were found in the top 5 in this dimension, is encouraging for business educators as it indicates that business professionals have high trust in their learning. 
A result that stands out is that people with longer working experience have strong trust in the learning potential, whereas those with less years at work have less trust in learning. Surprisingly, people in manager positions have lower trust in learning, especially when it comes to Soft Skills related to manager and leader work (people management, leadership). The reason for this is not evident, but it could reflect a kind of 'me and my skills cannot be substituted' phenomena.

Reviewing the lowest rated skills in 'Learning', a part of them (empathy, self-control self-confidence) can be explained by being close to inborn abilities and thus possibly assessed low. On the other hand, some of them (e.g., commitment to organization, customer orientation) are a little bit ambiguous, as they are commonly included in training programs of Organizations, however obviously not established as university skills. The low scores given to self-confidence are somewhat concerning, as this skill was rated among the most significant ones in working positions. This passes a particular challenge to higher education.

In international consideration, remarkable variations between countries were found in this dimension, particularly in Portugal where trust in Learning was rated over all higher than other countries. It is possible that this is - at least partly - due to the studentemphasized Portuguese sample, which may likely cause a general trust in education. However, it may additionally imply an impact of cultural characteristics comprising a more extensive attitude towards the role of education in cultural basic assumptions. This has importance for both education and HRD, and should thus be studied more in detail.

As for the dimension 'Level of graduates', the highest scoring skills (communication, work in team and cooperation, flexibility and change management) involve some surprise, as they have scored low in some of the previous research (e.g., Mourshed et al., 2014; Cappelli, 2012; Succi \& Canovi, 2019). Again, from Organizations' and HEls' point of view, this result is encouraging as these skills are considered highly important in working contexts. It may indicate that recent graduates are more skilled than graduates from 8-10 years ago.

As for the backgrounds of the respondents, the results suggest that people with long working experience tend to give low scores to graduates. This outcome is not very easy to explain, hence it would deserve additional research. However, as a 
phenomenon this leads to think about slightly negative attitudes towards the skills level of junior colleagues in general, perhaps also gaps between generations. In terms of organizational performance, this would likely be an unwanted factor.

As for the comparison between countries, there are interesting differences also in this dimension. Remarkably, the Finns assessed the Level of graduates significantly higher than in other countries. This outcome differs from the two previous outcomes, where Portugal was outstandingly positive. This result probably has cultural valuations in the background. One explanation could be that the Nordic countries have less hierarchical distances than the southern countries (Hofstede, 2011), which may involve smaller gaps between generations in working places. This outcome is interesting as it reflects the relationships and attitudes between senior and junior colleagues in Organizations.

\subsubsection{Regarding the Outcomes from Classification 3Si}

The main part of the Method is the Classification, which originates from a threedimensional consideration of the 21 skills. According to their values received in the $3 \mathrm{Si}$ survey (higher or lower than average), they were defined as High or Low. As a result, from the three dimensions' consideration, we yield eight skills classes (3.2.3). For Organizations and HEls, the four first classes with High in significance $(\mathrm{H}-\mathrm{H}-\mathrm{H}, \mathrm{H}-\mathrm{H}-\mathrm{L}$, $\mathrm{H}-\mathrm{L}-\mathrm{H}, \mathrm{H}-\mathrm{L}-\mathrm{L})$ are perhaps of most interest, as they display skills that exceed the average significance in working life and Organizations.

From the educators' point of view, the first class, the Core Soft Skills, display the most essential Soft Skills in many senses. Showing a high level in all dimensions, they are most likely to support the organizational performance, and in addition they are assessed to have learning potential, thus likely to be valued by the learners. From this aspect, the results from this sample were encouraging as the whole of seven skills ended up in this class. For an educator or HR professional, this provides such information as "Due to its high significance this skill must be included in our skills maps; fortunately, our graduates/employees seem to master this skill. However, in the case that it needs to be trained, it seems to have high trust in learning ".

Nevertheless, the second class $(\mathrm{H}-\mathrm{H}-\mathrm{L})$, the Ignored Skills, can be considered highly notable especially for educators, as these skills are needed to a high extent in 
Organization, also considered high for their learning potential, however, showing low mastering level by graduates or employees. Although they can alternatively be learned through trainee periods, from an educator's aspect the conclusion could sound like 'We should really put effort on this skill due to its importance - it is up to us to find the right methods'. When selecting Soft Skills in disciplines, these skills should perhaps be emphasized more than the majority of other skills.

Again, the third class $(\mathrm{H}-\mathrm{L}-\mathrm{H})$, the External Skills, displays high scores both in significance and graduate level, and this is likely to indicate that these important skills are mastered to a sufficient level, thus not in the first range of importance for educators. Perhaps they are learned by part-time working during studies, or they have been learned before studies in familial contexts. The skills ended in class 3 in this survey, self-confidence and customer orientation, are good examples of the character of this class.

From the aspect of skills gap between HEls and Organizations, the class $4(\mathrm{H}-\mathrm{L}-\mathrm{L})$ Neglected Skills, may include an alarming signal, as it tells that there are significant skills that have low learnability, and even mastered poorly by graduates. Educators, in particular, should keep an eye on skills that end up in this class. In this survey, initiative and self-control were located in this class.

As for the classes $5(\mathrm{~L}-\mathrm{H}-\mathrm{H}), 6(\mathrm{~L}-\mathrm{H}-\mathrm{L}), 7(\mathrm{~L}-\mathrm{L}-\mathrm{H})$ and 8 (L-L-L), they seem to be slightly less important for Organizations. Class 5, the Unvalued Skills, present skills that have high trust in learning and high level, yet not among the most significant in Organizations. This gives reason to think that it may concern skills that have traditionally been important, but currently they are not. Again, we must remember the role of the threshold value: a lower threshold in the first dimension would raise additional skills in this class to the class 1.

Class 6 (L-H-L), the Redundant Skills, with low significance and graduate level but high trust in learning, can in the first hand be figured to present skills that are familiar from educational contexts and therefore assessed learnable. If they are not considered highly significant in Organizations generally, a suggestion would be that these skills may be given less importance in the HEl disciplines. However, being an average from 
a big number of working tasks and positions, this class and result does not exclude that certain working contexts may need these skills. For instance, in the current survey, analytical and conceptual thinking were found in this class. Although they are not likely to be needed in certain, more operative working positions, their significance can be high in certain contexts, not less as future skills (Bughin et al., 2018)

In addition to the six classes of Soft Skills mentioned, there are skills that are well mastered by graduates, although having been assessed low in significance and in learnability. These skills (H-L-L) are probably learned individually in contexts of private life, wherefore we can call them Personal Skills. In this survey, creativity became positioned in this class, being a good example of the class.

Finally, there are certain skills that got lower-than-average scores in each of the three dimensions (L-L-L). Evidently, this would indicate for the educators that these skills are not among the most obvious to choose in curricula. As a result of this survey, we have commitment to organization, strategic orientation, negotiation and empathy in this class. It is likely that the two first mentioned can be learned in the organization of employment. Yet, somewhat surprisingly, we also have people management and leadership in this class. Nevertheless, their position in this class can be explained by the low share of people in managerial positions in this survey.

To sum up, it is obvious that the proposed method Soft Skill Status indicator (3Si) allows to position Soft Skills in classes, displaying features of them that are interesting for educators and trainers in Organizations. As the experiment shows, it can reveal the most significant and potential Soft Skills (classes 1 and 2). It must be noted that the current classification was created by using average values as classification criteria, and thus the classes would obviously look different if other (lower or higher) threshold values were used. The role of the threshold was described in 4.3.2. 


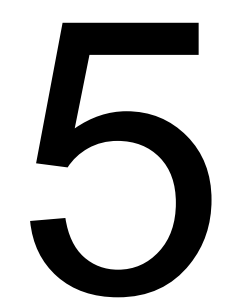




\section{Discussion}

\subsection{About the outset of the research project}

This research locates in the field of competences, focusing especially in detecting the Soft Skills that are highly needed in Organizations in the beginning of the 2020s, yet showing a deficit in graduates. Higher Education has been repeatedly encouraged to provide students with them (Eurydice, 2014, 2019). However, these skills have not been defined as well as the traditional 'hard skills', therefore they are somewhat challenging for educators, also as there are different opinions whether these skills can be learned and to what extent (Schulz, 2008; Tulgan, 2015). To reduce the reported skills gaps between Higher Education and Organizations (Mitchell et al., 2010; Mourshed et al., 2014; OECD, 2016), more knowledge is evidently needed of their character, importance and potential.

A major problem is that each professional and societal field has their specific appellations (Cinque, 2015; Schleutker, 2017) and moreover, a big number of titles are used when referring to Soft Skills (Mitchell et al., 2010; Succi, 2015; Silber-Varod \& Eshet-Alkalai, 2019). The vagueness regarding the definitions have been an essential obstacle that has made the discussion between educators and Organizations difficult (Tedesco et al., 2014; Succi, 2015).

For these reasons, this thesis research was initiated by reviewing the wide range of Soft Skills maps from academic, educational and organizational sources, and defining the most used and most relevant skills for the scope of this thesis. Although the original focus of the thesis is on the context of Business, the Framework that was created (in 2.2.3) is a compilation that is based on academic, educational and organizational sources. Due to its comprehensiveness, it can be used in most Organizations that are working in a context that involves goal-oriented working and customers.

Previous research has examined Soft Skills by their perceived importance in the business field (Andrews \& Highson, 2008; Mitchell et al., 2010; Robles, 2012), in 
project management and engineering (Stevenson \& Starkweather, 2010; Wikle \& Fagin, 2015; Oladiran et al., 2015; Redomero et al., 2019) and in the teacher profession (Nganga, Yunusa \& Hashima, 2015; Tynjälä et al., 2016). Recent research has focused on Soft Skills and their role in employment and recruitment processes (Vieira \& Marques, 2014; Cinque, 2015; Cimatti, 2016). In most cases, the research has been focused on one of the stakeholders (e.g., educator, employer or student) and their perceptions of Soft Skills.

Due to my work as business teacher, my intention has been to create a more multidimensional angle on Soft Skills and their learning potential. The need for Soft Skills is at this moment quite acknowledged and evident, whereas HEls and trainers are lacking the next step; how to define the essential Soft Skills and promote them.

To seize comprehension of the learnability of Soft Skills, their formation process was modelled and considered in the scope of lifelong learning (Steffe \& Gale, 1995; Field, 2000). From this point of view, the acquisition of skills can be examined as a process that continues not only during higher education studies, but also all the way through one's professional life. This consideration allows us to identify three stakeholders in this learning process, namely the educational institutions (HE/s), the learners and finally, the Organizations. Hence, according to the principles of lifelong learning the acquisition of professional skills is not a responsibility of one body in particular, but all the three stakeholders.

Based on this approach, I designed three statistical dimensions, covering 'Significance', 'Learnability' and 'Level of performance' to represent the aspects of the three stakeholders. My approach is expected to provide novel understanding on Soft Skills, regarding their importance and learnability, as well as their current level of graduates or employees. The results and outcomes are expected to be valuable for all the stakeholders. In particular it is essential for educators, when making decisions which skills to include in curricula and which to discard.

\subsubsection{About the survey}


In the next phase, the named statistical dimensions were used to build a systematic and dynamic method, able to assess Soft Skills and classify them in accordance with their Significance, Learnability and Level. The outcome can be applied for instance in higher business or ICT educational institutions or Organizations the named fields, for detecting the essential Soft Skills needed in different degree programs and/or working positions.

The method strongly builds on assessments of professionals that work in the fields related to the degree program and/or the organizations in question. These people are supposed to possess the best insight on the three dimensions mentioned, as they have a remarkable experience from the respective working positions. They are asked to assess a matrix of Soft Skills (introduced in the 'Framework', 2.2.3), in the three dimensions named. With respect to that the majority of previous research targeting on Soft Skills have focused on quite a small number of skills (e.g., Andrews \& Highson, 2008; Stevenson \& Starkweather, 2010; Mitchell et al., 2010; Robles, 2012; Wikle \& Fagin, 2015), the number of Soft Skills included in the method (21 skills) can be considered ambitious, aiming to detect novel, potential Soft Skills, important for business and ICT Organizations.

The survey had two purposes: first it was expected to provide insights on different dimensions of Soft Skills $(3.2 .2,4.2 .2,4.4 .1)$, especially from the educators' point of view. Second, the data was collected to experiment the method 3Si (Soft Skills Status indicator) created in this research $(3.2 .3,4.3 .1,4.4 .2)$. As some other universities of applied sciences, partners of the CoSki21 project (described in 6.2.1) shared an interest in the research project, there was an option to launch the survey in the respective countries (Finland, Spain, Portugal, the Netherlands).

To some extent, the results of the survey were in line the outcomes of previous research. They confirm that Soft Skills considered important, as well as the Top five skills, such as communication, initiative and flexibility and change management (as in Mitchell et al., 2010; Mourshed et al., 2014; WEF, 2015; Bughin et al., 2018).

As an important finding we can note that the respondent's working position seems to have an impact on the assessment: people in higher positions rate certain skills, 
especially managerial skills (e.g., leadership, people management, creativity) higher than those in operative or mid-level working positions. This finding emphasize that these types of Soft Skill are likely to be important especially for people in managerial positions. Thus they should be included in the curricula of higher business education, as most of the managers are educated in these institutions

The second dimension, Learning, is less researched and thus perhaps the most interesting dimension, at least for educators. Soft Skills have generally been considered hard to teach (Bereiter \& Scardamalia, 2006; Tulgan, 2015). Perhaps due to this, certain types of skills, familiar from academic curricula, such as analytic thinking, planning and organization or learning and use of knowledge were rated highest. On the other hand, skills like communication and work in team and cooperation ended among the highest rated, which is a positive signal to educators and trainers, as these skills are highly needed in Organizations.

As an important finding, people with longer working experience tend to assess the learning potential higher than those with less experience. This could stem from the observation that Soft Skills grow along with personal and working experiences (Muir, 2004; Tulgan, 2015). This phenomenon gives reason to suggest that older colleagues could teach certain Soft Skills to their younger colleagues in Organizations, or at least they can create a positive atmosphere towards learning them.

Another main finding, although slightly discouraging, was that people with longer working experience seem to rate the level of graduates' skills lower than people with less working years. This outcome can possibly indicate that more experienced people have a high level of Soft Skills themselves, wherefore they feel a longer skills distance to their youngest colleagues. Another reason could be that this assessment originates from a 'generation gap' more than a real gap between skills.

The comparison between countries (Finland, Spain, Portugal, the Netherlands) displayed interesting differences that were statistically significant. In essence, the Portuguese rated all skills higher both in 'Significance' and 'Learning' than the rest of the participating countries. In both dimensions, a predominant south to north difference was visible, as Finns scored lowest in both dimensions. Regarding this research, the Portuguese predominance may be explained by the high share of part-time students 
in the sample, showing high belief in skills and education due to their actual situation. Further, the phenomenon could possibly be explained with cultural factors, for instance the belief in institutions versus individual actions (Hofstede, 2011). This aspect may have implications in multicultural Organizations and co-projects; hence it would deserve further study.

However, the graduates' 'Level' in skills was assessed highest in Finland. This could possibly be explained with the high rate of Finnish business students doing part-time sales work during their studies, in particular regarding such skills as communication, work in team and cooperation, initiative and customer orientation.

\subsubsection{About the Method 3Si and the Classification}

As a result of the research on Skills maps (in 2.2) several skills maps and clusters of Soft Skills were invented. Accordingly, the skills maps analysis affirmed that it is necessary to create a classification of Soft Skills that can display not only the importance of the skills, but also indicate their potential of learning and their current level in a learner (student, graduate or employee). This kind of classification is needed especially by those who are involved with education and training of Soft Skills. To match this need, the method Soft Skills Status indicator (3Si) was created.

The main advantage of the method $3 \mathrm{Si}$ is its ability to classify skills according to their significance in work, their learnability and current level of the skills (graduates or employees). This data is essential for HEls and Organizations for making decisions of whether to include certain skills and to reduce the number of skills in the skills maps. The classification offers eight classes, whereby each class can be interpreted as a specific Soft Skill profile $(3.2 .3,4.3 .1,4.4 .2)$. The classes with High significance $(\mathrm{H}-\mathrm{H}-$ $\mathrm{H}, \mathrm{H}-\mathrm{H}-\mathrm{L}, \mathrm{H}-\mathrm{L}-\mathrm{H}, \mathrm{H}-\mathrm{L}-\mathrm{L})$ are the most interesting ones, as they are rated high in their 'Significance' by professionals in respective fields, and thus essential for the performance of Organizations.

Class 1 (Core Soft Skills) represents the most favourable situation, as the graduates seem to possess the skills that the Organizations appreciate and rate high. In addition, 
these skills are considered to have a rather high learning potential. While skills remain in this class, there is no skills gap between the HEI and Organizations.

In class 2, graduates have a low level of the Soft Skill albeit their role in working positions seems high and also, the trust in learning is high. The skills in this class should be taken into special account by HEls and educators as they seem to be kind of 'Ignored skills'. Indeed, they can be considered from the point of view of hard skills. Some advanced disciplines, for example maths or physics, may be necessary in an Organization and provided by the university, yet not mastered by graduates. Delightfully, in this survey, none of the skills ended in this class.

In class 3, there is an apparent need for the skills, but low trust in learning them. In this survey, customer orientation and self-confidence were positioned in this class, assumingly because graduates learn these skills while part-time working during their studies. As the graduate level is assessed relatively high, there is no immediate shortage. However, this aspect is a challenge for HEls (universities) and other educators. Educators are suggested to rethink how to make the student acquire this Soft Skill, perhaps secondary school should be responsible or HEI teachers' methodologies should change to teach these Soft Skills.

Class 4 is somewhat concerning, as it is appreciated by Organizations, but graduates' level as well as learnability are assessed rather low. In this research, initiative and selfcontrol ended up in this class. This class is a challenge for the education system in general. On the other hand, this leads to the question, to what extent higher education is responsible for promoting (all) the skills. Could there be agreement between HEls and Organizations, concerning the acquisition of skills in general? Regarding Soft Skills, it is generally agreed that they develop along with working experiences; hence, at least some of them could be left to the Organizations to be promoted.

\subsubsection{Limitations of the research and the Method}

In the initiating phase of the research, it was necessary to reduce the number of workable Soft Skills, which was conducted by exploratory research and consecutive desktop studies. Obviously, due to the time resources, this research was not able to 
cover $100 \%$ of Soft Skills titles used in the fields of education and business Organizations. However, it covered a comprehensive number $(31+2)$ of academic, educational and organizational sources, thus ensuring the inclusion of the most important Soft Skills titles. The Framework of most essential Soft Skills (in 2.2.6), used in the survey and the Method 3Si, was compiled from these sources.

The Taxonomy (3.1.2) was created to highlight the intrapersonal and interpersonal levels of communication and their role in practicing the rest of the 20 Soft Skills. It aimed to elucidate the character of communication and plan measures for its training, especially combined with training of other Soft Skills. However, it must be noted that the Taxonomy is a suggestion with practical implications for training and education rather than a scientific outcome. Furthermore, in some working enviroenments, communication may include other important elements, not included in this study.

In experimenting the Method 3Si, the three dimensions were operationalized into the survey questionnaire, applying the Likert scale. The questionnaire had been pre-tested by interviews and focus groups of experienced people with insights on skills maps. However, it can be argued that the Likert scale may cause bias, as it allows the respondents to rate all skills to 5 if they feel so. Thus, the Likert scale does not always provide proper indication of the mutual significance and order of the skills. This option would direct the respondent to make an even clearer distinction between the skills, which is recommendable in case of re-conducting the research.

The survey received quite a high number $(\mathrm{N}=381)$ online responses, which allowed conducting a statistical analyzis. Yet, the number can be considered quite low to represent four different countries. In addition, the composition of the samples may have been somewhat biased in the different countries as it included a high share of adult business student. Thus, it is possible that a renewed survey a new would produce slightly differing results.

In addition, it would have been justified to consider the influence of gender as a background variable. Previous research has indicated that Soft Skills are related with gender (Ahmad, 2013), and in addition, it has been reported that Soft Skills possessed by females are considered differently from those possessed by males (Grugulis \&Vincent, 2009; Hong, 2016). 
Regarding the 3Si Classification, it positions the 21 skills in eight classes. Here, the definition of the skills to either High or Low may, for some, seem too simple. Yet, if we would diversify the definition base, the number of classes would be remarkably higher. For this reason, eight classes were considered relevant for the practical purposes of the research.

Although the 3Si Method is based on quantitative data, and can be thus considered unprecise in some respects, its benefit is that it is easy to use, needing only a reduced number of respondents in each case, and thus viable for educators as well as Organizations. Moreover, it can be adjusted according to the needs of any professional environment, as the location into High or Low in Significance, Learnability and Level depends on the selected threshold value, which can be chosen in each case.

\subsection{Contributions of the Research/Results}

The research is related to working life environments, especially business and ICT, and the current skills needed in them. Organizations seek to recruit graduates with relevant Soft Skills to keep up and reinforce their internal and external performance. Accordingly, higher education has recently been expected to provide their graduates with the appropriate skills of this kind. However, this has turned out to be a challenge for many HEls, for reasons presented and discussed in chapter 2.

For this reason, the research was initiated with exploratory research on Soft Skills titles used in both educational and business contexts. Subsequently, a Framework covering 21 most appropriate skills was compiled (2.2.6). This Framework is viable for both for higher education in business and ICT, as well as for Organizations.

Next, the role of communication was elucidated. The inter- and intrapersonal levels and their interdependence with the 21 Soft Skills were examined in detail. The outcome is a five-level Taxonomy that enables novel approaches to communication in educational and training contexts. As it can be applied to a big range of Soft Skills skills, it becomes possible to identify the precise forms of communication for different 
professional contexts. As a novelty, the Taxonomy distinguishes intra- and interpersonal levels of communication and provides descriptions of them. These descriptions are useful for all educators and trainers in the design of learning methods and environments for Soft Skills.

The main advantage of the method $3 \mathrm{Si}$ is its ability to classify skills according to their significance in work, their learnability and current level of the skills (graduates or employees). This data is essential for HEls and Organizations for making decisions of whether to include certain skills and to reduce the number of skills in the skills maps. The classification offers eight classes, whereby each class can be interpreted as a specific Soft Skill profile $(3.2 .3,4.3 .1,4.4 .2)$.

\subsubsection{To Higher Education in business and ICT}

At HEls, one of the main reasons for the skills gap is that their curricula and its skills often descend from traditional curricula. It has been challenging for the HEls to cope with changing skills needs of working environments, as well as to update the curricula $(1.2,2.1 .5)$. Basically, the Framework created in this research provides a solid and well-argued source to select appropriate Soft Skills.

The third dimension 'Learnability' is particularly interesting for the educators, as it indicates the trust in learning of the skills. As a result of this dimension, it is possible to consider the learning potential of Soft Skills and use this aspect in the selection and training of them.

The main contribution of the thesis is the Method 3Si and the derived Classification 3Si. Their core is the three-dimensional approach to the learning process of Soft Skills. For HEls, this approach conveys 'the missing piece of a puzzle', i.e., the angle of Organizations. This knowledge has been lacking previously (Mitchell et al., 2010; Tedesco et al., 2014), thus being a reason for the skills gap between HEls and Organizations (OECD, 2016). The outcomes enable the discussion between HEIS and Organizations on which skills should be selected in curricula. Furthermore, the Classification provides indication on where the skills should be learned. 
As for the Classification, for HEls the classes with High significance $(\mathrm{H}-\mathrm{H}-\mathrm{H}, \mathrm{H}-\mathrm{H}-\mathrm{L}, \mathrm{H}-$ $\mathrm{L}-\mathrm{H}, \mathrm{H}-\mathrm{L}-\mathrm{L})$ are the most interesting ones, as they are considered high by their 'Significance' by professionals in respective fields. Hence, the Method 3Si provides a systematic tool for HEls to find and select the skills that should be included and those that can be discarded.

\subsubsection{To Business and ICT Organizations}

Along with changing conditions in working environments, also the majority of Organizations face the problem 'which Soft Skills are the most essential ones?' (e.g., Mitchell et al., 2010; Robles, 2012; Redomero et al., 2019). The created Framework provides a basic answer to this question, equally as it does to HEls.

The contribution of the Taxonomy, described previously in 5.2 .1 , is equally valid to Organizations. Trainers can use it to take diversify their training of communication skills and connect them with other Soft Skills in the professional in-service training of their Organizations.

In addition, Organizations can apply the survey 3Si for providing them with indication on the current level of these skills, either in graduates or employees, according to which data is needed. The third dimension, 'Level', also indicates possible skills gaps. If most of the people recruited or employed staff show a low level in a skill, it indicates a gap in these skills, which obviously means a need of training, either in the HEls or in the Organizations themselves. In such situations, the Framework and the Classification are tangible means for planning the training.

Also for Organizations, the Method 3Si offers a systematic approach to detect essential and potential Soft Skills for any Organization, especially in the areas of business and ICT. To fit the method 3Si efficiently to the needs of each Organization, their specific needs must be considered. It may concern perhaps the whole Organization, or a department, or a project. Within these, there may be a need to emphasize specific skills. For this purpose, the threshold (in 4.3.2) can be applied to adjust the cutting point between High and Low. 
The outcomes can be applied to some extent even in other professional fields, as the Method is able to detect and classify essential Soft Skills and characterize them according to their importance and potential. It enables HR professionals and managers to detect needs in particular working departments or projects by surveying persons working in these positions. This, again, helps them to choose and focus on skills that are more relevant than others, for instance in recruitment or training issues. Especially this can be applied for recently recruited graduates and young professionals. By this means, the Method 3Si by Organizations and HEls to reduce the existing skills gap (e.g., Cappelli, 2012; Mourshed et al., 2014; OECD, 2016; Bughin et al., 2018). 


\section{Scientific Publications and Dissemination of the Results}

The phases of the research and its outcomes have been diffused on many fora, first, they have been presented at Conferences of applied sciences mostly in the context of 'Development of Learning and Education', starting from the year 2017, mostly in Spain and Finland. Along with the research proceeding, articles have been sent and published in scientific journals. These activities are presented in 6.1.

A further forum for promoting the research and sharing the outcomes has been the coalition of universities of applied sciences (UPV/Spain, IPP/Portugal, $\mathrm{HU} /$ Netherlands). Due to a joint funding received with these partners, it was possible to promote the importance of Soft Skills and their practicing to students, teachers and organizations in the partnering countries. These activities are reported in 6.2.

\subsection{Scientific Publications}

The experiments, elements and outcomes of the thesis have been published in several scientific journals and presented on academic conferences over the years 2017-2020. A summary is presented in figure 19. 


\begin{tabular}{|c|c|c|c|c|c|}
\hline \multicolumn{3}{|c|}{ Status doctoral studies 10.10 .2020 Kai Schleutker } & \multicolumn{3}{|c|}{ UPV, Industrias de la Comunicación y Culturales } \\
\hline & Title & & Joumal/Conference & Status & \begin{tabular}{|l} 
Hours \\
admitted
\end{tabular} \\
\hline \multirow[t]{7}{*}{ Article } & $\begin{array}{l}\text { About the Learning Potential of Soft Skills Needed } \\
\text { in the } 2020 s^{\prime} \text { Orqanizations - Cultural and Digital } \\
\text { Aspects }\end{array}$ & $\begin{array}{l}\text { Schleutker, Joshi, Ahonen, } \\
\text { Bastos, Poza Lujän \& } \\
\text { Cagqiano }\end{array}$ & $\begin{array}{l}\text { New Work Technology and } \\
\text { Employment }\end{array}$ & submitted 10/2020 & \\
\hline & $\begin{array}{l}\text { Soft Skills - inborn abilities or skills with } \\
\text { development potential? Confiquration based on a } \\
\text { Finnish sample }\end{array}$ & $\begin{array}{l}\text { Schleutker, Poza Luján, Varis, } \\
\text { Caqqiano, Lloret Romero \& } \\
\text { Taatila }\end{array}$ & Journal of Education for Business & submitted 08/2020 & \\
\hline & $\begin{array}{l}\text { Towards including Soft Skills in Curricula. Finnish } \\
\text { and Italian Students Self-evaluation indicates } \\
\text { individual differences }\end{array}$ & $\begin{array}{l}\text { Caggiano, Schleutker, } \\
\text { Petrona \& Goozalez Bernal }\end{array}$ & $\begin{array}{l}\text { Psychology of Sustainability and } \\
\text { Sustainable Development (JCR 2) }\end{array}$ & published 5/2020 & 60 \\
\hline & $\begin{array}{l}\text { A Soft Teacher? Updating the Skills Set of } \\
\text { Teachers, needed in the 2020s' }\end{array}$ & $\begin{array}{l}\text { Caggiano, Schleutker, } \\
\text { Cinqueqrani, Gopzalez } \\
\text { Bernal \& Poza Lujajn }\end{array}$ & $\begin{array}{l}\text { International Jouma/ for Eolucational } \\
\text { Development }\end{array}$ & sent $4 / 2020$ & \\
\hline & $\begin{array}{l}\text { Soft Skills and European Labor Market. Comparison } \\
\text { between Italian and Finnish Manaqers. }\end{array}$ & $\begin{array}{l}\text { Schleutker, Caggiano, Coluzzi } \\
\text { \& Poza Luján }\end{array}$ & $\begin{array}{l}\text { Educational, cultural and } \\
\text { psychological studies Journal. }\end{array}$ & $\begin{array}{l}\text { published 7/2019 } \\
\text { sent } 4 / 2019\end{array}$ & 50 \\
\hline & $\begin{array}{l}\text { Entrepreneurial skills - widely needed but } \\
\text { challenging to learn. }\end{array}$ & $\begin{array}{l}\text { Schleutker. Amenuodini \& } \\
\text { Coluzzi. }\end{array}$ & TALKMagazine & published 09/2018 & 30 \\
\hline & $\begin{array}{l}\text { How to facilitate development of soft skills in } \\
\text { business studies? Description of a Portuquese and } \\
\text { a Finnish pilot. }\end{array}$ & Bastos, Schleutker, \& Azevedo. & UAS Journal & $\begin{array}{l}\text { published } 06 / 2018 \\
\text { sent } 03 / 2018\end{array}$ & 50 \\
\hline \multirow[t]{5}{*}{$\begin{array}{l}\text { Conference } \\
\text { presentation }\end{array}$} & $\begin{array}{l}\text { Aspects on Soft Business Skills and their learning. } \\
\text { Comparison Finland - Portugal }\end{array}$ & $\begin{array}{l}\text { Schleutker, Poza Luján, } \\
\text { Carvalho \& Bastos }\end{array}$ & AET/2020 & $\begin{array}{l}\text { Daper accepted } \\
\text { conference cancelled }\end{array}$ & \\
\hline & $\begin{array}{l}\text { CoSki2 } 1 \text { tool; una herramienta para administrar } \\
\text { competencias transversales en las orqanizaciones y } \\
\text { en los planes de estudio de educación superior }\end{array}$ & $\begin{array}{l}\text { Schleutker, Poza Luján, } \\
\text { Conejero \& Lloret Romero }\end{array}$ & ETSINF 2019, Valencia. & 2019 & 50 \\
\hline & $\begin{array}{l}\text { ¿Qué visión tienen las empresas sobre las } \\
\text { competencias transversales de la Universidad? }\end{array}$ & $\begin{array}{l}\text { Poza Luján, Conejero, } \\
\text { Schleutker \& Lloret Romero }\end{array}$ & ETSINF 2018, Valencia & 2018 & 30 \\
\hline & $\begin{array}{l}\text { How to embrace the new challenges of } \\
\text { education? Experiences from Business Education }\end{array}$ & Bastos, Schleutker \& Azeveda & EAPRIL 2017, Hermeenliana & 2017 & 30 \\
\hline & Soft skills boxes. & $\begin{array}{l}\text { Schleutker, Poza-Lujan \& } \\
\text { Conejero }\end{array}$ & ETSINF 2017, Valencia. & 2017 & 30 \\
\hline \multirow{3}{*}{$\begin{array}{l}\text { Transversal } \\
\text { academic } \\
\text { courses }\end{array}$} & $\begin{array}{l}\text { High standards for scientific production and } \\
\text { communication }\end{array}$ & & & $2-4 / 2020$ & 20 \\
\hline & Estrategias de divulgasión & & & $3-5 / 2019$ & 20 \\
\hline & Re-writing science & & & $1-3 / 2019$ & 20 \\
\hline
\end{tabular}

Figure 19 Summary of scientific publications and academic conferences participated during the thesis.

\subsubsection{Journal articles}

\section{ABOUT THE LEARNING POTENTIAL OF SOFT SKILLS NEEDED IN THE 2020S' ORGANIZATIONS - CULTURAL AND DIGITAL ASPECTS}

Sent to New Technology, Work and Employment, 02.10.2020

Authors: Schleutker, K., Joshi, M., Ahonen, J., Caggiano, V., Bastos, S. \& Poza-Luján, J.L.

\section{Abstract}

The changing working environments of the 2020 s with increasing change, digitalization and diversity propose new types of skills, whereby educational institutions are urged to provide graduates with them. The character of these 'Soft Skills' is inherent and probably culture-bound, whereby their learning forms a challenge for educators. This research is based on a survey directed to business professionals in four European countries, focusing on their assessment of the learning potential of Soft Skills. The results suggest that certain skills have higher learning potential than others. In addition, 
the research gives indication on significant differences in these assessments between the countries involved. They can partly be explained by cultural values.

The results are interesting especially for business educational institutions and HR professionals in Organizations working in international environments.

Key words: Soft Skills; Diversity; Cultural differences in Soft Skills; Digital Learning Environments for Soft Skills 


\title{
SOFT SKILLS - INBORN ABILITIES OR SKILLS WITH DEVELOPMENT POTENTIAL? CONFIGURATION BASED ON A FINNISH SAMPLE
}

Sent to Journal of Education in Business, 27.08.2020

Authors: Schleutker, K., Poza-Luján, J.L., Varis, K., Caggiano, V., Lloret Romero, N. \& Taatila, V.

\begin{abstract}
Although Soft Skills have been reported indispensable elements of personal and Organizational performance in business environments, their role in business education is not fully acknowledged. Being often considered as inborn abilities, guidelines for their development are needed. This study aims to provide business educators insights on essential Soft Skills and their promotion by asking business professionals to assess them in three dimensions. The results exhibit variations in the perceived significance of Soft Skills and suggest certain skills appropriate for higher versus secondary business education. As a main contribution, a configuration (3Si) is introduced. The findings are expected to be of interest for teachers and curricula designers in Business Education.
\end{abstract}

Keywords: Soft Skills; business education; developing Soft Skills; development potential of Soft Skills 
TOWARDS IDENTIFYING THE SOFT SKILLS NEEDED IN CURRICULA: FINNISH AND ITALIAN STUDENTS' SELF-EVALUATIONS INDICATE DIFFERENCES BETWEEN GROUPS

Published in Sustainability. Wellbeing in Education, Career and Work, 14.05.2020

Authors: Caggiano, V., Schleutker, K., Petrone, L. \& Gonzalez-Bernal, J.J.

\begin{abstract}
Background: The identification of Soft Skills by Higher Education (HE) students is important for curriculum design, as is to evaluate if the students' Soft Skills are adapted to the needs of the socioeconomic environment. This paper presents a study conducted to determine to what extent Finnish and Italian students' perceptions of their own Soft Skills differ. Methods: The cohort of the study consisted of 80 Finnish and 80 Italian HE students. Results: The results reveal that, regardless of cultural aspects, both groups share specific Soft Skills whilst showing significant differences in others. The observed differences in the profiles of the two countries are explained on the basis of the cultural and curricula design frameworks that are well established in Finland and Italy.
\end{abstract}

Conclusions: The implications of the findings for teachers and researchers are presented, which may bear relevance in guiding the implementation of curriculum design in Finland, Italy and beyond.

Keywords: Soft Skills; curriculum design; competence; Organizational culture; higher education 


\title{
A SOFT TEACHER? COMPARATIVE STUDY BETWEEN ITALIAN AND FINNISH TEACHERS
}

Sent to Journal of Curriculum Studies, 13.04.2020

Authors: Caggiano, V., Schleutker, K., Cinquegrani, A., Gonzalez Bernal, J. J. \& Poza-Luján, J.L.

\begin{abstract}
In the age of globalization and technology, the society calls for graduates with new types of personal competencies, which are often called 'soft' or 'transversal' skills. Accordingly, the education system is expected to produce such skills. Ultimately, this situation is challenging teachers in terms of their skills and the learning methods that they use.
\end{abstract}

The general aim of this article is to examine the skills needs and their acquisition by higher education teachers in Italy and Finland, to cope with the constantly evolving European labour market of the 2020s'. The article envisages the importance of Soft Skills in the teaching profession. Our hypothesis is that teachers' Soft Skills profiles vary in different countries. The empirical part consists of a comparative study with Italian and Finnish teachers. The results show some clear cultural differences between these two groups. Finnish teachers seem to be stronger assertiveness and team working orientation whereas the Italians have higher levels in sensitivity and generally capacity of establishing contacts.

As a recommendation, the architects of curricular reform are urged to incorporate Soft Skills courses as elements of teacher education, with the view of enhancing the values of a humanistic pedagogy, in order to motivate teachers.

Keywords: Teacher competences, Soft Skills, Cultural Values, European Education System 


\section{SOFT SKILLS AND EUROPEAN LABOUR MARKET: INTERVIEWS WITH FINNISH AND ITALIAN MANAGERS}

Published in Journal of educational, cultural and psychological Studies, 28.06.2019

Authors: Kai Johannes Schleutker, Valeria Caggiano, Fabiana Coluzzi, Jose Luis Poza-Luján

\section{Abstract}

Recent reports have suggested that many employees in the labour market today lack essential Soft Skills. Yet, the specific relevance of these skills for particular job occupations is still to explore. We investigated perceptions of skill requirements and their development potential reflected against cultural impacts, using close interviews of 64 managers at firms in different fields of industries in Italy and Finland. Managers reported that, due to heightened competitive pressure, specific Soft Skills, particularly Work in team and flexibility to develop, are becoming increasingly important. The study indicates that the perceived significance of Soft Skills seems to vary according to the working environment and occupation. Furthermore, some Soft Skills seem to have a higher potential for development and thus suggested to be implemented in the university curricula. The paper concludes that a country characterized by working environments conducive to the development of Soft Skills, must however promote research for the identification and relevance of the skills themselves.

Keywords: Competencies; Curriculum design; Job occupation; Labour market; Soft Skills 


\title{
ENTREPRENEURIAL SKILLS - HIGHLY NEEDED BUT NOT EASILY ACQUIRED?
}

Published in TALK Entrepreneurship, 16.11.2018

Authors: Schleutker, K., Amenundini, F. \& Coluzzi, F.

\begin{abstract}
Entrepreneurship and entrepreneurial skills appear in most strategic plans and vision papers. A growing number of new companies is expected to revive employment and boost regional economy, and furthermore entrepreneurship can be seen as a mindset which involves a high level of positive attitude, goal orientation and responsibility. Thus, the entrepreneurial attitude is a skill which every employer and manager ranks high on his most-important-skills list.
\end{abstract}

Keywords: Entrepreneurial skills, Soft Skills, Innopedagogy 


\title{
HOW TO FACILITATE DEVELOPMENT OF SOFT SKILLS IN BUSINESS STUDIES? DESCRIPTION OF A PORTUGUESE AND FINNISH PILOT.
}

Published in UAS Journal, 27.06.2018

Authors: Susana Bastos, Kai Schleutker \& Liliana Azevedo

\begin{abstract}
Latest research indicates that business graduates are expected to possess Soft Skills in addition to their substance related hard skills. In working environments, Soft Skills are needed for communication and adaptation, as well as for employability reasons. For higher education institutes this means an increasing challenge.
\end{abstract}

Even if the need of Soft Skills is widely acknowledged, new efforts to build appropriate learning environments are needed continuously. Soft Skills have been highlighted in social care and nursing education, whereas in business fields they have received less attention.

In this article, two learning environments for business studies at Universities of applied sciences are presented. The ISCAP (Porto) model bases on Business simulation, whereas the TUAS (Turku) model involves team-based learning. These learning environments have been designed particularly for fostering Soft Skills of the graduates, and thus implementing the idea of skills-based curriculum.

\subsubsection{Conference presentations}

\section{BUSINESS SKILLS NEEDED IN THE 2020S' - ARE TRANSVERSAL SKILLS SOMETHING YOU CAN DEVELOP? A PILOT STUDY IN FOUR COUNTRIES}

Accepted to Applied Education, Technology and Innovation (AETI2020), supposed to take place Turku, April 2020 (the Conference was prohibited due to the pandemic)

Authors: Schleutker, K., Poza-Luján, J.L., Carvalho, P. \& Bastos, S.

\section{Abstract}

Regarding professional competence, transversal skills form an ever more essential part of it in most professional fields. Transversal skills consist of a variety of 
communication skills, team working skills and innovative skills. They play a key role in improving individual and Organizational performance and development.

The increased need of these skills has recently been reported by employers (Mourshed et al. 2014) and Organizations (WEF 2016). For individuals, a lack of transversal skills causes problems in employability and career development (Robles 2012), and for Organizations a deficit in individual performance (Jones et al. 2017). Therefore, further understanding is needed on how to identify, develop and assess these skills. This knowledge will help higher education institutes and Organizational trainers to cope better with the needs of the labour market of the 2020's. Our study focuses especially on the transversal skills needed in business Organizations.

\section{Aim of the study}

Transversal skills are often considered as personal skills and characteristics, rather than learned competencies. In the educational context, they have traditionally been judged as in-born abilities, possessing thus quite an invisible role in curricula (Tedesco et al. 2014). For the time being, there is much discussion upon whether transversal skills can be learned and what kinds of methods should be used. Evidently, they cannot be learned with traditional 'teacher-to-student' methods (Cimatti et al. 2017). This study is conducted as a part of the project Core skills for 21. Century Professionals, funded by Erasmus + Strategic Partnership program. It aims on creating a novel insight on the character of transversal skills and their learning potential. The research questions are 'To what extent do you think the following skills can be developed?", and to identify expectations related to the first aspect, 'In your opinion, can these skills be learned at higher education institutions?".

In especial, the study focuses on 21 essential transversal skills needed in business environments. The results enable a better understanding on the fostering of these skills in higher education units and Organizations.

\section{Method}

To answer the research questions, an online survey was launched to business professionals with at least three years' work experience. The data was collected in 
four European countries (Finland, Portugal, Spain and Netherlands) during May September 2018. Close to 400 respondents attended the survey.

\section{Preliminary results}

The preliminary results seem to show a large variation in the perceived learning potential. The highest ratings (e.g., team working skills, communication) exceed the average of 4 , as the lowest (e.g., empathy, customer orientation) remain under 3 . Some background factors, such as position and working experience, seem to correlate with individual valuations. The final results and comparison between countries are under process and will be completed during January 2020. In all, the results give some very interesting indications to educational institutions and other training Organizations regarding business competences in the 2020s'. 
COSKI21 TOOL: UNA HERRAMIENTA PARA ADMINISTRAR COMPETENCIAS TRANSVERSALES EN LAS ORGANIZACIONES Y EN LOS PLANES DE ESTUDIO DE EDUCACIÓN SUPERIOR

Published at Jornada de Innovación docente (JIDINF 2019), Valencia, July 2019

Authors: Schleutker, K., Poza-Luján, J.L., Conejero Casares, A., Lloret Romero, N., CalduchLosa, A. \& Torró, C.

\section{Abstract}

Las competencias necesarias para un titulado superior pueden ser técnicas (hard skills) o transversales (Soft Skills). Actualmente, los planes de estudios de las titulaciones se centran principalmente en los hard skills, debido a que existe un cierto consenso acerca de las necesidades técnicas de los titulados. Sin embargo, para decidir qué Soft Skills hay que integrar en un plan de estudios de grado universitario se debe considerar otro tipo de necesidades relacionadas con los métodos de trabajo que los estudiantes van a emplear en su entorno de trabajo.

En el proyecto Europeo Erasmus+ CoSki21 (Core Skills for 21th Century Professionals) se ha desarrollado una taxonomía centrada en los elementos que influyen a la hora de determinar las particularidades de los Soft Skills para cada perfil profesional.

La taxonomía presentada se emplea como esquema para la organización de los datos a partir de los cuales se analizarán para determinar los Soft Skills más adecuados para un tipo de empresa en concreto. A partir del análisis, se puede determinar fácilmente el mapa de Soft Skills de una empresa. Dicho mapa tendrá la ventaja de ser específico del ámbito de negocio de dicha empresa. Para probar la validez de la taxonomía y del método de análisis de los Soft Skills, se ha desarrollado una aplicación web que permite generar mapas de competencias concretos.

En el trabajo presentado, se muestran cómo se han analizado diferentes mapas de competencias para nutrir de datos a la base de datos y cómo se agrupan dichas competencias. A partir de dichas agrupaciones, es posible relacionar las competencias para determinar el mapa de competencias adecuado a la organización. 
DETECTING, DEFINING AND DEVELOPING SOFT SKILLS IN BUSINESS AND ICT CONTEXTS Kai Schleutker 


\section{QUE VISIÓN TIENEN LAS EMPRESAS SOBRE LAS COMPETENCIAS TRANSVERSALES DE LAS UNIVERSIDADES?}

Presented at Foro internacional sobre la evaluación de la calidad de la investigación y de la educación superior (fecies), Granada, Spain, July 2018

Authors: Schleutker, K., Calduch-Losa, A., Robles-Mateo, E., Poza-Luján, J.L., Lloret Romero, N. \& Taatila, V.

\section{Background of the study}

When a company hires to a titled university graduate for a specific position, it expects that the graduate has the specific skills of his degree, but also some more generic skills, like "leadership" or "effective communication". Consequently, the universities should form their students in Soft Skills. We pose us if the skills that are practiced in the university are those that the companies sue.

\section{Method}

To see the point of view of the companies, we passed them a survey asking the value of Soft Skills. The study was initiated in Finland, although it is expanding to other countries, among them Spain.

\section{Result}

According to the responses to the surveys, the skills map designed by our project was considered very useful.

\section{Conclusions}

We think that the communication among the university and the companies has to be constant and fluent, in order to form the graduates that sues the society needs. 


\title{
HOW TO EMBRACE THE NEW CHALLENGES OF EDUCATION? EXPERIENCES FROM BUSINESS EDUCATION
}

Presented at European Association for Practitioner Research on Improving Learning (EAPRIL), Hämeenlinna, Finland, December 2017

Authors: Bastos, S., Azevedo, L. \& Schleutker, K.

\begin{abstract}
The existent concern in suppress all the identified gaps in the traditional teaching of Accounting and Administration has led to the creation of a new way to be in Higher Education. This new way to be, denominated by Business Environment resulted in the implementation of two curricular units designated by Project of Business Simulation.
\end{abstract}

The present article has as purpose study not only the potentialities, but also the constraints of the innovative methodology of the teaching-learning process and the assessment used. We intend to analyze in what measure the Simulator of the Business Environment beneficiates the school success, in result of an improvement in the teaching-learning process and, consequently, in the development of the students' competences.

The results of the study raised issues related to the teaching-learning methodologies traditionally used and the methodology of the Simulator, as well with the assessment methodology and how it develops in students a different attitude regarding the teaching and learning process. The centrality at the student as the focus of this rating system allows self-regulation of learning through feedback. Individual and group work are presented as key factors in the development of generic skills and behavioural in addition to technical inherent to the profession. 


\section{SOFT SKILLS BOXES}

Presented at Jornada de Innovación docente 2017 (JIDINF), Valencia, Spain, January 2017 Authors: J.L. Poza-Luján, A. Conejero \& K. Schleutker

\section{Abstract \\ Qué son los Soft Skills?}

Basándose en el principio de la informática: sin hardware, no hay software... y sin software el hardware no tiene valor, los Soft Skills son las competencias transversales que recubren a los hard skills (competencias técnicas) y les dan valor.

\section{Cómo se organizan los Soft Skills?}

En la asignatura optativa del máster en ingeniería Informática se imparten por medio de la metodología ágil SCRUM, siendo el backlog el conjunto de competencias y cada uno de los cinco sprints (de tres semanas cada uno) desarrolla un ámbito concreto del estudiante.

\section{Cómo se imparte cada Soft Skill?}

Basándonos en el "Círculo de Deming" y teniendo en cuenta que en las metodologías ágiles la planificación no es relevante, se tienen tres fases para cada actividad.

Qué es un Soft Skills Box? La inspiración es el "qué se va a hacer". Es el equivalente a la teoría de un Hard Skill. Consiste en una lectura, un audio de un podcast, un vídeo o incluso seguir en una red social a alguien relevante para el skill. El alumno debe poder hacer esta fase de forma autónoma. La acción es la forma de "comprobar" cómo funciona el Skill. Se realiza por medio de una actividad gamificada (cartas, role playing, storytelling, etc.) donde el profesor es un facilitador de la actividad. La reflexión es la forma de " actuar" basándose en el skill practicado. Consiste en aplicar lo aprendido en alguna situación profesional o académica y escribir acerca de la experiencia en un blog o medio similar (desde portafolio hasta red social ). 


\subsection{Dissemination of the Results}

As an applied research and development project, my thesis study was substantially connected to the European project CoSki21 (Core Skills for 21. Century Professionals, 2017-2020), conducted by partners in six European countries (Spain, Finland, Portugal, Netherlands, Austria and Slovenia). This project aimed on increasing the awareness of Soft Skills as an important part 21. century working competence, among universities and students. Mainly this was carried out by creating a website https://www.skills-4u.eul, and a Facebook account. I was the main responsible for the named dissemination activities.

Furthermore, the consortium of the project enabled to collect research data from the partnering countries, which enlargened the frame of my research. In the research process, my role was to coordinate the creation of the online survey tool and translation to six languages. In addition, I was responsible for data collection and analyzing the data.

The dissemination phase also included workshops in all the partnering countries, directed to the target groups, i.e. business and ICT teachers, students and managers. In the following I will shortly describe these activities, and their impact, on both the target groups as well as my research process.

\subsubsection{Project Coski21 - creation of project website}

\section{Step one: Technical frames, main layout and main contents}

This phase covered the technical frames of the website. Regarding the technical frame, three alternatives were considered (WIX, Wordpress and Drupal), from which Wordpress was chosen because of its user friendliness and potential of enlargement.

\section{Fundamental assumptions:}

* Soft Skills have a significant role as a part of Business competence (e.g., Robles 2012; Mourshed et al., 2014; Bughin et al., 2018)

* The awareness of Soft Skills is low, and should be heightened

* Practitioners (teachers, trainers, HR-experts) need a framework for Soft Skills to find the most appropriate ones for their Organizations

* They also need methods for developing Soft Skills 


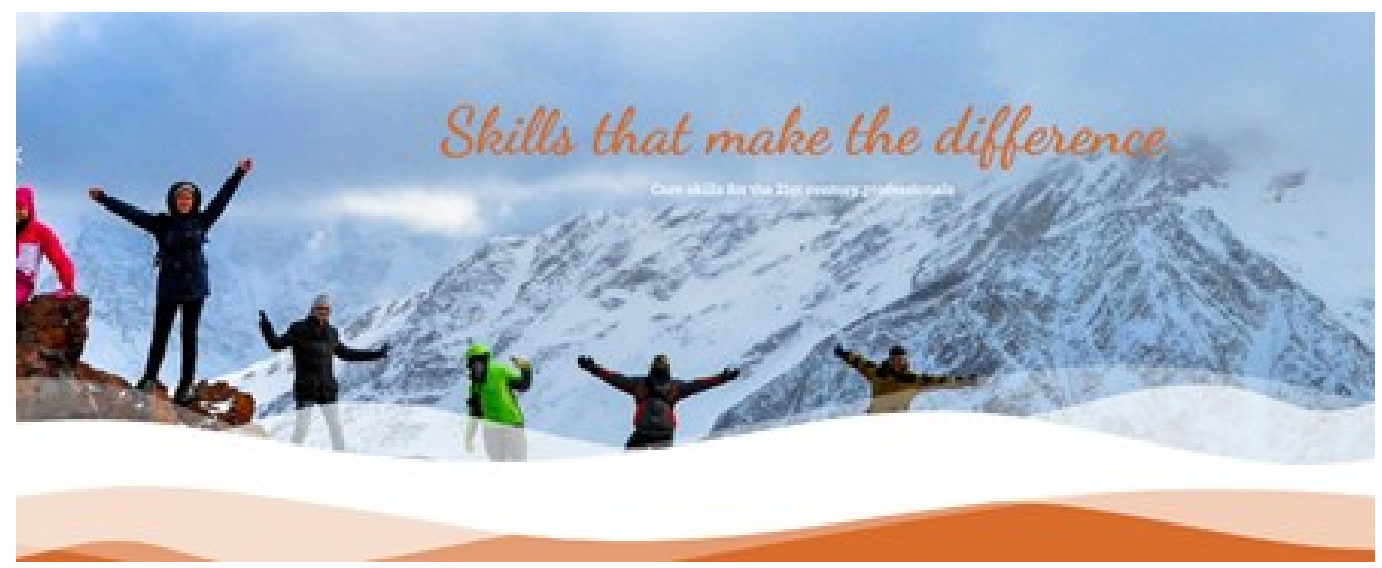

Figure 20 The outlook of the website www.skills-4u.eu.

Target groups:

* students, teachers, curricula planners

* Business faculties

* Organizations (professionals, managers, HR-experts)

My role in this phase was to assemble the Turku UAS team, plan the structure of the website (tabs and headers), approve the visual proposals and coordinate the work of the team.

\section{Step two: Creating contents to the webpage}

The goal was to invent material that has significance to the target groups, named in the previous paragraph. Subsequently, the following topics were selected:

* "What are Soft Skills?", "Why are they important?"

* "Practical benefits you can get from possessing Soft Skills"

* Which Soft Skills fit with which job positions? - Framework on Soft Skills

* Scientific info on Soft Skills - articles

* Is development of Soft Skills possible - how? 


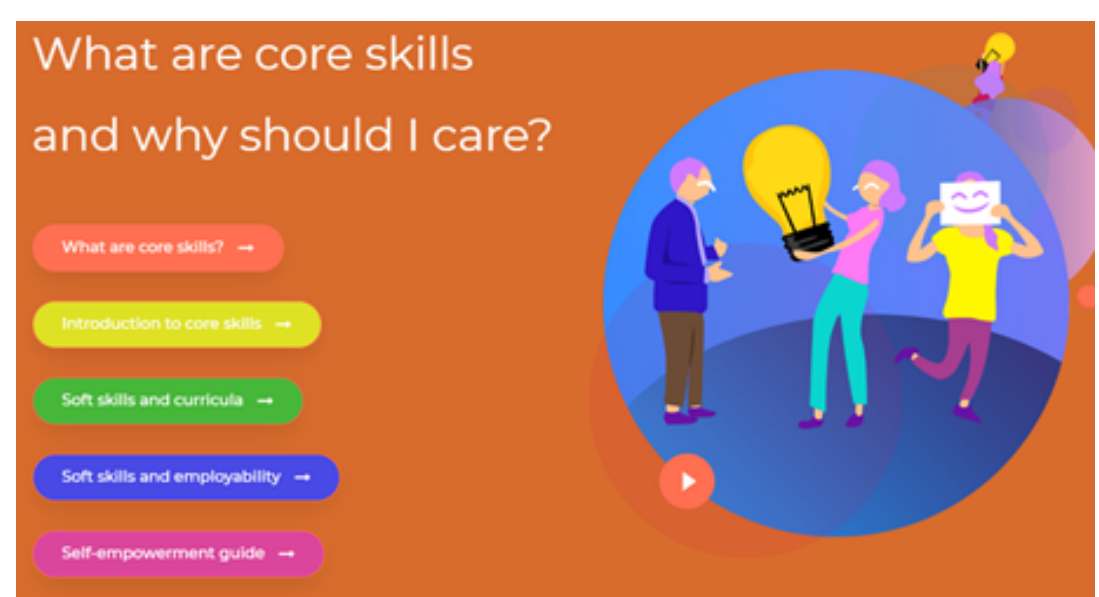

Figure 21 The visitor can choose different initiations.
This capture, to give an example, shows a presentation for the first bullet, "What are soft/core skills?" and "Why are they important?"

Each of the buttons include a link to a short video (20-30 sec.)

presenting the topic in a relaxed but informative way. The aim was to attract the visitor to the extent that they will seek more detailed information on the website. For those who get interested and search for more information, the site contains articles, tests, videos and other material, designed for teaching-learning activities (educators) and training sessions (companies and Organizations).

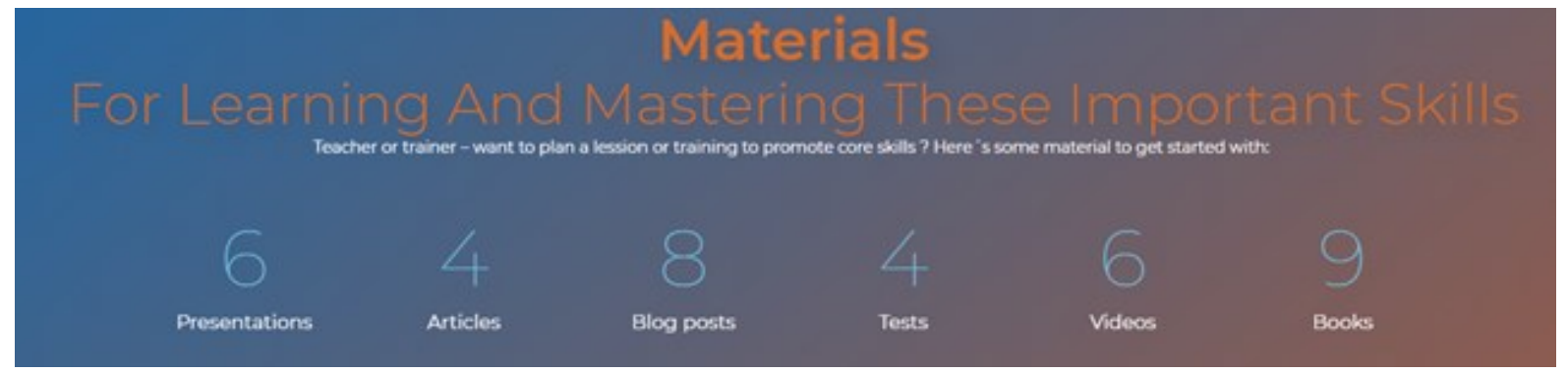

Figure 22 Free material can be loaded from the website.

In addition to literal material, articles and videos, development methods were tailored for the following Soft Skills:

\footnotetext{
* Communication skills

* Team working skills

* Leadership

* Self-management
}

As development of any skill should start from self-awareness and self-knowledge (Sawyer, 2006), all the development activities are recommended to be started with a 
respective test, available online, followed by the specific, skill-related training methods (figure below).

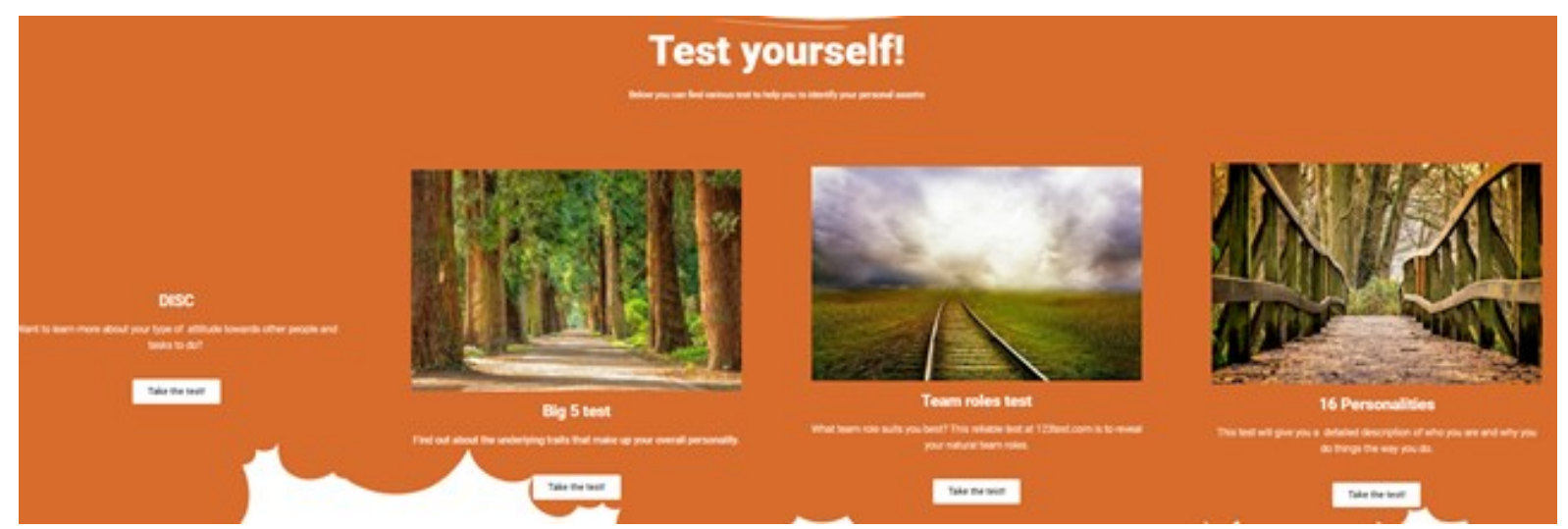

Figure 23 Promotion of Soft Skills begins from self-awareness.

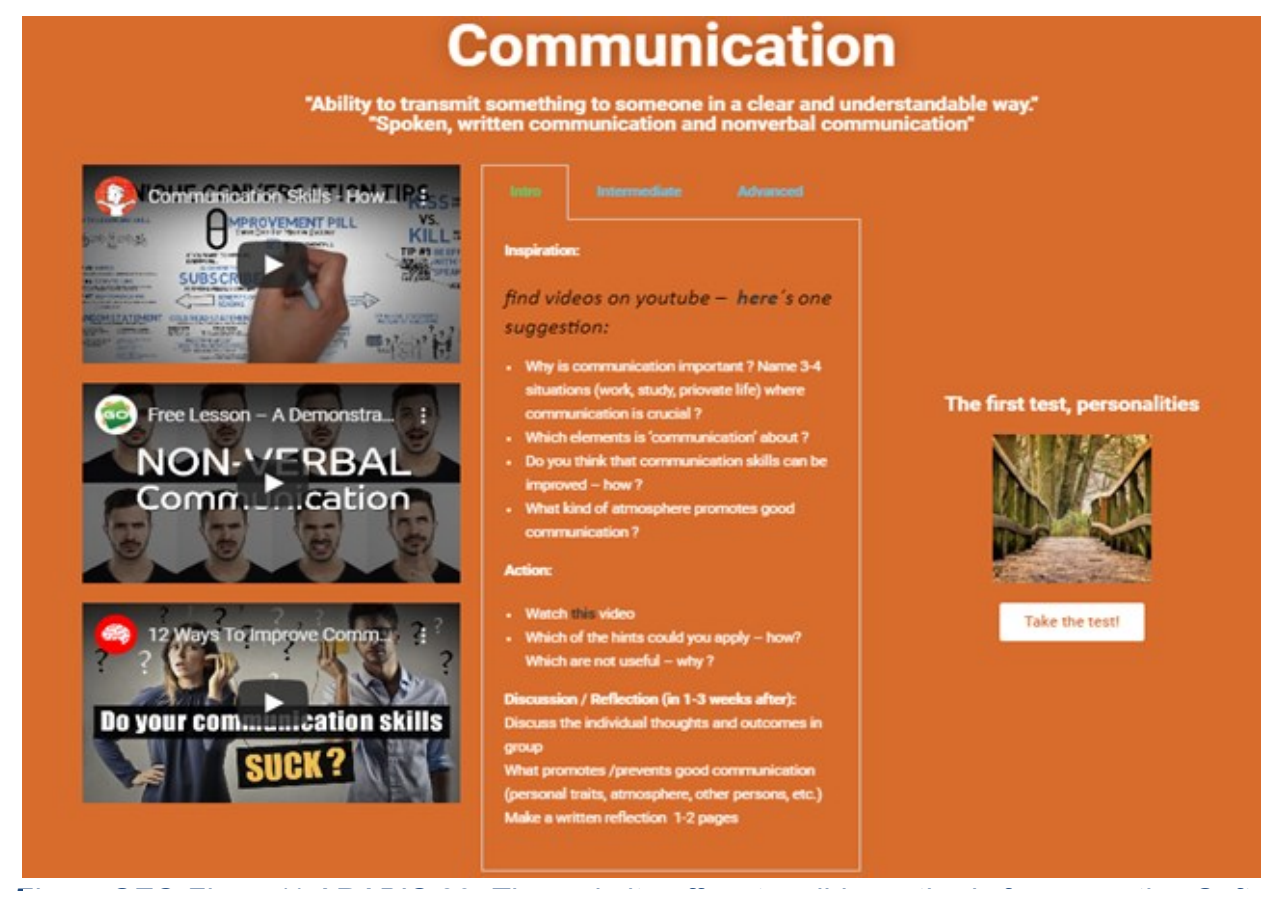

\section{Step three: Creating audiences for the website}

After creating the website structure and contents, one challenge is how to reach the target audience and create accumulated traffic on the site. In this case, the social media channels were considered relevant, as they reach targeted groups in big volumes, in the selected countries. In addition, the cost for promoting publications and ads is relatively low. To find the right channels, it is important to be aware of the target 
groups. (McDonald, 2019). The following social media were chosen as main spreading channels:

* Facebook (students and teachers)

* Linkedln (graduates, managers, HR experts)

The project profile was created in Facebook and Linkedln, wherein both media were linked to the website to get mutual synergy. Social media posts can be a good way to attract visitors to the website, and respectively social media posts are a praxis for creating continuously changing contents to the website (Wollan, Smith \& Zhou, 2011).

In social media it is important to post contents that appeal to the target groups, and, in addition, keep feeding them with contents that make them appreciate the profile, follow and share it (McDonald, 2019). Consequently, a major plan was created for accumulating contents:

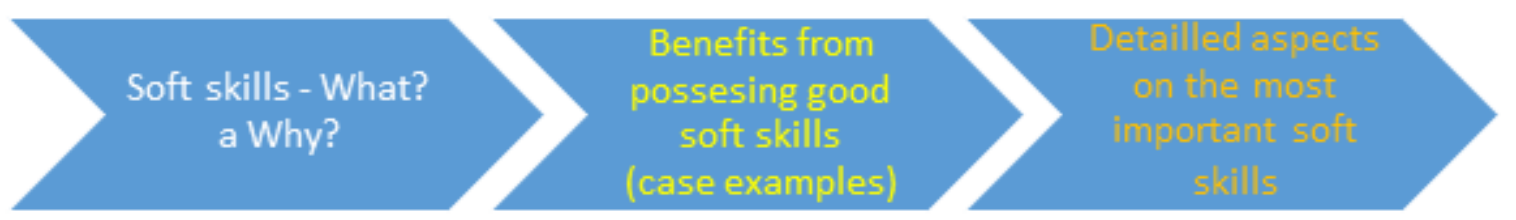

Figure 24 The content strategy for promotion in social media.

The first phase 'What \& Why?' took place in September - December 2018, the second lasted from January 2019 to May 2019, and finally the details were presented in JuneSeptember 2019. Posts were written in a multinational team consisting of nine teachers and students in Finland, the Netherlands, Portugal and Spain.

\section{Results achieved}

- the website promotion project lasted from September 2018 to September 2019

- in total, 123 posts were published on Facebook and 45 in Linkedln

- the number of followers exceeded 300 on Facebook and 100 in Linkedln

- the best organic posts earned over 300 impressions and 30 reactions (shares, comments)

- also paid promotion was used, the best posts reached over 2000 impressions 
- the number of visitors on the website increased at a steady pace during the project; totally the visits on the site exceeded 8000.

\begin{tabular}{|c|c|c|c|c|c|c|c|}
\hline Date & Topic & \multicolumn{3}{|c|}{ Content form } & Impressions & \multicolumn{2}{|c|}{ Reactions } \\
\hline $\begin{array}{l}25.3 .2019 \\
9.11\end{array}$ & & $\begin{array}{l}\text { Why are soft } \\
\text { skills so }\end{array}$ & $\mathscr{S}$ & $\theta$ & ? & $\begin{array}{l}4 \\
3\end{array}$ & | \\
\hline $\begin{array}{l}22.3 .2019 \\
11.00\end{array}$ & & $\begin{array}{l}\text { Trust implies the } \\
\text { willingness to }\end{array}$ & $\mathcal{S}$ & $\theta$ & 71 & $\begin{array}{l}4 \\
3\end{array}$ & 1 \\
\hline $\begin{array}{l}20.3 .2019 \\
18.27\end{array}$ & & $\begin{array}{l}\text { This is the } \\
\text { second of the }\end{array}$ & e4 & $\theta$ & 331 & $\begin{array}{l}27 \\
22\end{array}$ & i \\
\hline $\begin{array}{l}17.3 .2019 \\
16.30\end{array}$ & & $\begin{array}{l}\text { In the } 21 \text { - } \\
\text { century, most of }\end{array}$ & $\mathscr{S}$ & $\theta$ & 89 & $\begin{array}{l}3 \\
5\end{array}$ & I \\
\hline $\begin{array}{l}14.3 .2019 \\
15.29\end{array}$ & Y & $\begin{array}{l}\text { In this spring we } \\
\text { are going to }\end{array}$ & ed & $\theta$ & 224 & $\begin{array}{l}20 \\
13\end{array}$ & \\
\hline
\end{tabular}

Figure 25 Statistics from Facebook posts and data from March 2019.

In the statistics provided by Facebook, the topics of the posts and the impressions can be easily retrieved and compared. Along with the project, the posts with high impression rates were increased, and they turned to trend at a better rate.

\section{Conclusions of the dissemination activities on website and social media}

○ the amount of website visitors was increasing along with the acceleration of the social media activities

○ it was important to exploit the synergy between the different media

$\circ$ on the website, the most viewed contents were the teaching and selfdevelopment methods for Soft Skills

$\circ$ the highest trading posts both in $\mathrm{Fb}$ and $\mathrm{LI}$ were authentic, i.e., posts with pics or videos with our own staff, students or events

○ posts that shared others' contents (blogs, videos) were not as successful

\subsubsection{Workshops with Teachers, Managers and Researchers}

In the dissemination phase of the CoSki21 project, several workshops were organized for teachers, managers and HR experts. They are the core persons in the process of reducing the Soft Skills gap. For their part, these workshops provided me essential response regarding my research process. In the following, I describe shortly each workshop and in addition, the contribution it provided to my research project. 
As for my role in the workshops, I was the responsible organizer for all the workshops held in Turku (August and September 2019). In the remaining ones, I was invited key note speaker.

\section{Soft Skills for Business Teachers 21.08.2019 Turku, Finland}

A workshop on Soft Skills to all teachers of the department 'Business and sales' at Turku University of Applied Sciences was held for 45 business teachers. The topics agreed with the head of the unit were 'How to include Soft Skills in curricula' and 'Which methods to use for practicing Soft Skills in business'.
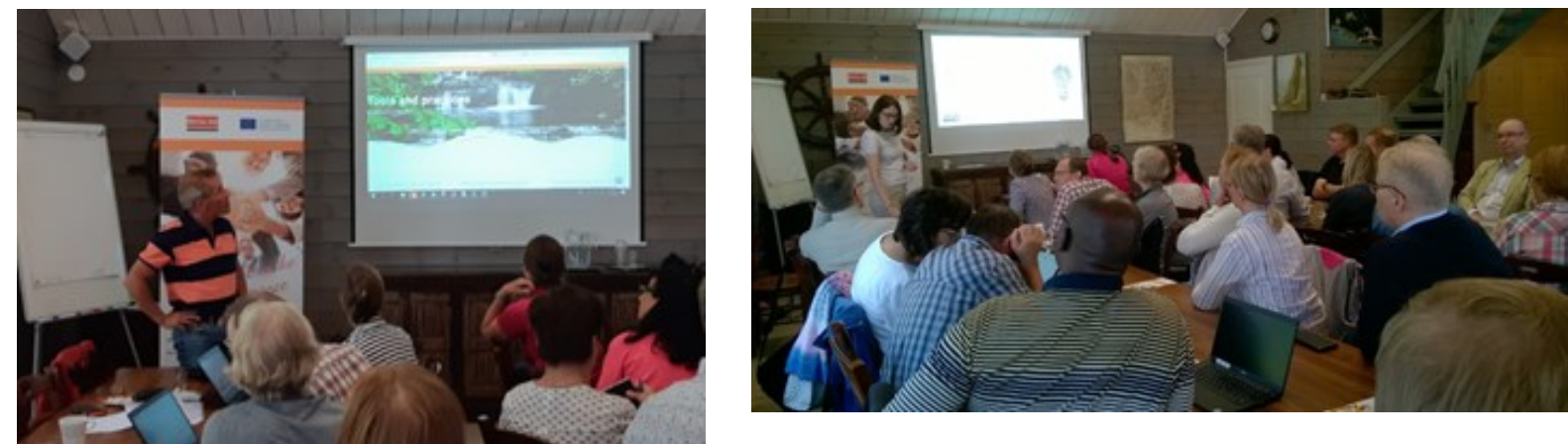

Figure 26 Workshop with Business Teachers in Turku. The author acting in the left photo.

As the audience consisted of the very target group of the project, this workshop was providing highly important experiences. In addition, I had one more good opportunity to present the outcomes of my research project. The discussion and the feedback gave me confidence in the importance of my study. The good discussions upon the most important Soft Skills' showed that Soft Skills are essential for many business professors. Furthermore, the workshop included hands-on practice to include Soft Skills in their study units and curricula and promote them in practice.

\section{Workshop Soft Skills to Managers, 25 September 2019 Turku, Finland}

This event was arranged for Business managers and HR experts. Along with teachers, they are the key persons in assessing and promoting Soft Skills in Organizations. It was a joint effort of several actors: HR professionals' association Henry r.y., Association of Entrepreneurs in Southwestern Finland, Start-Up enterprise community 
and Turku Business Region. These partners have been especially interested in my research project.

The session was opened with a short presentation of the results of the Finnish survey carried out in the first phase of the research project. Next, there was a panel discussion on the topics 'Are Soft Skills needed?', 'How does your Organization tackle the question?' and 'Can Soft Skill be learned?'. The discussion indicated that most Organizations and working environments seem to acknowledge the high role of Soft Skills. However, when discussing their fostering, often there are more questions than answers. Accordingly, the event was wrapped up by discussing the topic 'How to learn Soft Skill A/B/C/D' smaller workshops and finally, sharing the findings..
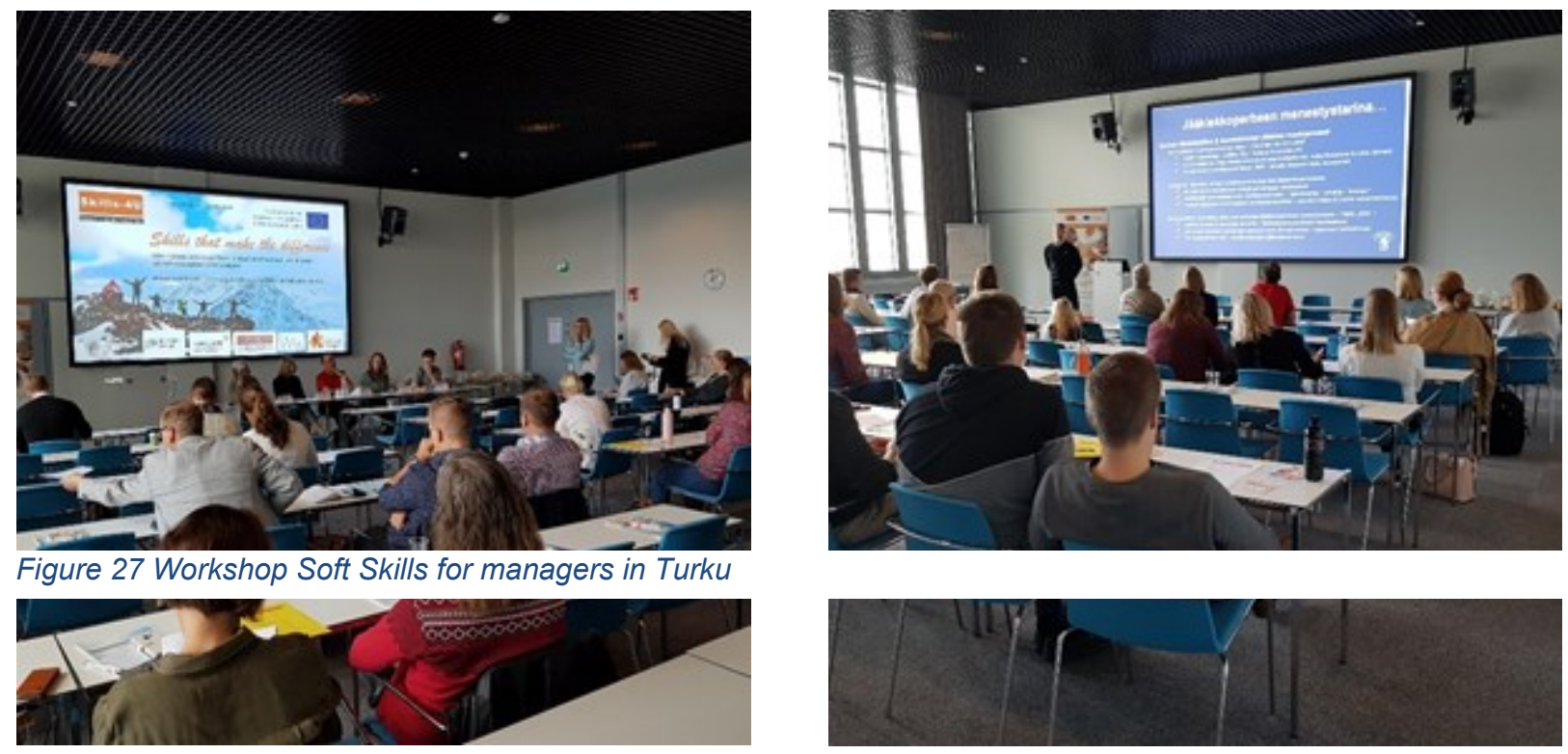

Due to my research topic, it was a memorable

occasion to present the results to managers and obtain their opinions and experiences on Soft Skills. The event confirmed that Companies need hands-on tools for developing these skills.

\subsubsection{Workshops with researchers}

In addition, a few workshops and conferences were arranged at Soft Skills research centers along Europe. Next, shortly about their topics and the contributions to the research. 
DETECTING, DEFINING AND DEVELOPING SOFT SKILLS IN BUSINESS AND ICT CONTEXTS Kai Schleutker 
"How to increase the awareness of Soft Skills?" held at ISCAPI Polytechnic of Porto, Portugal 18-19 January 2018

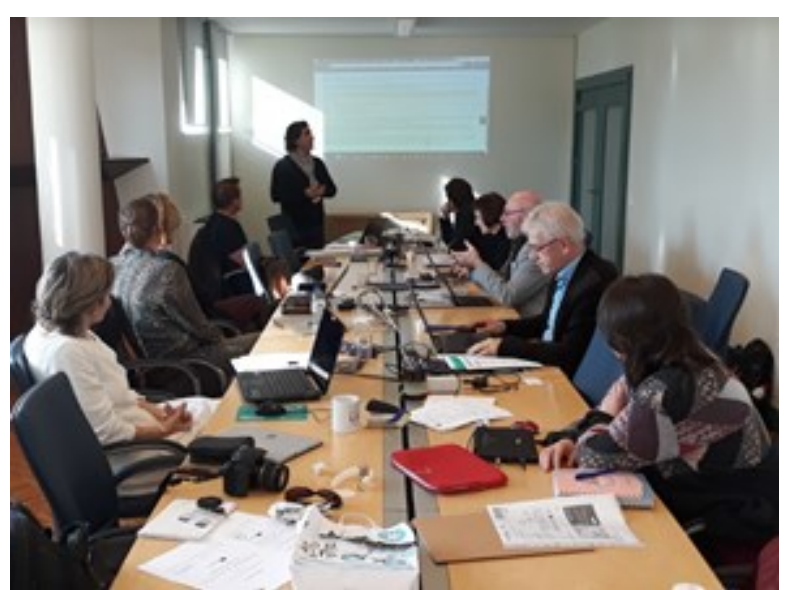

Figure 28 Soft Skills are included in studies of business accounting.
Main topics of the meeting

* A worldwide revision of development projects regarding Soft Skills was carried out

* How to increase awareness of Soft Skills for students, teachers, managers and HR professionals?

\section{Contribution to the research}

In this conference several common interests were found between Mediterranean and Nordic researchers regarding the teaching and learning of Soft Skills. As ISCAP and Turku UAS both run Business faculties, it was agreed to cooperate in developing Soft Skills in these disciplines. In addition, the Portuguese claimed their will to participate in research of Soft Skills needed in business working contexts. Consecutively, decisions were also made to start co-writing scientific articles on the topic.

“How to research Soft Skills?” at UniTre Rome, Italy 15-16 March 2018

Main topics:

* Soft Skills in Pedagogy

* How to research Soft Skills in different professional contexts (business, engineering, education)? 
* Learning method 'Bricks for Tips'

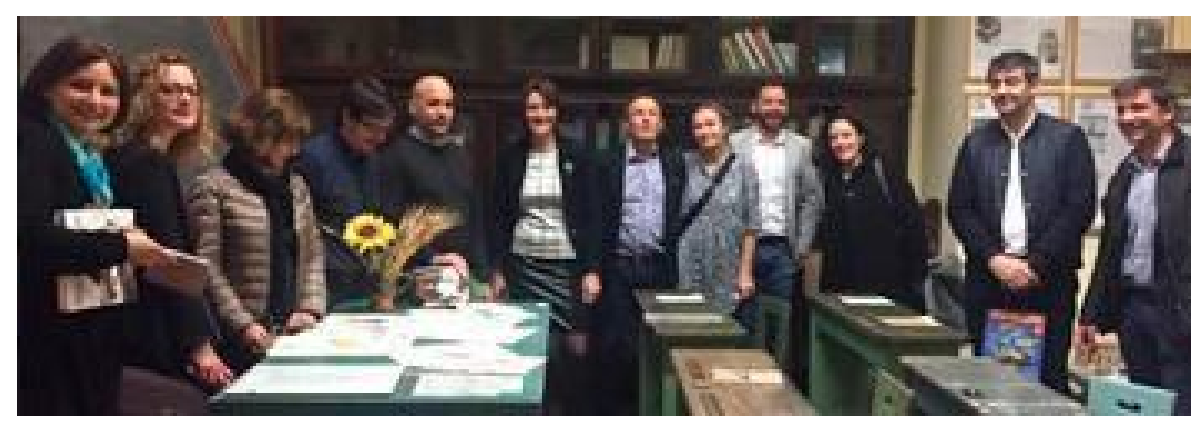

Figure 29 Numerous Soft Skills research is conducted at UniTre.

\section{Contributions to the research}

In the Roman seminars and workshops various researchers from Italy, Spain, Portugal and Finland presented their studies. They focused on following topics: 1. Soft Skills in secondary education; 2. Development methods (Bricks for Tips, BIP test); 3. Soft Skills in Engineering. Also research software and other techniques were presented.

The planning of the event 'Nordic Summer School' to take place in September 2019 was initiated. In addition, 3-4 smaller studies and articles to be produced with prof. Caggiano and her PhD students were started. 
"How do bridge the 'Soft Skills gap"? At Turku University of Applied Sciences, Turku, Finland, 27-29 May 2018

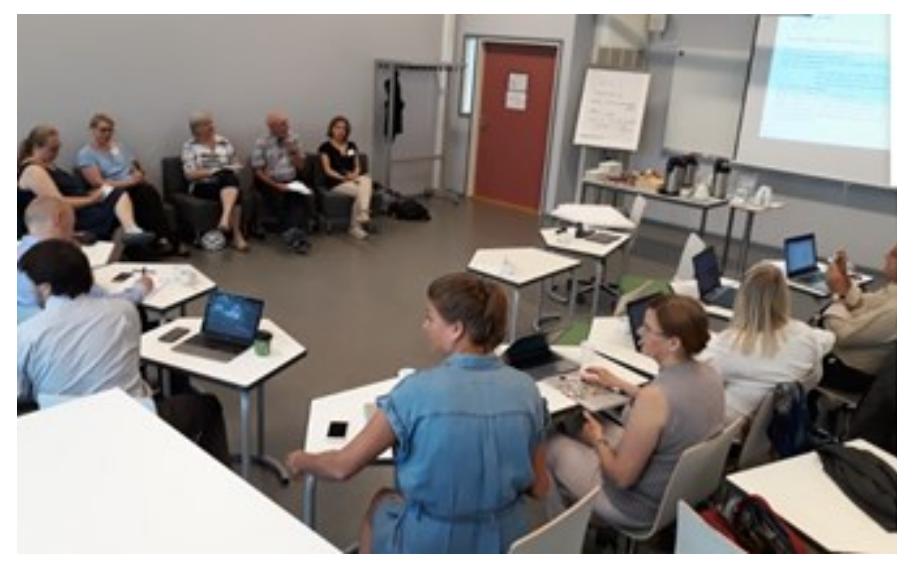

Figure 30 The Turku conference brought together business and higher education.
Main topics:

* What is the role of Soft Skills in different working positions, especially in Business?

* How can the 'skills gap' between Higher education and working life be bridged?

- How far is it possible to promote Soft Skills by means of higher education?

\section{Contributions to the research}

The meetings and discussions with the managers from companies confirmed the obvious high significance of Soft Skills in real-life working tasks, and consequently their importance for graduates. This was mentioned numerous times in the workshops and discussions. I had the occasion to present my questionnaire and the aimed survey. The discussion affirmed the topics and question-setting of the survey, directed to business professionals. Moreover, a cooperation was started with Dutch colleagues, from the Communication department. 
"Self-Promotion of Soft Skills" Workshops at RDI Center "Wissenschaftsinitiative", Vienna, Austria, 10-11 December 2018

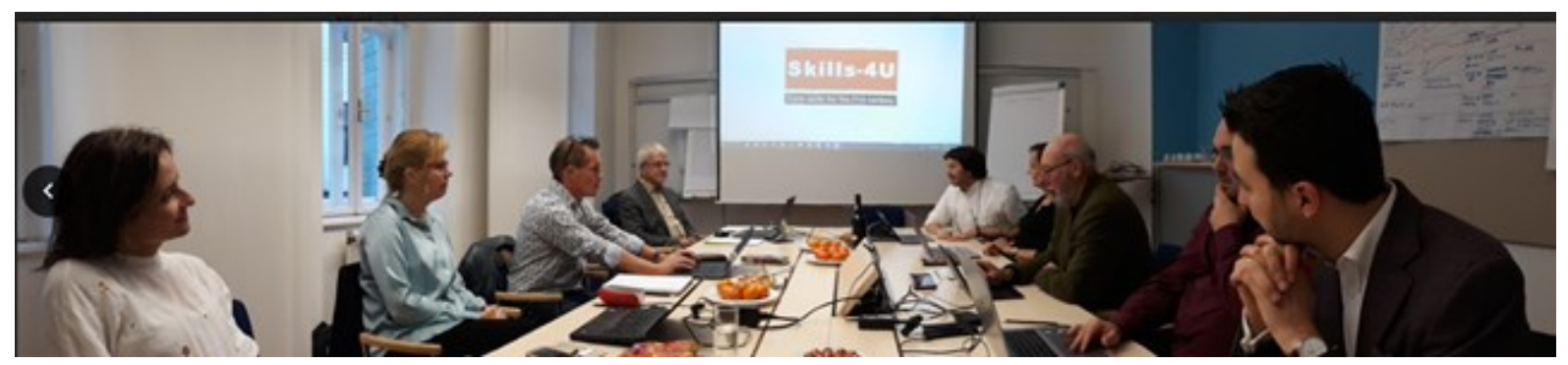

Figure 31 In Vienna, self-promotion activities for Soft Skills were presented.

This meeting was arranged by a psychological research institute Wissenschaftsinitiative (WIN) in Vienna, engaged in numerous development projects funded by the European Union, with focus on bridging skills gaps by graduates, youth, and immigrants. They have developed special 'Self-empowerment programs' for these groups, in order to develop their employability skills and awareness of their future possibilities and competencies needed. Practitioners from Austria, Slovenia, Portugal and Spain attended this event.

\section{Contribution}

The discussions in this meeting induced me to a deepened understanding of individual psychological elements (motivation, values) as driving forces of human behaviour. Also, new ideas regarding the connection between values and behaviour in terms of Soft Skills (having an inherent character). Various pending articles were proceeded in the meeting with Portuguese and Spanish colleagues. 


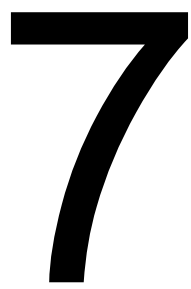




\section{Conclusions}

The motivation of this thesis has been to elucidate the character and potential of Soft Skills for making their definition easier and enable the detection of the most essential ones in different working positions at Organizations. This knowledge is needed by educators, trainers and managers to reduce the skills gap that is reported recently.

The following main hypothesis had been set:

"Based in the communication process, Soft Skills can be organized according to their significance to Organizations, universities and employees, and their development potential can be detected. "

The research process was initiated by creating a Framework of 21 Soft Skills that can be considered most appropriate for HEls and Organizations. Next, a three-dimensional inspection on them was conducted. The novelty of this inspection is that is represents the aspects of all the 'stakeholders' of the Soft Skills acquisition process, i.e., HEls, Organizations and graduates/employees, thus bringing these parts closer. The created method has been named Soft Skills Status indicator (the 3Si Method).

The main advantage of the method $3 \mathrm{Si}$ is its ability to classify skills according to their Significance in work, their Learnability and current Level of the skills (by graduates or employees). The classification offers eight classes, each of which can be interpreted as a specific Soft Skill profile.

The Method can be applied by various means for defining the need and learning potential of Soft Skills of particular persons, teams or whole departments enter in new positions or working modes. HEls can use the Method 3Si for defining the Soft Skills need in certain working positions, whereby they are conveyed insights of experienced Business and ICT professionals.

The data is essential for HEls and Organizations for making decisions of whether to include or discard particular skills in the curricula of degree programs and training programs. Furthermore, the data indicates which skills are likely to have more potential of learning and which have less. The contributions are reported in detail in chapter 5 . 


\subsection{Targets reached}

The foundations for the research were set by extensive exploratory research on Soft Skills maps in academic, educational and organizational sources (reported in 2.2). As a result, a Framework of Soft Skills was composed that includes 21 skills, divided in five clusters (in 2.2.3). This Framework was utilized in further steps of the research. Along with defining the most appropriate skills for business organizations, it was stated that communication has an outstanding and intermediating role among the 21 skills. By applying the intrapersonal and interpersonal dimensions of communication, all the other Soft Skills could be examined in relation to this skill. The Taxonomy exposes the interdependence communication and the resting Soft Skills on functional level. It offers novel insights on how Soft Skills are practiced in professional contexts. As such, it is useful for all educators and trainers working on Soft Skills.

These outcomes affirm the first and second sub-hypothesis

\section{1: Soft Skills can be organized based on the communication process}

O2: Certain Soft Skills are more significant in working contexts than others

The goal of the next phase was to build a model, able to share and exhibit the insights of the stakeholders (in 2.4). The three-dimensional approach enables to examine Soft Skills from three aspects. It provides the base for the suggested Method 'Soft Skills Status indicator (3Si)' (in 3.2). The Method and the Survey allow to suggest a Classification (in 3.3) with eight classes, implying specific characteristics with reference to importance and potential of Soft Skills. These aspects are highly interesting not only for educators, but also for managers and Human Resource developers in Organizations. The Method can be applied in any Organization.

After creating the elements of the Method 3Si (model, questionnaire), the Method was experimented by surveys in four countries (Finland, Spain, Portugal and the Netherlands). The results offered multiple interesting data with respect to Soft Skills (4.2) and the Classification (4.3). The results indicate Soft Skills that are important for all education, and those that are more appropriate for Higher Education. The findings 
also suggest that the position and working experience have significant correlation with the assessment of many Soft Skills.

Based on the survey, Soft Skills were located in eight classes, whereby each class can be interpreted as a specific Soft Skill profile. The profiles can be considered according to their importance and learning potential. Often educators and trainers have an excess of skills to be trained, this classification offers remarkable guidance in the selection, as it displays features of the skills that are interesting for these people.

The Method is easy to use, needing only a reduced number of respondents in each case, and thus viable for educators as well as Organizations. Hence, it is applicable in many types of Organizations. Moreover, it can be adjusted according to the needs of any professional environment, as the location into High or Low in Significance, Learnability and Level depends on the selected threshold value, which can be chosen in each case.

As such, the suggested Method $3 \mathrm{Si}$ and the Classification offer a viable means to answer the sub hypothesis

O3: at least some of these skills can be detected

O4: and developed

The phases and the findings of the research have been presented in Conferences with themes close to Higher Education and its development in Spain, Finland and Portugal. In addition, I have had the opportunity to present my topics and findings as an invited guest in specific Soft Skills researchers' workshops. In the final phase of the research, the results and findings have been published in Italian, Spanish, Finnish scientific journals.

\subsection{Future work}

The results of the survey exposed interesting correlations between the background of the respondents (position, working experience) and their assessments, and these correlations were statistically significant. One of the findings indicated that those in a managerial position assess Learnability lower than people in lower positions. If true, this would obviously have some influence on managers' attitudes towards the 
instruction of the recruited, for instance graduates. For this reason, the correlation deserves additional study.

Second, as there is previous evidence of difference in female vs. male Soft Skills (Hong, 2016) and differing attitudes towards women's vs. men's Soft Skills (Grugulis \& Vincent, 2009; Ahmad, 2015), the next similar type of survey is recommended to include gender as a background variable.

Furthermore, the results (in 4.2.2; 4.4.1) exhibited a statistically significant correlation between cultures and assessments of skills. The impact of cultural differences upon valuation and assessment of skills was found because of this survey. Cultural differences, regarding a variety of levels, have been stated in earlier research (e.g., Hofstede, 2011; Gibson, 1995) and consequently this is an object for future research regarding our topic as well. Many researchers focus on multicultural management, and ever more companies include different cultures working together within one country or on international level. As companies and Organizations also cooperate ever more with other companies from different cultures within today's globalized world, the role of companies' values is obtaining an increasing interest.

For these reasons, a more comprehensive study with a sample representing various cultures would give more detailed knowledge about Soft Skills needed in business environments. Knowing if there is a bias of Soft Skills, or a differentiation at the level of students, employees, HEls or in companies is possible from the method presented. 


\section{Bibliography}




\section{Bibliography}

Ahmad, S. B. S. (2013). Soft skills level of Malaysian students at a tertiary institution: A comparative case study based on gender, area of residence and type of schools. International Journal of Asian Social Science, 3(9), 1929-1937.

Andrews, J. \& Highson, H. (2008) Graduate Employability, 'Soft Skills' versus 'Hard Business Knowledge': A European Study. Higher Education in Europe, 33:4, 411-422.

Anthony, S. \& Garner, B. (2016). Teaching Soft Skills to business students: An analysis of multiple pedagogical methods. Business and Professional Communication Quarterly 2016, 79(3), 360-370.

Azim, S., Gale, A., Lawlor-Wright, T., Kirkham, R., Khan, A., \& Alam, M. (2010). The importance of Soft Skills in complex projects. International Journal of Managing Projects in Business, 3, 387-401.

Barcelona Activa Treball. Diccionario de competencias clave.

https://treball.barcelonactiva.cat/porta22/es/altres/diccionari.jsp

Barrett, R. (2006). Building a values-driven organization. Routledge.

Baumeister, Roy F., Kathleen D. Vohs, and Dianne M. Tice. "The strength model of self-control." Current directions in psychological science 16, no. 6 (2007): 351-355.

Berdrow, I. \& Evers, F.T. (2010) «Bases of competence: an instrument for self and institutional assessment». Assessment \& Evaluation in Higher Education, Vol. 35, $\mathrm{n}^{\circ}$. 4, pp. 419-434, 1-10. Harvard Business School.

Bereiter, C., \& Scardamalia, M. (2006). Education for the Knowledge Age: DesignCentered Models of Teaching and Instruction. 
Berger, T., \& Frey, C. B. (2015). Bridging the skills gap. Technology, globalisation and the future of work in Europe: Essays on employment in a digitized economy, 75-79.

BIP Business-Focused Inventory of Personality. Available at https://eu.hogrefe.com/shop/media/downloads/sample-reports/5507002 mr.pdf

Blazquez, M. (2014). Skills based Profiling and Matching in PES. The European Commission Mutual Learning Programme for Public Employment Services.

Bovée, C. L., Thill, J. V., \& Raina, R. L. (2016). Business communication today. Pearson Education India.

Bradburn, N. M., Sudman, S., Blair, E., Locander, W., Miles, C., Singer, E., \& Stocking, C. (1979). Improving interview method and questionnaire design: Response effects to threatening questions in survey research. San Francisco: Jossey-Bass.

Broadbent, D. E., Cooper, P. F., FitzGerald, P., \& Parkes, K. R. (1982). The cognitive failures questionnaire (CFQ) and its correlates. British journal of clinical psychology, 21(1), 1-16

Budhwar, P. S., \& Bhatnagar, J. (2007). Talent management strategy of employee engagement in Indian ITES employees: key to retention. Employee relations.

Bughin, J., Hazan, E., Lund, S., Dahlström, P., Wiesinger, A. \& Subramaniam, A. (2018). Skills Shift. Automation and the Future of Workforce. McKinsey \& Company.

BRM Business Research Methodology. Research methods.

https://research-methodology.net/research-methods/

Caggiano, V., Schleutker, K., Petrone, L., \& González-Bernal, J. (2020). Towards Identifying the Soft Skills Needed in Curricula: Finnish and Italian Students' SelfEvaluations Indicate Differences between Groups. Sustainability, 12(10), 4031. 
Caggiano, V., Akanazu, H., Furfari, A., \& Hageman, A. (2016). Entrepreneurship education: A global evaluation of entrepreneurial attitudes and values (a transcultural study). Journal of Educational, Cultural and Psychological Studies (ECPS Journal), 1(14), 57-81.

Cambridge Dictionary. Competence.

https://dictionary.cambridge.org/dictionary/english/competence

Cappelli, P. (2012). Why good people can't get jobs: The skills gap and what companies can do about it. Wharton Digital Press.

Childs, L., Coles, L., \& Marjoram, B. (Eds.). (2009). Essential skills clusters for nurses: theory for practice. John Wiley \& Sons.

Cimatti, B. (2016). Definition, development, assessment of Soft Skills and their role for the quality of Organizations and enterprises. International Journal for quality research, 10.

Cinque, M. (2016). "Lost in translation". Soft Skills development in European countries. Tuning Journal for Higher Education, 3(2), 389-427.

Dabke, D. (2015). Soft Skills as a predictor of perceived internship effectiveness and permanent placement opportunity. IUP Journal of Soft Skills, 9(4), 26.

Dehmel, A. (2006). Making a European area of lifelong learning a reality? Some critical reflections on the European Union's lifelong learning policies. Comparative education, 42(1), 49-62.

Dictionary.com. Skill.

https://www.dictionary.com/browse/skill.

EBN35 Innovation network.

https://ebn.eu/index.php?Ink=KzF0aDVES1/3bG9TYXFGeEhLL2dQMENMM081NIc1 $\underline{\text { RXdzSEQ3dkJVRkQzMD0 }}=$ 
ESCO. European Skill, competences, Qualifications and Occupations.

https://ec.europa.eu/esco/portal/home?resetLanguage=true\&newLanguage=en

European Commission (2015). Measuring Skills Mismatch. Luxembourg: Public office of the European Union.

Eurydice (2014). Modernization of higher education in Europe: Access, retention and employability 2014. Luxembourg: Publications Office of the European Union.

Eurydice (2019). European Commission/EACEA. Modernization of Higher Education in Europe: Access, Retention and Employability. Luxembourg: Publications Office of the European Union.

Focus Group. What can be researched by means of Focus Groups?

https://www.focusgroup.com/

Forbes Business Review (2018).

https://www.forbes.com/sites/bernardmarr/2018/09/02/what-is-industry-4-0-heres-asuper-easy-explanation-for-anyone/\#23ec4e3a9788

García-Aracil, A., \& van der Velden, R. (2008). Competencies for young European higher education graduates: labour market mismatches and their payoffs. Higher Education, 55, 219-239.

Gauch Jr, H. G., \& Gauch, H. G. (2003). Scientific method in practice. Cambridge University Press.

Gilbert, R., Balatti, J., Turner, P., \& Whitehouse, H. (2004). The generic skills debate in research higher degrees. Higher Education Research \& Development.

Gravetter, F. J., \& Forzano, L. A. B. (2018). Research methods for the behavioral sciences. Cengage Learning. 
Grugulis, I. \& Vincent, S. (2009). Whose skill is it anyway? Soft Skills and Polarization. Work, Employment and Society, 23(4): 597-615.

Heckman, J. and Kautz, T. (2012). Hard Evidence on Soft Skills. Labour Economics Vol 19, issue 4, 451-464.

Hofstede, G. (2011). Dimensionalizing cultures: The Hofstede model in context. Online readings in psychology and culture, 2(1), 2307-0919.

Hong, R. (2016). Soft skills and hard numbers: Gender discourse in human resources. Big Data \& Society, 3(2), 2053951716674237.

Hughes, J. C., \& Rog, E. (2008). Talent management: A strategy for improving employee recruitment, retention and engagement within hospitality Organizations. International Journal of Contemporary Hospitality Management, 20(7), 743-757.

Human resources Edu. What is human Resource?

https://www.humanresourcesedu.org/what-is-human-resources/

ILO (International Labour Organization). What is skills mismatch and why should we care?

https://www.ilo.org/skills/Whatsnew/WCMS 740388/lang--en/index.htm

Jones, A. (2019). Essential skills cluster in palliative care. British Journal of Healthcare Assistants, 13(3), 136-138.

Jones, M., Baldi, C., Phillips, C., \& Waikar, A. (2017). The hard truth about Soft Skills: What recruiters look for in Business Graduates. College Student Journal, 50, 422-428.

Keinänen, M., \& Oksanen, A. (2017). Students' perception of learning innovation competences in activity-based learning environment. Ammattikasvatuksen aikakauskirja, 19(4), 48-61. 
Kikoski Kano, C. \& Kikoski, J.F. (2004) The inquiring Organization: Tacit knowledge, conversation, and knowledge creation: Skills for 21st-century Organizations. Greenwood Publishing Group.

Koenig, J. A. (2011). Assessing 21st century skills: Summary of a workshop.

Le Boterf, G. (1997). De la competence à la navigation professionnelle. Paris: Les Éditions d'Organization.

Lehtinen, U. (2006) IImiö nimeltä liiketoimintaosaaminen. Teoksessa Lehtinen, U. \& Mittilä, T. (toim.) Liiketoimintaosaaminen kilpailukykymme keskiössä. Jyväskylä: Kauppatieteellinen yhdistys.

Lindgren, R., Henfridsson, O., \& Schultze, U. (2004). Design principles for competence management systems: a synthesis of an action research study. MIS quarterly, 435472.

Mason, G., Williams, G., \& Cranmer, S. (2009). Employability skills initiatives in higher education: what effects do they have on graduate labour market outcomes? Education Economics, 17, 1-30.

McDonald, J. (2019). Social Media Marketing Workbook - How to market your Business on social media. JM Internet.

Mitchell, G. W., Skinner, L. B., \& White, B. J. (2010). Essential Soft Skills for success in the twenty-first century workforce as perceived by business educators. Delta $\mathrm{Pi}$ Epsilon Journal, 52, 43-53.

MOSSA project and Soft Skills map.

http://valorize.odl.org/outputs/IO1 Framework soft skill Report.pdf

Mourshed, M., Patel, J., \& Suder, K. (2014). Education to employment: Getting Europe's youth into work. McKinsey \& Company. 
NACE (2010). Codes for branches.

http://ec.europa.eu/competition/mergers/cases/index/nace all.html

Muir, C. (2004). Learning Soft Skills at work: An interview with Annalee Luhman. Business Communication Quarterly, 67(1), 95-102.

Nealy, C. (2005). Integrating Soft Skills through active learning in the management classroom. Journal of College Teaching \& Learning (TLC), 2(4).

Nganga, T.K., Yunusa, H.M. and Hashima, N.H. (2015) Soft Skills Integration in Teaching Professional Training: Novice Teachers' Perspectives. Procedia - Social and Behavioural Sciences 186, 835 - 840.

OECD (2016). Getting Skills right. Assessing and anticipating changing skills needs. OECD Publishing, Paris.

Oladiran, M.T., Uziak, J., Eisenberg, J.M. and Scheffer, C. (2011) Global engineering teams - a programme promoting team working in engineering design and manufacturing. European Journal of Engineering Education, Vol. 36, No. 2, May 2011, 173-186

Oxford Reference. Hard Skills.

https://www.oxfordreference.com/view/10.1093/oi/authority.20110803095920725

Paarlberg, L. E., \& Perry, J. L. (2007). Values management: Aligning employee values and organization goals. The American review of public administration, 37(4), 387-408.

Parker, A., \& Tritter, J. (2006). Focus group method and methodology: current practice and recent debate. International Journal of Research \& Method in Education, 29(1), 23-37.

Perrenoud, P. (1999). Avaliação. Da Excelência à Regulação das Aprendizagens. Entre duas Lógicas. Porto Alegre: Artmed Editora. 
Redomero, T., Caggiano, V., Poza Lujan, J. L., \& Piccione, V. A. (2019). Fostering and assessing Soft Skills of engineering students. The International journal of engineering education, 35(6), 1656-1666.

Rego, R., Zózimo, J., Correia, M. J., \& Ross, A. (2016). Bridging volunteering and the labour market: a proposal of a Soft Skills matrix. Voluntary Sector Review, 7(1), 8999.

Research Methods Guide. Research Design \& Method https://guides.lib.vt.edu/researchmethods/design-method

Robles, M. M. (2012). Executive perceptions of the top 10 Soft Skills needed in today's workplace. Business Communication Quarterly, 75, 453-465.

Sanghi, S. (2016). The handbook of competence mapping: understanding, designing and implementing competence models in Organizations. SAGE publications India.

Sawyer, K. (2006) The new science of learning. In Cambridge handbook of learning. Cambridge University Press, 1-16.

Schleutker, K. (2017) Yksilötason liiketoimintaosaamisen määrittelyä ja liiketalouden opiskelijoiden oppimisen taustalla vaikuttavista tekijöistä ammattikorkeakoulutuksessa. Publications of the Pedagogic Faculty. University of Tampere.

Schleutker, K. J., Caggiano, V., Coluzzi, F., \& Poza Luján, J. L. (2019). Soft Skills and European Labour Market: Interviews with Finnish and Italian Managers. Journal of Educational, Cultural and Psychological Studies (ECPS Journal), (19), 123-144.

Schulz, B. (2008). The importance of Soft Skills: Education beyond academic knowledge. Nawa Journal of Communication, 2(1), 146-154.

Schutte, N. S., Malouff, J. M., Hall, L. E., Haggerty, D. J., Cooper, J. T., Golden, C. J., \& Dornheim, L. (1998). Development and validation of a measure of emotional intelligence. Personality and individual differences, 25(2), 167-177. 
Silber-Varod, V., Eshet-Alkalai, Y., \& Geri, N. (2019). Tracing research trends of 21stcentury learning skills. British Journal of Educational Technology, 50(6), 3099-3118.

Southerland, S. A., Sinatra, G. M., \& Matthews, M. R. (2001). Belief, knowledge, and science education. Educational Psychology Review, 13(4), 325-351.

Stevenson, D. \& Starkweather, J. (2010). PM critical competence index: IT execs prefer Soft Skills. International Journal of Project Management 28, 663-671.

Stebbins, R. A. (2001). Exploratory research in the social sciences (Vol. 48). Sage.

Succi, C. (2015). Soft Skills for the Next Generation: Toward a comparison between Employers and Graduate Students' Perceptions. Sociologia Del Lavoro.

Succi, C., \& Canovi, M. (2019). Soft Skills to enhance graduate employability: comparing students and employers' perceptions. Studies in Higher Education, 1-14.

Qualtrics. Survey as a Research Method.

https://www.qualtrics.com/experience-management/research/survey-basics/

Tedesco, J. C., Opertti, R., \& Amadio, M. (2014). The curriculum debate: Why it is important today. Prospects, 44, 527-546.

ThoughtCo. Six steps of the academic method.

https://www.thoughtco.com/steps-of-the-scientific-method-p2-606045

Tulgan, B. (2015). Bridging the Soft Skills Gap. How to teach the missing Basics for Today's Young Talent. Hoboken (N.Y., USA): Wiley.

Tynjälä, P., Virtanen, A., Klemola, U., Kostiainen, E., \& Rasku-Puttonen, H. (2016). Developing social competence and other generic skills in teacher education: applying the model of integrative pedagogy. European Journal of Teacher Education, 39(3), 368-387. 
Vieira, D. A., \& Marques, A. P. (2014). Preparados para trabalhar? Forum Estudante/Consórcio Maior Empregabilidade.

UNESCO (2013) Unevoc.

https://unevoc.unesco.org/home/TVETipedia+Glossary/filt=all/id=577

WEF, World Economic Forum. (2016). The future of jobs: Employment, skills and workforce strategy for the fourth industrial revolution. In Global Challenge Insight Report, World Economic Forum, Geneva.

Wikle, T. A., \& Fagin, T. D. (2015). Hard and Soft Skills in preparing GIS professionals: Comparing perceptions of employers and educators. Transactions in GIS, 19, 641652.

Wollan, R., Smith, N., \& Zhou, C. (2011). The social media management handbook: Everything you need to know to get social media working in your business. John Wiley \& Sons.

Zigarmi, D., Nimon, K., Houson, D., Witt, D., \& Diehl, J. (2009). Beyond engagement: Toward a framework and operational definition for employee work passion. Human Resource Development Review, 8(3), 300-326. 
Attachments 


\section{Attachment}

\section{Attachment: The 3Si questionnaire}

\section{The role of personal core skills in the working life competency of graduates}

According to recent studies (McKinsey 2014; WEF 2015; OECD 2016) there are gaps in certain personal skills of graduates which prevent them from performing in an optimal way. The purpose of this project is to reduce this skills gap by identifying skills gaps and foster their formation at universities.

We appreciate your contribution, thanks !

Contact information

Finland: kai.schleutker@turkuamk.fi; (coordinator)

Spain: jopolu@upv.es

Portugal: susanass@iscap.ipp.pt

Netherlands: kim.vanderheijden@hu.nl

Austria: office@wissenschaftsinitiative.at

Slovenia: sonja.bercko@eu-integra.eu

Questions Phone: +34 xxx xxx xxx (inlcuding Whatsapp)

Project information: https://www.facebook.com/CoSki21

EU Project: http://ec.europa.eu/programmes/erasmus-plus/projects/eplus-project-details/\#project/ce9217b8-

71bc-410d-a717-b10e683d87

Your position: *

1. Managers and Superiors

2. Professionals

3. Technicians and associate professionals

4. Clerical support workers

5. Other (if your position is not included in the previous categories) 
Your total working experience in years *

Experience in several branches/occupations -brief description

Lyhyt vastausteksti

Do you find competence maps or skills dictionary useful for your company? (optional)

If you have no opinion on competence maps, please pass this question.

$\begin{array}{llllllll} & 1 & 2 & 3 & 4 & 5 & \\ \text { Strongly disagree } & \bigcirc & \bigcirc & \bigcirc & \bigcirc & \bigcirc & \text { 5. Strongly useful }\end{array}$

Please rate the significance of the following skills in your current position: *

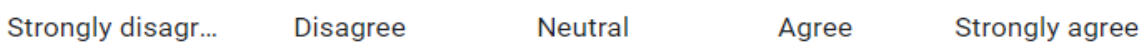

Initiative:React ...

Goal orientation...

Planning \& Orga...

Preoccupation ...

People manage...

Leadership:Lea...

Work in team a...

Self-confidence...

Self-control: Abi...

Commitment to... 
Flexibility and c...

Communication...

Empathy: Sensi...

Negotiation: Ab...

Networking: To ...

Customer orien...

Learning and us...

Creativity: Abilit...

Strategic orient...

Analytic thinkin...

Conceptual thin...

Flexibility and c...

Communication...

Empathy: Sensi...

Negotiation: Ab...

Networking: To ...

Customer orien...

Learning and us...

Creativity: Abilit...

Strategic orient...

Analytic thinkin...

Conceptual thin... 
In your opinion, is it possible to learn these skills at schools or universities? *

\begin{tabular}{|c|c|c|}
\hline Strongly disagr... & Disagree & Neutral \\
\hline
\end{tabular}

Initiative:React ...

Goal orientation...

Planning \& Orga...

Preoccupation ...

People manage...

Leadership:Lea...

Work in team a...

Self-confidence...

Self-control: Abi...

Commitment to...

Flexibility and c...

Communication...

Empathy: Sensi...

Negotiation: Ab...

Networking: To ...

Customer orien...

Learning and us...

Creativity: Abilit...

Strategic orient...

Analytic thinkin...

Conceptual thin... 
In your field, do recent graduates possess these skills? *

$\begin{array}{llll}\text { Strongly disagr... } & \text { Disagree } & \text { Neutral } & \text { Agree }\end{array}$

Initiative:React ...

Goal orientation...

Planning \& Orga...

Preoccupation ...

People manage...

Leadership:Lea...

Work in team a...

Self-confidence...

Self-control: Abi...

Commitment to... 
Flexibility and c...

Communication...

Empathy: Sensi...

Negotiation: Ab...

Networking: To ...

Customer orien...

Learning and us...

Creativity: Abilit...

Strategic orient...

Analytic thinkin...

Conceptual thin...

Are there other core skills that should be included in the above list?

Pitkä vastausteksti

To what extent do you agree that developing these skills should be a greater priority in further and higher education?

$\begin{array}{llllllll} & 1 & 2 & 3 & 4 & 5 & \\ \text { Strongly disagree } & - & \bigcirc & \bigcirc & \bigcirc & \bigcirc & \text { Strongly Agree }\end{array}$

\section{Want to receive the results?}

If yes, please add your email address (it will not be added in any database !)

Lyhyt vastausteksti 
The number of people who report to you: *

Put the maximun personnel in charge that you have

Lyhyt vastausteksti

\section{Company/organization size}

1. Small $(<50)$

2. Medium $(50>250)$

3. $\operatorname{Big}(>250)$

\section{Company/organization possession}

1. Private

2. Public 
Branch of your Company/organization

Based on the NACE classification http://ec.europa.eu/eurostat/ramon/nomenclatures/index.cfm?

TargetUrl=LST_NOM_DTL\&StrNom=NACE_REV2\&StrLanguageCode=EN

1. J. Information and communication

2. K. Financial and insurance activities

3. I. Hospitality and accommodation

4. N. Administrative and support service activities

5. M. Professional, scientific and technical activities (managers, experts, company owners)

6. G - Wholesale and retail trade (sales work)

7. P Education

8. L - Real estate activities

9. Human health and social work activities

10. $\mathrm{R}$ - Arts, entertainment and recreation

11. Agriculture, forestry and fishing

12. Public administration and defence; compulsory social security

13. B - Mining and quarrying

14. C-Manufacturing

15. D - Electricity, gas, steam and air conditioning supply

16. E - Water supply; sewerage; waste managment and remediation activities

17. F-Construction

18. $\mathrm{H}$ - Transporting and storage

19. I - Accommodation and food service activities

20. T - Activities of households as employers; undifferentiated goods - and services - producing activities of h...

21. $\mathrm{U}$ - Activities of extraterritorial organisations and bodies

22. Not contemplated in the previous groups 
Your country *

Spain

Netherlands

Finland

Portugal

Austria

Slovenia

Any comments?

Pitkä vastausteksti 


\section{Attachment: Tables and Graphs}

\subsection{The 3Si Survey material}

Data of the 3Si Survey

Results of the 3Si Survey

\subsection{About the definition of skills/competences (relates to 2.2.1)}

\begin{tabular}{|c|c|c|c|c|c|c|c|}
\hline Term & Google & Scholar & ResearchGate $^{3}$ & Academia $^{4}$ & LinkedIn $^{5}$ & RefSeek & Eurostat $^{6}$ \\
\hline "competency map" & 20800 & 654 & $8 / 17$ & $0^{\prime}$ & 333 & 4880 & 9 \\
\hline "competency mapping" & 240000 & 1550 & $14 / 50+$ & 2 & 69 & 44300 & 73 \\
\hline "map of competences" & 19400 & 109 & $2 / 100+$ & 0 & 35 & 297 & 8 \\
\hline "map of competencies" & 31300 & 129 & $8 / 20$ & 0 & 213 & 353 & 1 \\
\hline "competence map" & 5630 & $543^{8}$ & $22 / 23$ & 7 & 3 & 1680 & $30^{9}$ \\
\hline "competencies map" & 2150 & 132 & $8 / 6$ & 3 & 317 & 741 & 0 \\
\hline "competences map" & 1260 & $68^{10}$ & $2 / 2$ & 0 & 10 & 238 & 7 \\
\hline "skill map" & 39500 & 401 & $25+/ 100+$ & 12 & 185 & 6540 & 1 \\
\hline "skills map" & 67500 & 1150 & $100+/ 1000+$ & 22 & 746 & 13700 & 62 \\
\hline "map of skills" & 310000 & 76 & $100+/ 1000+$ & 11 & 568 & 1160 & 3 \\
\hline "competency list" & 17800 & 1480 & $25+/ 25+$ & 0 & 94 & 5110 & 2 \\
\hline "list of competences" & $107000^{11}$ & $1500^{12}$ & $25+/ 100+$ & 0 & 38 & 2410 & 2920 \\
\hline "list of competencies" & 240000 & 7080 & $25+/ 100+$ & 0 & 209 & 16100 & 2410 \\
\hline "skills list" & 531000 & 2800 & $100+/ 1000+$ & 0 & 1400 & 215000 & 99 \\
\hline "list of skills" & 1900000 & 10400 & $100+/ 1000+$ & 9 & 2666 & 122000 & 7200 \\
\hline "competency framework" & 425000 & 15300 & $25+/ 1000+$ & 100 & 11 & 115000 & 356 \\
\hline "competence framework" & 94100 & 4900 & $100+/ 1000+$ & 100 & 1007 & 20800 & 671 \\
\hline "skiןls framework" & 190000 & 6800 & $100+/ 10000+$ & 0 & 14 & 61300 & 124 \\
\hline "trahsversal skills" & 452000 & 38100 & $18 / 100+$ & 0 & 16 & 0 & 0 \\
\hline
\end{tabular}

1 Questions/publications

2 Academia found the number of followers/and number of pages (in the case of publications)

3 Linkedln do not allow to search a sentence between "', but the result can be considered significant because the number of results is lower.

4 Eurostat does not allow to search with a sentence between "', hence a Google search was conducted with the key "site" for example: "competence map" site: http://ec.europa.eu/. results are not significant because google finds repeated files (as images or pdf files, for example)

5 Proposes "competence mapping"

6 But Scholar recommends using "competence map"

7 Google suggest "competence map"

8 But Scholar recommends using "competencies 


\section{Coski21 results (the whole sheet can be found here)}

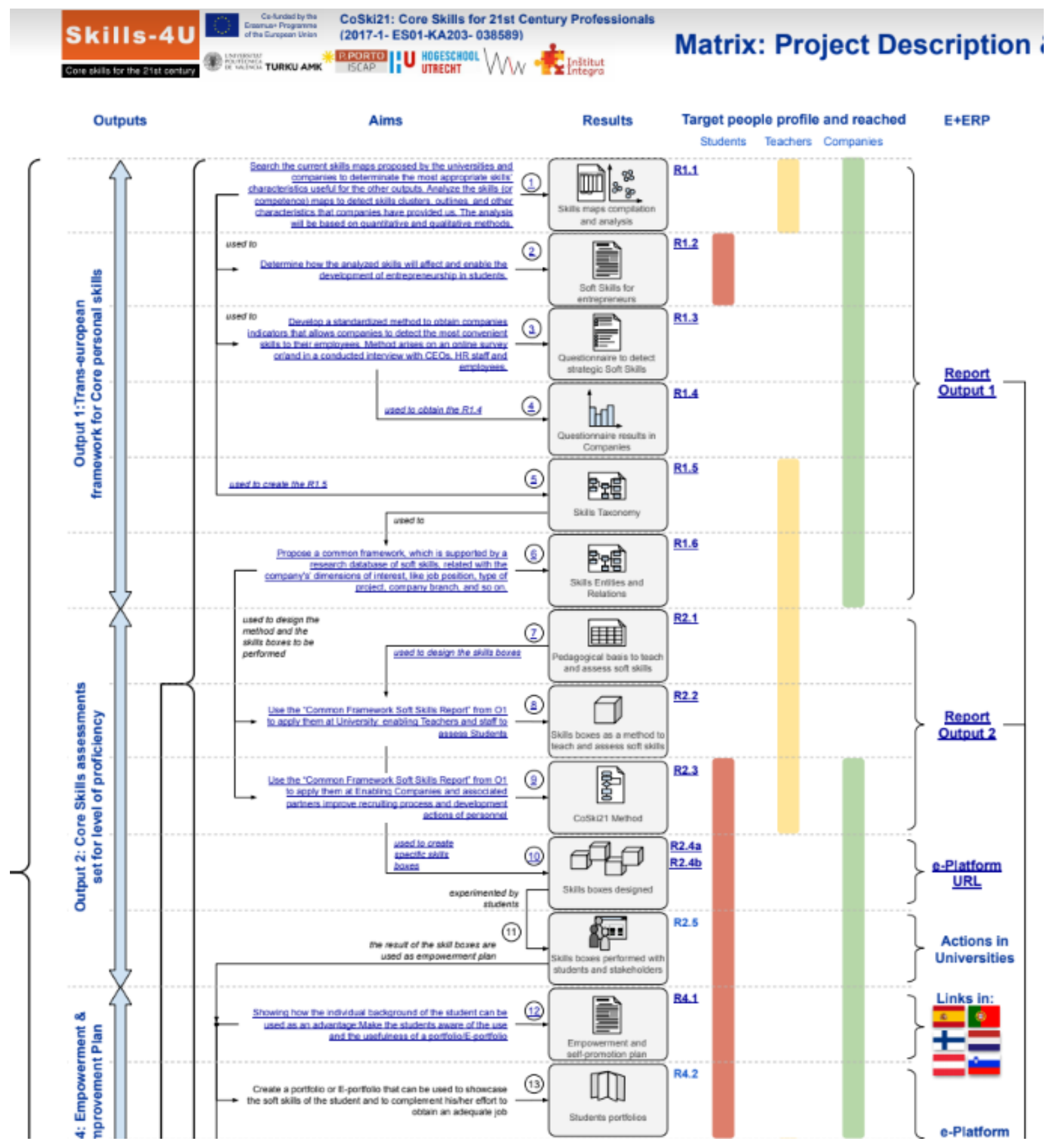




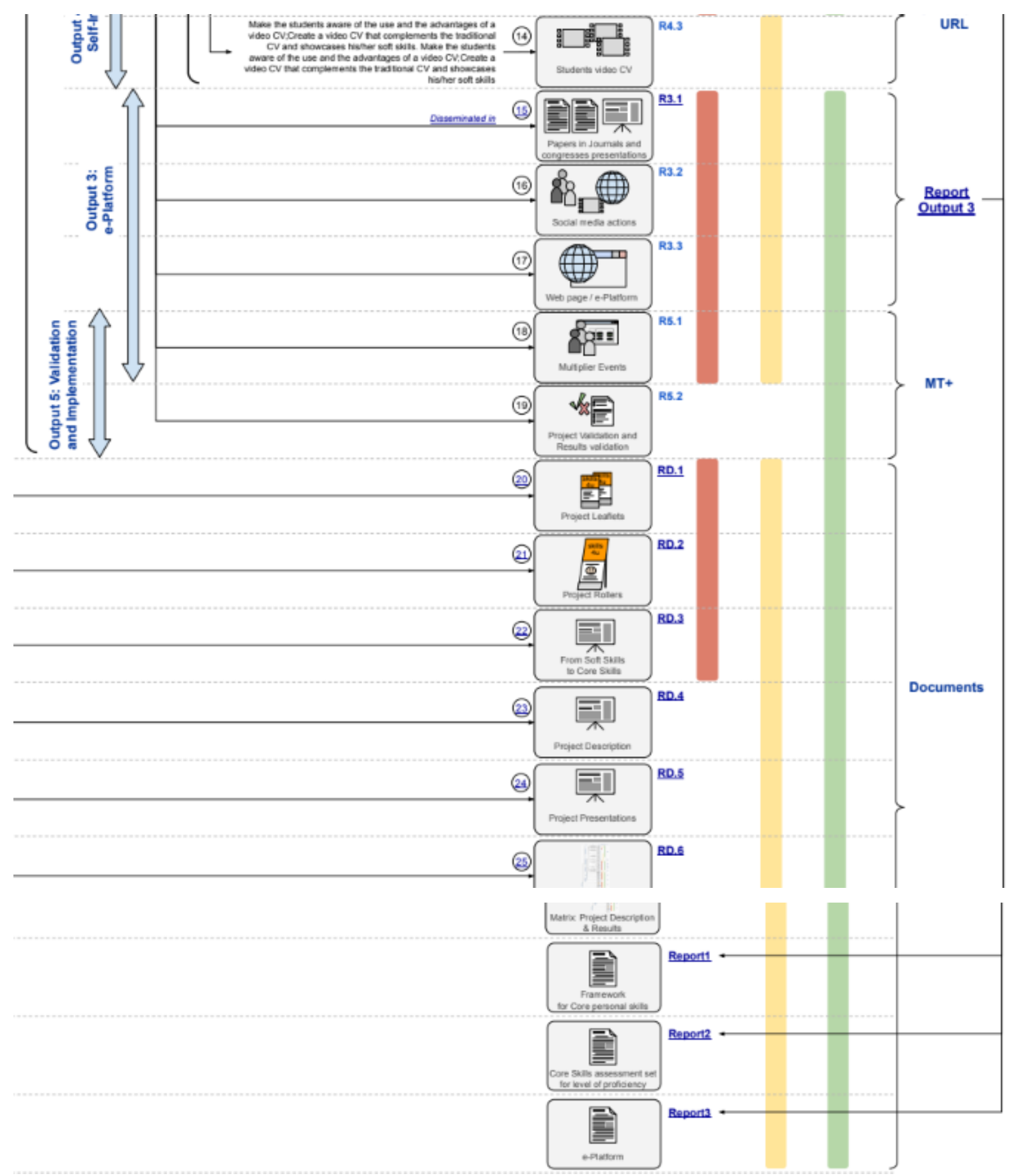

